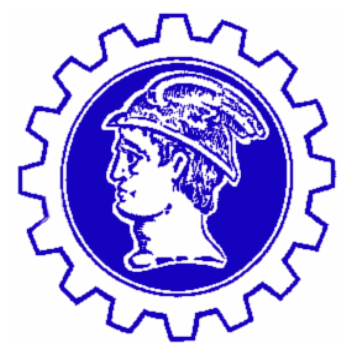

UNIVERSIDADE DE SÃO PAULO

FACULDADE DE ECONOMIA, ADMINISTRAÇÃO E CONTABILIDADE DEPARTAMENTO DE ADMINISTRAÇÃO

PROGRAMA DE PÓS-GRADUAÇÃO EM ADMINISTRAÇÃO

Manuel Antonio Molina Palma

\title{
A capacidade de inovação como formadora de valor: análise dos vetores de valor em empresas brasileiras de biotecnologia
}


Reitor da Universidade de São Paulo Prof. Dr. Adolfo José Melfi

Diretora da Faculdade de Economia, Administração e Contabilidade Profa. Dra. Maria Tereza Leme Fleury

Chefe do Departamento de Administração Prof. Dr. Eduardo Pinheiro Gondin de Vasconcellos

Coordenador do Programa de Pós Graduação em Administração Prof. Dr. Isak Kruglianskas 


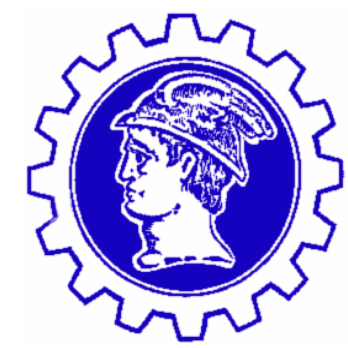

UNIVERSIDADE DE SÃO PAULO

FACULDADE DE ECONOMIA, ADMINISTRAÇÃO E CONTABILIDADE DEPARTAMENTO DE ADMINISTRAÇÃO

PROGRAMA DE PÓS-GRADUAÇÃO EM ADMINISTRAÇÃO

Manuel Antonio Molina Palma

\section{A capacidade de inovação como formadora de valor: análise dos vetores de valor em empresas brasileiras de biotecnologia}

Tese de Doutorado apresentada ao Departamento de Administração da Faculdade de Economia, Administração e Contabilidade da Universidade de São Paulo, como parte dos requisitos para a obtenção do título de Doutor em Administração.

Orientador: Prof. Dr. Roberto Sbragia 
Tese de Doutorado defendida e aprovada no Programa de Pós-Graduação em Administração da Faculdade de Economia, Administração e Contabilidade da Universidade de São Paulo, em 07 de outubro de 2004, pela seguinte Comissão Julgadora:

Prof. Dr. Roberto Sbragia, Orientador - EAD - FEA/USP

Prof $^{a}$ Dra. Ana Lúcia Delgado Assad - UNICAMP

Prof. Dr. José Manoel Carvalho de Mello - UFF, Niteroi

Prof. Dr. Isak Kruglianskas - EAD - FEA/USP

Prof. Dr. Milton de Abreu Campanário - EAE - FEA/USP

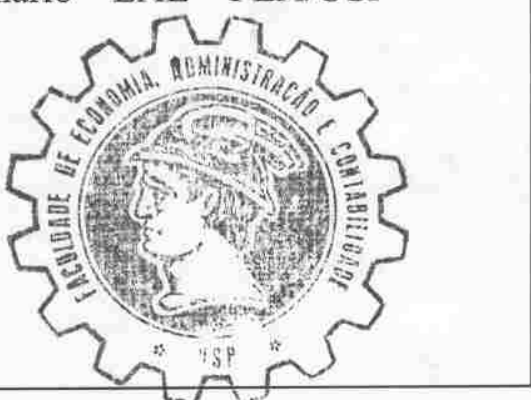

\section{FICHA CATALOGRÁFICA}

Elaborada pela Seção de Publicações e Divulgação do SBD/FEA/USP

\section{Molina-Palma, Manuel Antonio}

A capacidade de inovação como formadora de valor: análise dos vetores de valor em empresas brasileiras de biotecnologia / Manuel Antonio Molina Palma. -- São Paulo, 2004.

$175 \mathrm{f}$.

Tese (Doutorado) - Universidade de São Paulo, 2004

Bibliografia: f. 162 - 171

1. Administração 2. Valor (Administração) 3. Inovações tecnológicas 4. Estratégia organizacional I. Faculdade de Economia, Administração e Contabilidade da USP II. Título.

CDD -658 
À Marília, Bernardo e Gabriel.

Para el Prof. Mario Jacob Molina (In Memoriam).

No fue mi profesor en el sentido estricto de la palabra pero, con su ejemplo, me enseñó todos los secretos de la docencia y la responsabilidad social implícita en la tarea de ser profesor. Solamente entendí estas lecciones cuando, por primera vez, estuve al frente de una sala llena de estudiantes. 
À Coordenação de Aperfeiçoamento de Pessoal de Nível Superior CAPES, Programa Demanda Social, pela bolsa que me outorgou, possibilitandome a realização do curso.

Desde o início do curso de doutorado contei com a confiança e a colaboração irrestrita do Prof. Dr. Roberto Sbragia. Como monitor na sua disciplina, foi-me dada a oportunidade de aprender e contribuir. Como Assistente Técnico da ALTEC pude participar de uma grande rede de cientistas na área da gestão da inovação tecnológica, o que representou uma oportunidade adicional de crescimento profissional. Sinto-me honrado e agradecido de tê-lo tido como orientador e mestre, por suas qualidades humanas, acadêmicas e profissionais.

Aos professores Dr. Isak Kruglianskas e Dr. Milton de Abreu Campanário, pelas valiosas contribuições por ocasião do exame de qualificação.

Agradeço o apoio e o aprendizado que recebi de grandes mestres como os professores Adalberto Fischmann, Isak Kruglianskas e Almir Ferreira de Souza. Consigo, por meio deles, renovar meu interesse pelo conhecimento e pela vida acadêmica.

Alguns amigos, colegas do curso, ofereceram sempre seus conhecimentos, alegria e uma palavra de apoio. Um agradecimento especial para Luciana Peixoto Santa Rita, José Enrique Louffat, Grace Becker, Everton Cancellier e Marie Anne Macadar.

Muitas das minhas realizações não teriam acontecido sem a participação especial de Mari Gonçalves, Ivete Rodrigues e Selma Baião, do Núcleo de Política e Gestão Tecnológica. Obrigado pela amizade, presteza e atenção.

Sou muito grato pela ajuda recebida durante todo o período de convivência com os funcionários Dirce Rodrigues Soares, Edílson de Sousa e Sidney Terlizzi, da Unidade de Processamento de Dados da FEA 5.

Um agradecimento especial a Valéria Lorenção, Maria Aparecida Sales, Márcia Gomes Novo, Francisco Costa Oliveira e Luciene Cibele Soares, da Secretaria de Pós-Graduação, pela dedicação, competência e disposição em ajudar sempre que solicitados.

Sou muito grato a Eloísa Aléssio, Fabiana Caseiro e Daniela Alves Martins, da Coordenação do Programa de Pós-Graduação em Administração, pelo suporte administrativo recebido.

Finalmente, quero agradecer a Luster Borges Salama, Seu Zarzur, pela calorosa acolhida na sua família na minha permanência em São Paulo. 
"[...] as teorias, em geral, não são capazes de ser estabelecidas ou justificadas; e embora possam ser sustentadas por argumentos críticos, esta sustentação nunca é conclusiva."

Sir Karl R. Popper 


\section{RESUMO}

Trabalhos acadêmicos têm procurado explicar o impacto do uso estratégico da tecnologia no desempenho das empresas e identificar as práticas adotadas pelas empresas para o gerenciamento de sua estratégia tecnológica, bem como a relação desta com a sua competitividade. Porém, o entendimento da inter-relação entre os fatores que geram o processo de inovação e seu impacto econômico sobre as empresas ainda é deficiente. Neste sentido, na busca de elementos que possam contribuir para minimizar esta lacuna, este estudo procurou um melhor entendimento sobre a relação entre a capacidade de inovação e a formação de valor, através da identificação dos vetores de valor da capacidade de inovação capazes de gerar fluxos de caixa que contribuam para a formação de valor da empresa. A capacidade de inovação foi definida como o potencial interno para gerar novas idéias, identificar novas oportunidades no mercado e desenvolver uma inovação comercializável através dos recursos e competências existentes na empresa. Operacionalmente, a capacidade de inovação é um construto formado pela inter-relação sinérgica de sua cultura organizacional, de seus processos internos e de suas relações interorganizacionais. Estudos de casos múltiplos foram realizados em cinco empresas que trabalham com produtos e processos biotecnológicos. Foram observados valores e comportamentos peculiares da cultura organizacional, alguns processos internos característicos das empresas inovadoras e as relações interorganizacionais. Dentre os processos internos, foram analisados a gestão da carteira de projetos, a formulação e implementação da estratégia da empresa e a forma de assegurar uma melhor contribuição dos profissionais de P\&D para a empresa. Através do uso de Mapas Cognitivos, foram identificados os traços dos vetores de valor da capacidade de inovação e a forma como estes vetores se inter-relacionam. A análise comparativa dos mapas traçados em cada caso estudado revelou serem o fator humano e a gestão participativa potentes vetores de valor, os quais não foram contemplados nas premissas deste estudo e devem ser estudados com maior profundidade em estudos posteriores.

Palavras-chave: capacidade de inovação, cultura organizacional, processos internos, relações interorganizacionais, vetores de valor. 


\section{ABSTRACT}

Academic works have tried to explain the strategic use of technology and its impact in the companies' performance, and to identify practices adopted by companies for the management of their technological strategy, as well as the relation of these with its competitiveness. However, the understanding of the relationship between factors that generate the innovation process and its economic impact on companies is still deficient. In order to minimize this gap, this study searched for a better agreement on the relationship between innovation capacity and the formation of value by identifying the existing value drivers in the innovation capacity capable to generate cash flows that contribute to the company value capture. Innovation capacity was defined as the internal potential to generate new ideas, identify new opportunities in the market and develop a marketable innovation by leveraging existing resources and competences. Operationally, innovation capacity is a construct formed by the synergistic interrelationships of its organizational culture, its internal processes and networking. Five biotechnology companies were analyzed through multiple case studies. In each case, particular attention was given to values and behaviors of the organizational culture, some characteristic internal processes of the innovative companies and their networking. Among internal processes, project portfolio management, strategy formulation and implementation and the way to assure a better contribution of the R\&D personnel were analyzed. Using Cognitive Maps, it was possible to identify the innovation capacity value drivers and the way they interact. The comparison of the cases showed that human factors and participative management are powerful value drivers. Since these two factors have not been contemplated in the premises of this study, they need to be extensively analyzed in future studies.

Keywords: innovation capacity, organizational culture, internal processes, networking, value drivers. 


\section{LISTA DE FIGURAS}

FIGURA 1 Construto "capacidade de inovação" 18

FIGURA 2 Curva Clareza de Informação x Oportunidade 24

FIGURA 3 Como a cultura organizacional impacta o desempenho e a satisfação dos funcionários

FIGURA 4 O Fluxo de Caixa Líquido da Empresa e os vetores de valor

FIGURA $5 \quad$ Níveis de identificação de vetores de valor 54

$\begin{array}{lll}\text { FIGURA } 6 & \text { Modelo de Pesquisa Proposto } & 69\end{array}$

FIGURA 7 Vetores de valor da Capacidade de Inovação da Empresa 193

FIGURA 8 Análise do conceito dominante e de cluster no Mapa Cognitivo da Capacidade de Inovação da Empresa 1. 101

FIGURA 9 Vetores de valor da Capacidade de Inovação da Empresa 2. 105

FIGURA 10 Análise do conceito dominante e de cluster no Mapa Cognitivo da Capacidade de Inovação da Empresa 2.

FIGURA 11 Vetores de valor da Capacidade de Inovação da Empresa 3. 114

FIGURA 12 Análise do conceito dominante e de cluster no Mapa Cognitivo da Capacidade de Inovação da Empresa 3.

FIGURA 13 Vetores de valor da Capacidade de Inovação da Empresa 4.126

FIGURA 14 Vetores de valor da Capacidade de Inovação da Empresa 5.132

FIGURA 15 Análise do conceito dominante e de cluster no Mapa Cognitivo da Capacidade de Inovação da Empresa 5. 


\section{LISTA DE QUADROS E TABELAS}

QUADRO 1 Modelo de implementação e o questionamento do principal executivo.

QUADRO 2 Caracterização das Táticas de Implementação

QUADRO 3 Características básicas das pesquisas qualitativas e quantitativas

QUADRO 4 Definição das variáveis contribuintes

TABELA 1 Diretório Nacional de Empresas de Biotecnologia 2001: Distribuição total e percentual por estados brasileiros e o DF

TABELA 2 Diretório Nacional de Empresas de Biotecnologia 2001: Distribuição das empresas por segmentos de mercado e percentuais gerais de participação por segmento em estados de maior concentração

QUADRO 5 Relação das variáveis do estudo com as questões formuladas no instrumento auxiliar de coleta de dados.

QUADRO 6 Relação dos indicadores de resultado e das questões formuladas no instrumento auxiliar de coleta de dados para cada um deles

QUADRO 7 Qualificação dos Entrevistados e tempo de entrevista.

QUADRO 8 Síntese da análise dos principais traços dos valores e comportamentos que caracterizam a Cultura Organizacional.

QUADRO 9 Síntese da análise dos principais traços das variáveis estudadas nos Processos Internos.

QUADRO 10 Síntese da análise dos principais traços das variáveis estudadas nas Relações Interorganizacionais

QUADRO 11 Síntese das inovações alcançadas. 


\section{SUMÁRIO}

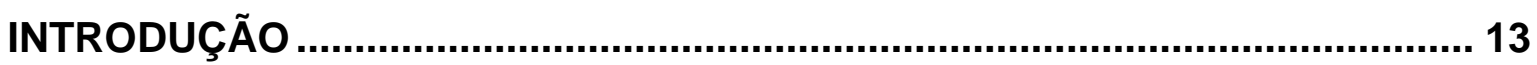

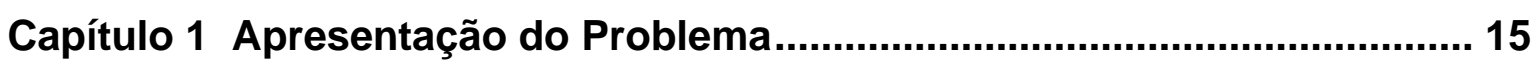

1.1 Definição da situação do problema ........................................................ 15

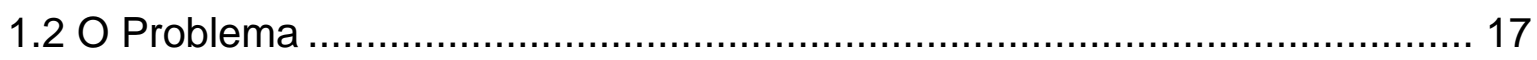

1.3 Objetivos e Contribuições do Estudo .................................................... 19

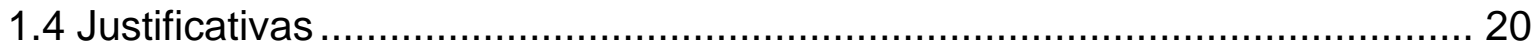

Capítulo 2 Marco Conceitual .......................................................................... 22

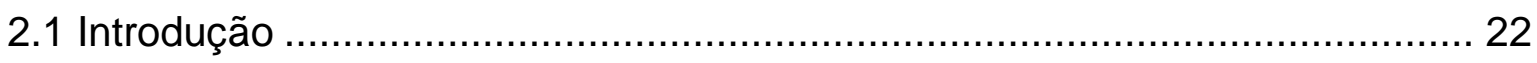

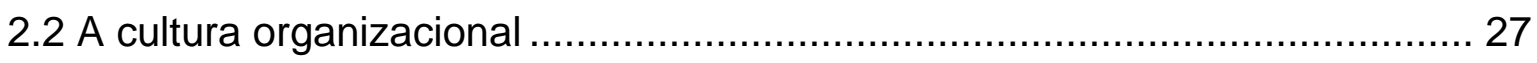

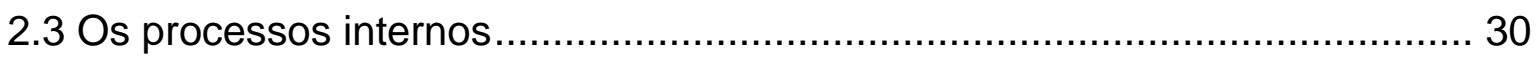

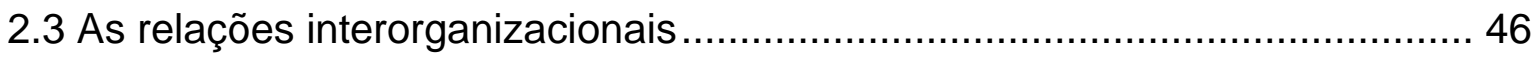

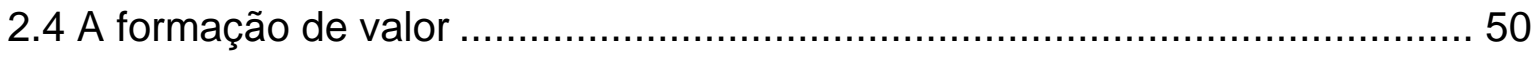

2.5 Síntese e contribuições da literatura para o estudo ..................................... 57

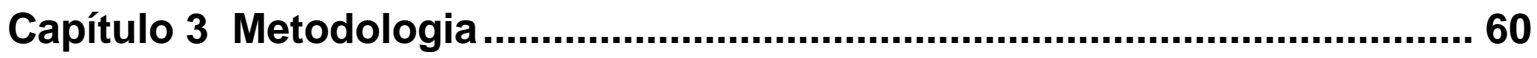

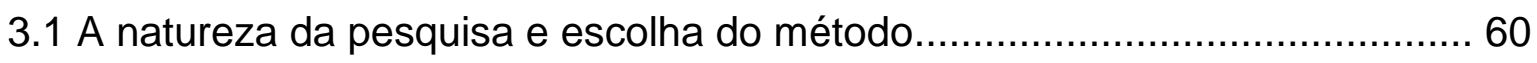

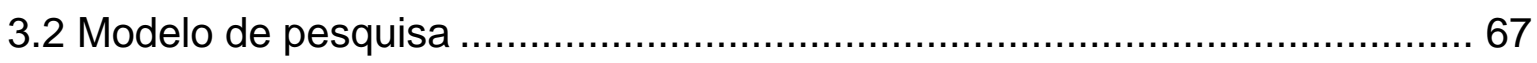

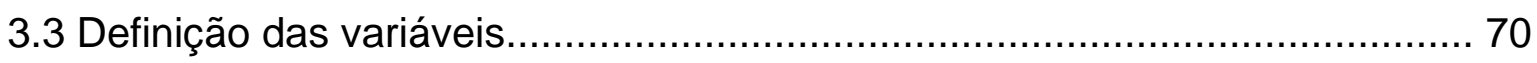

3.4 Identificação da amostra, critérios e procedimentos de seleção .................... 72

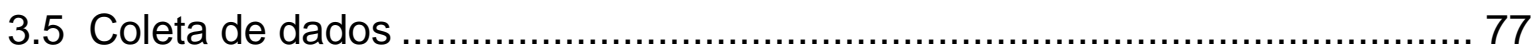

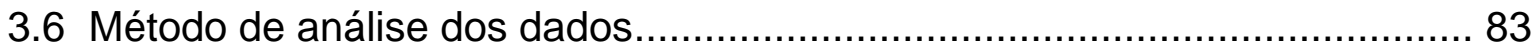

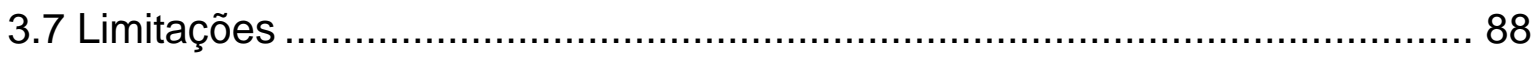

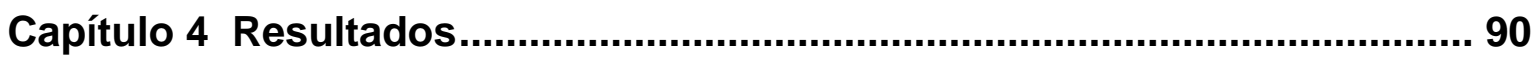

4.1 Empresa 1 - Empresa de Saúde Humana ............................................... 91

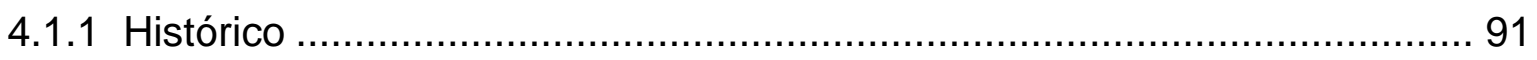

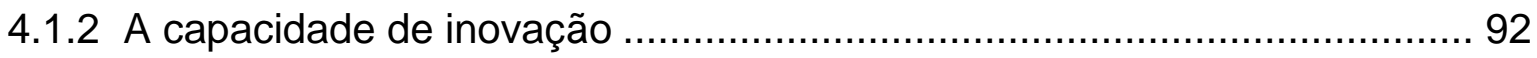

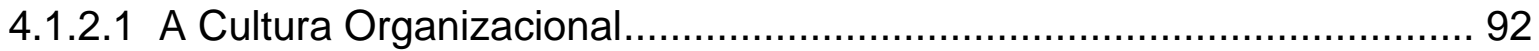

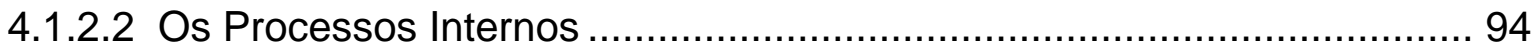

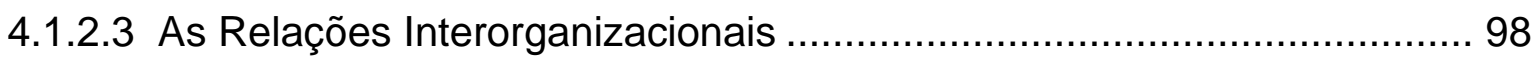

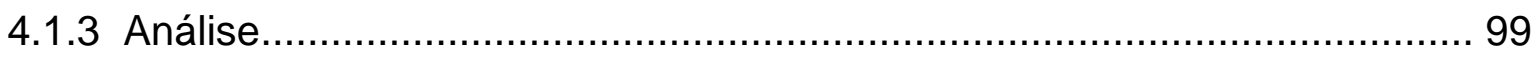

4.2 Empresa 2 - Empresa de Saúde Vegetal ..............................................103 


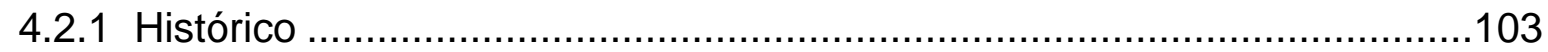

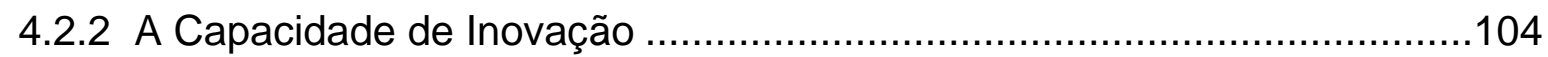

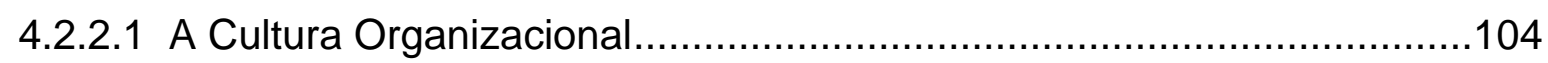

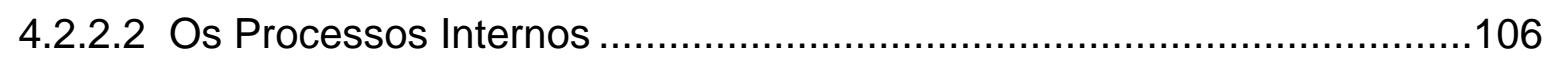

4.2.3.3 As Relações Interorganizacionais ..................................................109

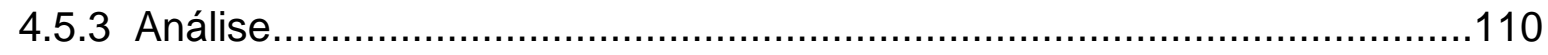

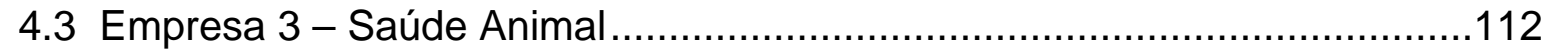

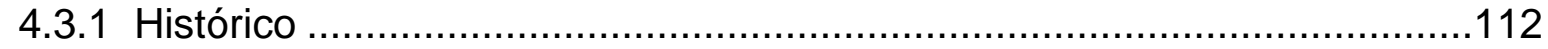

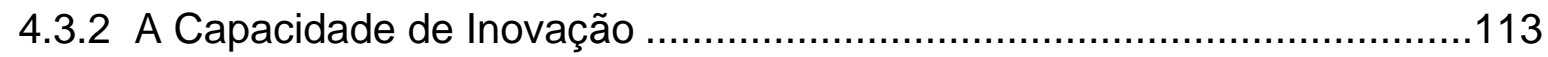

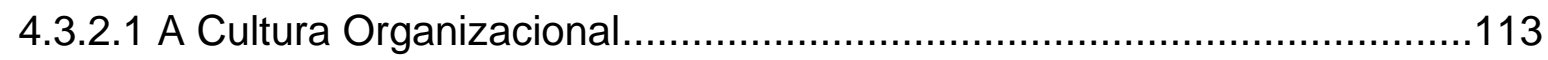

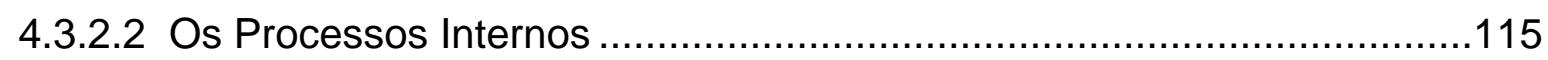

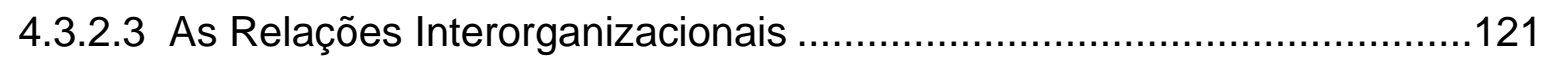

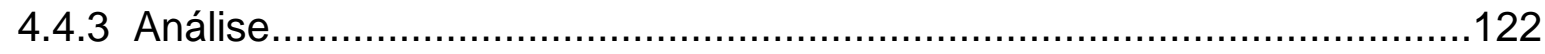

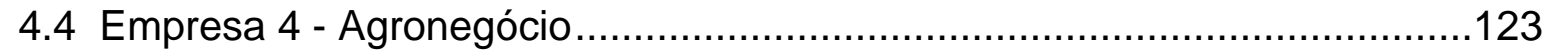

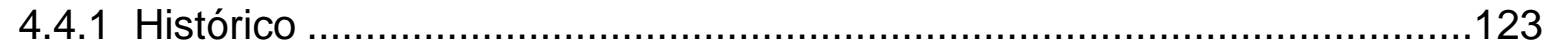

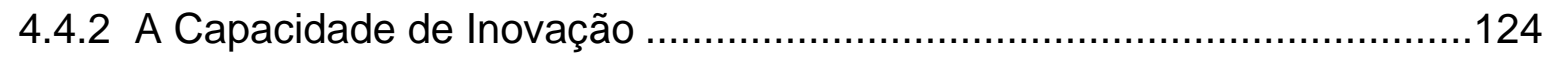

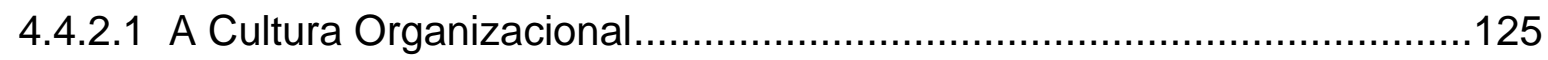

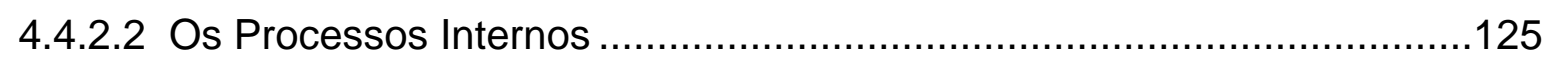

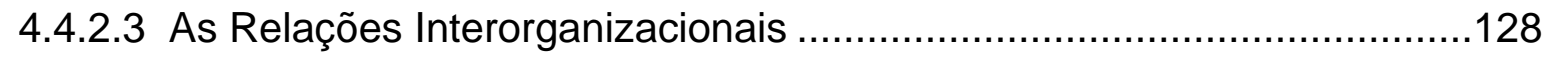

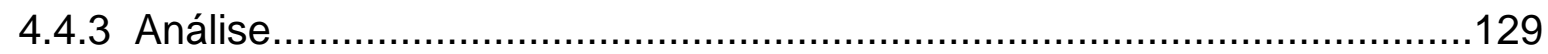

4.5 Empresa 5 - Empresa Multinacional Produtora de Insumos Químicos........130

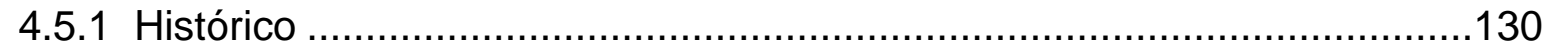

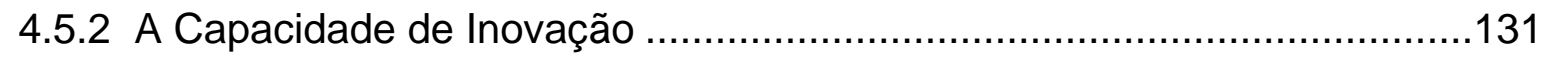

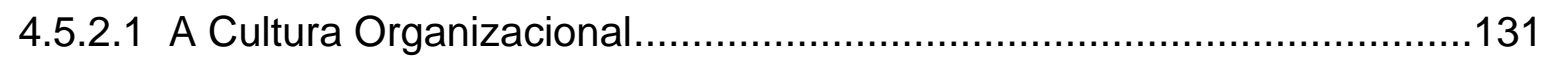

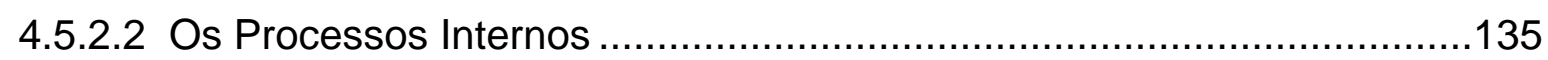

4.5.2.3 As Relações Interorganizacionais ………......................................140

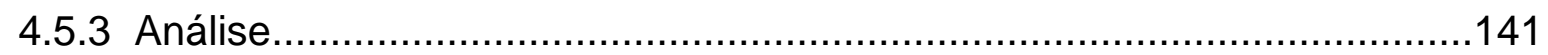

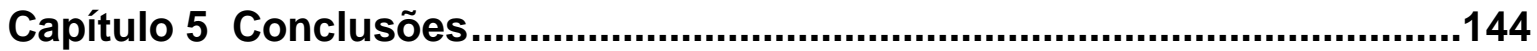

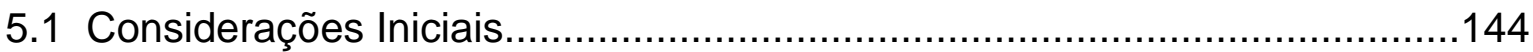

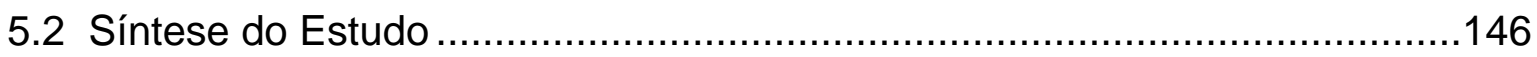

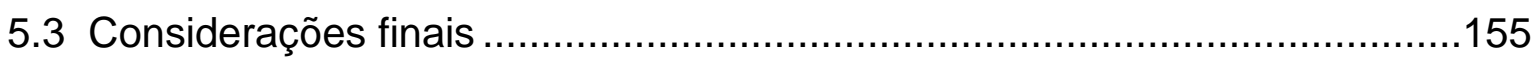

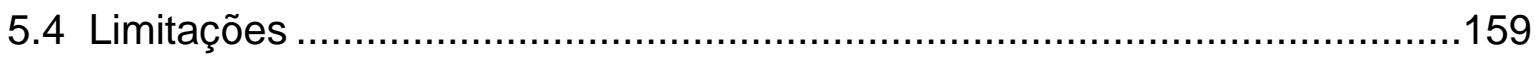

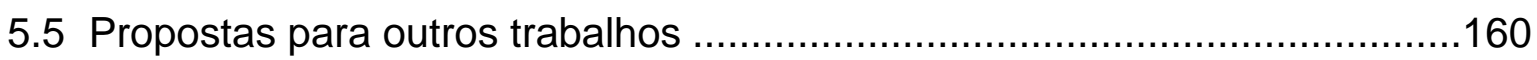




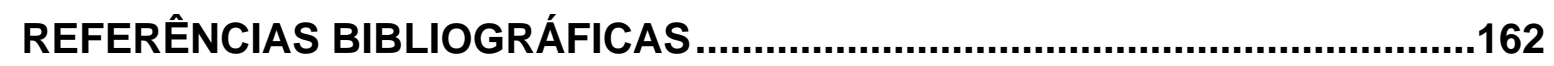

APÊNDICE INSTRUMENTO DE COLETA DE DADOS ..................................172 


\section{INTRODUÇÃO}

Pesquisas têm demonstrado que o desenvolvimento científico e tecnológico e a difusão de tecnologias estão intimamente relacionados ao aumento de produtividade e renda de nações, regiões e empresas. Igualmente, trabalhos científicos têm sido realizados no sentido de avaliar o impacto das atividades de Pesquisa e Desenvolvimento (P\&D) sobre o desempenho de empresas, sendo os indicadores de desempenho normalmente usados para este fim. Por tratar-se de um fenômeno multidimensional, qualquer avaliação que utiliza indicadores, sejam estes financeiros ou não, resulta apenas em apreciações parciais do fenômeno inovação. Ainda não está claro de que forma a capacidade de inovação de uma empresa pode afetar seu desempenho.

Este estudo, de caráter exploratório, pretende contribuir com a ciência administrativa ao buscar evidenciar elementos da capacidade de inovação que possam propiciar a formação de valor nas empresas, visto ser este o indicador mais completo que uma empresa pode ter com relação a seu desempenho. Especificamente, o estudo se baseou em dados fornecidos por cinco empresas de Biotecnologia, atuando em diferentes campos de aplicação no país.

O trabalho é apresentado em cinco capítulos. No primeiro, são apresentados o problema em estudo e seu marco contextual, abrangendo os objetivos, as contribuições do estudo para o conhecimento na área e as justificativas.

No segundo capítulo, ao apresentar as bases teóricas relativas ao tema em estudo, se discorre sobre o estado atual da arte, evidenciando alguns dos fatores 
mais característicos da capacidade da inovação com potencial para contribuir com o desempenho da empresa, bem como os fundamentos teóricos envolvidos na apreciação do valor e seu gerenciamento.

O terceiro capítulo versa sobre a metodologia utilizada na pesquisa, a qual abrange o desenho de pesquisa, a escolha do método de investigação, a definição das variáveis, o contexto industrial no qual foi realizado o estudo, os critérios e procedimentos usados para a seleção de casos de estudo, a forma de coleta dos dados, a metodologia de análise e as limitações impostas pela própria metodologia empregada.

Os resultados alcançados na análise dos dados obtidos em cada empresa são apresentados e discutidos no quarto capítulo. Os dados foram estruturados em forma de Mapas Cognitivos, os quais foram utilizados como ferramenta para elucidar as variáveis da capacidade de inovação que contribuem para a formação de valor, tomando como base os fatores cultura organizacional, processos internos e relações interorganizacionais.

O quinto capítulo apresenta as conclusões do estudo, tendo sido feita uma comparação entre as variáveis encontradas na análise de cada empresa, bem como discutidas as limitações que molduram este estudo e propostas para a realização de futuros trabalhos neste mesmo tema. 


\section{Capítulo 1}

\section{Apresentação do Problema}

\subsection{Definição da situação do problema}

É comumente aceito que o desenvolvimento e a difusão de novas tecnologias são fundamentais para o aumento do desempenho e da produtividade de empresas, regiões, setores econômicos e países. Pesquisa realizada por Morbey (1988), levando em consideração os gastos em pesquisa e desenvolvimento (P\&D), o crescimento das vendas e a lucratividade em empresas norte-americanas durante um período de 10 anos, mostrou que não existe uma relação significativa entre a intensidade de $P \& D$ e a rentabilidade, mas existe uma forte associação entre a intensidade de P\&D e o crescimento subseqüente nas vendas no longo prazo. No entanto, as conclusões do autor deixam claro que o investimento em P\&D é apenas um dos fatores que tem a capacidade de influir no resultado nas vendas no longo prazo. Sbragia (1993) apresenta uma contribuição ao tema ao avaliar as possíveis contribuições da atividade de P\&D para 0 desempenho da empresa. O autor parte da premissa que a eficácia de um grupo de P\&D é um conceito multidimensional, o qual compreende muitos aspectos, não existindo, portanto, uma medida única de eficácia. De fato, nas suas conclusões, o estudo apresenta um modelo sugerindo "um conjunto de indicadores de resultado estratificados segundo seu impacto sobre o grupo de $P \& D$, outras funções empresariais e sobre a firma como um todo" (SBRAGIA, 1993, p. 280).

Da mesma forma, trabalhos acadêmicos têm procurado explicar o impacto do uso estratégico da tecnologia no desempenho das empresas (CUNHA, 1994) 
ou, ainda, identificar as práticas adotadas pelas empresas para o gerenciamento de sua estratégia tecnológica e a relação destas com a sua competitividade (SOUZA, 1993). Porém, o entendimento da inter-relação entre os fatores que geram o processo de inovação e do impacto econômico destes sobre as empresas ainda é deficiente (OECD, 1997; NEELY e HII, 1998). Neste sentido, na busca de elementos que possam contribuir para minimizar esta lacuna, este estudo procura um melhor entendimento sobre a relação entre a capacidade de inovação e a formação de valor, como critério de avaliação do desempenho de uma empresa, focalizando o setor de biotecnologia.

Até um passado muito recente não se ouvia nem se lia em qualquer mídia a expressão "indústria de biotecnologia". A biotecnologia era vista apenas como um conjunto de técnicas ou, como definição dada pelo do Ministério do Meio Ambiente do Brasil, "qualquer aplicação tecnológica que utilize sistemas biológicos para fabricar ou modificar produtos e processos para utilização específica" (BRASIL, 2000). A biotecnologia permeia setores econômicos tradicionais como a saúde humana e animal, a produção vegetal, a indústria de alimentos e o manejo do meio ambiente, por exemplo. Atualmente, o termo indústria de biotecnologia já é usado por importantes empresas de consultoria e análise de investimentos, como a Robertson Stephens International (WILLIAMS e HANKS, 2001) e a Ernst \& Young (2004), para mencionar algumas, e já se estabelecem, igualmente, organizações de classe voltadas para a área como a BIO - Biotechnology Industry Organization (2004). Como as classificações setoriais da economia são realizadas para delimitar campos de ação, já estão sendo realizadas discussões para identificar as indústrias relacionadas com a biotecnologia na próxima revisão do ISIC - Internacional Standard Industrial Classification of Economic Activities. (OECD, 2002).

Diante do exposto, o termo Indústria ou Setor de Biotecnologia será utilizado neste trabalho para se referir ao conjunto de empresas que utilizam, de alguma forma, das técnicas da biotecnologia, guardados os devidos cuidados e limitações do uso do termo pela indústria. A indústria de Biotecnologia está em grande evidência entre as indústrias de alta tecnologia, com novas descobertas sendo realizadas numa freqüência elevada, o que permite o desenvolvimento de 
novos produtos e processos dirigidos ao diagnóstico, ao tratamento e à cura de doenças em humanos, assim como o desenvolvimento de animais e plantas geneticamente modificadas e novos alimentos.

A pesquisa e o desenvolvimento de um novo produto em uma empresa de biotecnologia numa área específica pode ser decorrente dos avanços científicos e das rupturas radicais na ciência (technology push), da demanda de mercado (demand pull) ou da combinação de ambas as forças. Em qualquer caso, a quantidade relativa de recursos alocados pela empresa na Pesquisa e no Desenvolvimento Experimental (P\&D) afeta a sua capacidade de inovação e o seu desempenho. Além desta variável, a intensidade de interação entre as empresas do setor, pelo uso de suas capacidades complementares e recursos estratégicos, possibilita o avanço das inovações (SALLES-FILHO et al., 2001; JUDICE, 2001).

\subsection{O Problema}

As empresas que trabalham com produtos e processos biotecnológicos passam por longos períodos de maturação até colocar seus produtos no mercado. Estas empresas são consideradas lentas se comparadas com a indústria de informática, por exemplo. Outras vezes, não chegam a colocar um produto no mercado, sendo elas mesmas o próprio produto de venda (JUDICE, 2001). A capacidade da empresa de sustentar-se durante um longo período de maturação ou de agregar valor para ser adquirida no futuro é um elemento característico da sua competitividade e esta uma função da capacidade de inovação. A capacidade de inovação de uma empresa pode ser definida como "o potencial interno para gerar novas idéias, identificar novas oportunidades no mercado e desenvolver uma inovação comercializável através dos recursos existentes e competências" (NEELY e HII, 1999, p.7). A partir desta definição pode-se dizer que a capacidade de inovação de uma empresa é um construto formado pela inter-relação sinérgica de sua cultura organizacional, de seus processos internos e de suas relações interorganizacionais (Figura 1). 


\section{Capacidade de Inovacão}

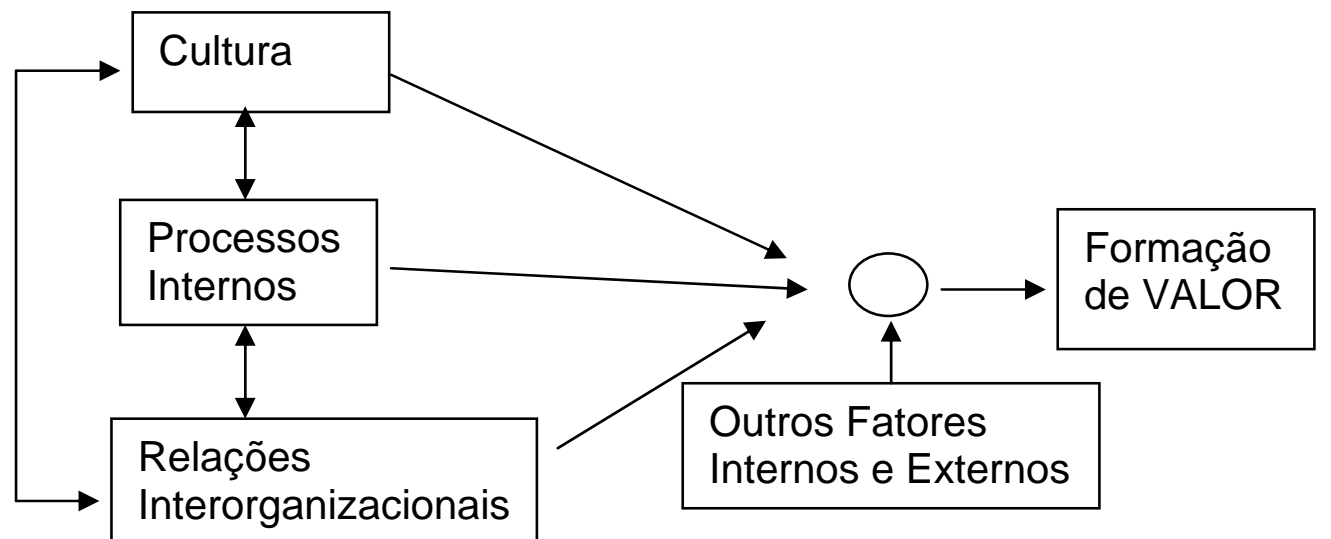

Figura 1 - Construto "capacidade de inovação"

Fonte: adaptado de Neely e Hii $(1999$, p.7)

O processo de inovação nas indústrias é caracterizado pela natureza intangível de muitos dos fatores nele envolvidos, e.g., criatividade, habilidades e destrezas dos funcionários e seus conhecimentos, entre outros. Numa economia baseada no conhecimento, a inovação desempenha um papel preponderante, porém, o complexo processo de inovação não é, ainda, suficientemente compreendido (OECD, 1997, NEELY e HII, 1998). O termo "Economia do Conhecimento" é a expressão usada comumente para descrever a tendência das economias avançadas em depender do conhecimento, informação e altos níveis de treinamento, e ainda poder acessar tudo isto de forma rápida. As nações que desenvolvem e efetivamente manejam os ativos baseados no conhecimento têm desempenho superior àquelas que assim não o fazem. Da mesma forma, as empresas com maior quantidade de ativos baseados no conhecimento superam aquelas com menor quantidade de ativos.

Para autores como Edvinsson e Malone (1998), Steward (1998) e Kaplan e Norton (1997) há uma necessidade vital de identificar os recursos de natureza intangível utilizando-se de indicadores de tendência (leading indicators) e de indicadores financeiros (lagging indicators, assim chamados por usar informações financeiras que representam eventos passados), uma vez que estes recursos proporcionam desempenho superior para as empresas e uma vantagem competitiva. Porém, ao medir o desempenho de uma empresa através de indicadores, mesmo utilizando uma ampla variedade deles, ter-se-á uma 
apreciação apenas parcial das relações causa-efeito, em função de seu próprio caráter multidimensional.

O valor é a melhor métrica de desempenho empresarial porque é a única que exige informação completa, sendo impossível tomar decisões corretas sem informação completa (COPELAND et al., 2000). O valor da empresa é determinado pelos fluxos de caixa futuros descontados e é criado quando as empresas têm retornos sobre o investimento que excedem seu custo de capital (FRIGO, 2002). "A administração baseada no valor é um processo integrador, cujo objetivo é melhorar o processo de decisões estratégicas e operacionais na organização como um todo, a partir da ênfase atribuída aos principais value drivers [ou vetores de valor] da empresa" (COPELAND et al., 2000, 87).

O propósito deste trabalho é examinar como determinados aspectos da capacidade de inovação se relacionam com alguns vetores de valor em empresas da indústria brasileira de biotecnologia. Desta forma, as perguntas que norteiam este estudo podem ser assim formuladas: Como determinados fatores da capacidade de inovação propiciam a formação de valor das empresas? Qual é a inter-relação existente entre os fatores que caracterizam a capacidade de inovação?

\subsection{Objetivos e Contribuições do Estudo}

O objetivo deste estudo é conhecer a dinâmica dos fatores que compõem a capacidade de inovação e determinar como estes fatores, nas suas inter-relações, contribuem para a formação de valor das empresas. Serão evidenciados os vetores de valor, os elos entre eles e, ainda, o grau em que estes podem ser administrados. A idéia é caracterizar as práticas gerenciais e os aspectos culturais associados a estes vetores necessários para promover a inovação.

Desta forma, as contribuições teóricas almejadas no presente estudo podem ser assim sintetizadas:

- Melhor entendimento de como a capacidade de inovação pode propiciar a formação de valor em empresas de biotecnologia; 
- identificação dos fatores da capacidade de inovação que propiciam a formação de valor e a forma como estes se inter-relacionam;

- identificação das práticas administrativas e da forma como estas são estruturadas para propiciar a formação de valor.

Por outro lado, ao analisar detalhadamente o processo de desenvolvimento da capacidade inovativa de algumas empresas de biotecnologia no Brasil, se estarão gerando dados que poderão se tornar subsídios para que as empresas alavanquem sua capacidade de inovação. Estas contribuições práticas podem ser assim destacadas:

- Desenvolvimento de um esquema analítico que subsidie o entendimento de como a gestão da capacidade de inovação em empresas de biotecnologia pode alavancar seu desempenho e a formação de seu valor no longo prazo;

- Identificação de variáveis que possam auxiliar futuras pesquisas que, de forma conclusiva e estatisticamente representativas do setor, mostrem caminhos para que as agências governamentais de fomento possam elaborar políticas que promovam o desenvolvimento das empresas e a formação de riquezas para estas e para a região onde estão localizadas.

\subsection{Justificativas}

A escolha deste tema obedece a critérios intrínsecos do pesquisador, ligados a aspectos subjetivos de afinidade pela área de especialidade e/ou concentração e a sua experiência profissional. Mas esta subjetividade, de modo paradoxal, sustenta-se também em critérios objetivos, os quais justificam a decisão de desenvolver o presente estudo, tais como:

- O tema é atual Entender e elucidar a interligação das variáveis ou fatores que compõem a capacidade de inovação de uma empresa e seu impacto no desempenho empresarial é motivo de preocupação e estudo, tanto por organismos internacionais como por núcleos de pesquisa, na área de 
gestão da inovação tecnológica. Pela própria característica multidimensional, ainda não há uma resposta precisa sobre o entendimento da dinâmica interna das variáveis que compõem o próprio construto capacidade de inovação, muito menos uma forma de mensurar seu impacto no desempenho empresarial que compreenda toda a extensão do fenômeno.

- O tema é importante Pretende-se contribuir para o desenvolvimento da ciência na área de gestão da inovação tecnológica. Embora o estudo esteja centrado nas empresas como unidades de análise, o enfoque será dado a um tipo especial de empresa que, por definição, já tem uma base de "alta tecnologia" como elemento distintivo. O resultado do estudo poderá dar subsídios tanto para os gerentes e empresários como para os formuladores de políticas científicas e tecnológicas, sugerindo áreas passíveis de intervenção para alavancar o desempenho da indústria de biotecnologia.

- O tema é original e inédito Não foi encontrado na literatura nenhum estudo que relacione a capacidade de inovação com a formação de valor no longo prazo. Por outro lado, existem estudos que relacionam a gestão da inovação tecnológica com alguns indicadores de desempenho empresarial, mas, devido ao caráter multivariado destes construtos, apenas permitem uma apreciação parcial do fenômeno. Será proposto um modelo teórico que buscará explicar, embora de forma exploratória, a relação existente entre a capacidade de inovação das empresas e seu impacto na formação de valor no longo prazo. 


\section{Capítulo 2}

\section{Marco Conceitual}

\subsection{Introdução}

A inovação tecnológica é um dos temas mais importantes e mais complexos a serem enfrentados pelas empresas e organizações no momento atual. Trata-se de um problema controlado ou restringido sob muitos aspectos, mas, por outro lado, é uma atividade cujo domínio é vital para o bem-estar de empresas e organizações, e, numa visão mais abrangente, nações, comunidades e famílias, uma vez que estas últimas são as que usufruem o benefício de uma melhora na sua qualidade de vida.

A inovação está no cerne da mudança econômica. Schumpeter (1991) propôs, na primeira metade do século $X X$, algumas formas de inovação: a introdução de um novo produto ou a mudança de alguma característica em um produto já existente; um novo processo de produção numa determinada indústria; a entrada ou criação de um novo mercado; o desenvolvimento de uma nova fonte de fornecedores de matéria-prima; e mudanças na própria organização industrial. É importante saber por que as mudanças tecnológicas ocorrem e por que as empresas inovam. De acordo com os escritos do autor, uma das razões é a busca de receitas pelas empresas. Segundo Porter (1992), uma nova tecnologia é uma fonte de vantagem competitiva para o inovador. No caso de uma tecnologia cuja implementação resulte em aumento de produtividade do processo, a empresa ganha uma vantagem em custo sobre seus concorrentes. Isto possibilita 
um aumento de sua margem de lucro, ao manter constante o preço de mercado, ou, ainda, a implementação de uma estratégia de penetração de mercado com a redução do preço de venda sobre seu produto. No caso de uma inovação de produto, a empresa pode ganhar um papel monopolístico através do uso de privilégios da propriedade industrial ou, ainda, ganhar o mercado pelo fato de ser a primeira a chegar a este mercado.

Um dos grandes desafios na gestão da inovação é conseguir associar tecnologias emergentes com mercados emergentes. Se fosse somente uma questão de atrelar os produtos das novas tecnologias com mercados existentes, ou vice-versa, a tarefa seria relativamente fácil (BROWN apud MILLER e MORRIS, 1999).

Associada aos desafios impostos pela introdução de produtos de novas tecnologias e pelos novos mercados está a mudança, em larga escala, das regras na economia. Se, durante quase oito décadas do século XX, os ganhos em produtividade eram alcançados através da aplicação do conhecimento nos recursos naturais, nas máquinas e no trabalho, as evidências indicam que os ganhos de produtividade, no ambiente atual, dependem da aplicação do conhecimento sobre o conhecimento (STEWARD, 1998).

A capacidade de gerenciar ativos intangíveis na forma de conhecimento é vital para as empresas, uma vez que o conhecimento é um recurso fundamentalmente distinto de outros ativos tangíveis. O conhecimento é criado e usado somente por indivíduos, não existindo uma forma palpável para expressá-lo que não seja a demonstração do conhecimento por parte das pessoas que o detêm. Gerenciar conhecimento requer habilidades e processos completamente diferentes daqueles usados para gerenciar ativos tangíveis (EDVINSSON e MALONE, 1998).

O tempo envolvido na inovação tecnológica é um problema complexo e se constitui em um desafio significativo. Quando as idéias para o produtos e serviços são verdadeiramente novas, apenas fracas evidências sustentam sua validade. A medida em que o tempo passa, mais evidências são acumuladas na forma de conhecimento, mas, por outro lado, esperar muito pelo estabelecimento do conhecimento pode significar o fim de uma oportunidade (MILLER e MORRIS, 
1999). Se fosse possível medir e representar graficamente esta idéia, a figura gerada teria o formato apresentado da Figura 2. Nesta são mostradas as trajetórias inversas das duas curvas que representam o paradoxo existente entre o conhecimento, representado pela clareza da informação, e as oportunidades de inovação. Assim, aguardar reunir todas as informações necessárias ao desenvolvimento de um novo produto ou processo pode significar que a oportunidade de inovação aconteça quando ela não seja mais uma novidade no mercado, o que está representado pelo ponto a da Figura 2. Todo gerente sabe que quanto maior for o volume de informações a respeito de um investimento, maior será a percepção da dimensão dos riscos que estão sendo assumidos.

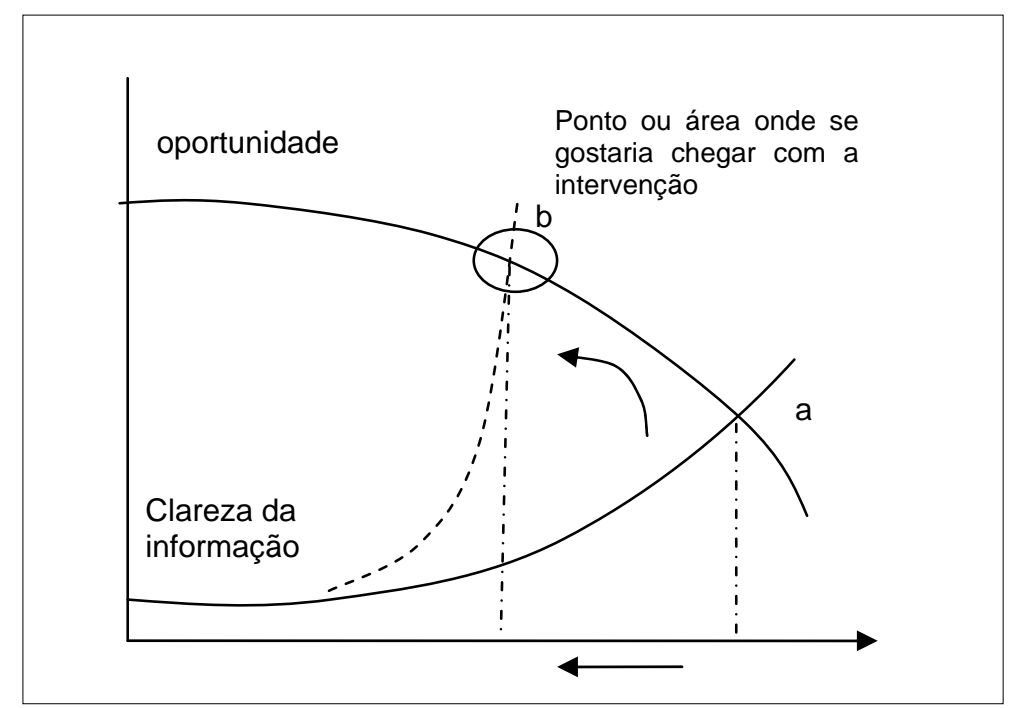

Figura 2: Curva clareza da informação x capacidade. Fonte: adaptada de Miller e Morris (1999, p. xv e xvi)

Neste sentido, a gestão da capacidade de inovação está centrada, especificamente, na gestão do conhecimento relevante, o qual permite identificar os fracos sinais das oportunidades existentes, de tal modo que se atinja a curva representativa das oportunidades de forma antecipada, ou seja, quando as oportunidades são ainda atrativas e substanciais, momento representado pelo ponto $b$ na Figura 2 (MORRIS e MILLER, 1999, p. xv).

Para lidar com as incertezas do ambiente e sentir os fracos sinais das oportunidades, os administradores devem coletar, processar e agir com base em enorme quantidade de informações (BATEMAN e SNELL, 1998). As informações 
fluem do ambiente externo para aqueles que tomam decisões dentro da organização. Para que as decisões sejam eficazes e as empresas prosperem, os gerentes devem desenvolver mecanismos eficazes de processamento de informações.

Malek e Bregger (2001) afirmam que o sucesso da P\&D depende de decisões corretas, tomadas de forma sumamente rápida, bem como da colaboração entre os pesquisadores da empresa e da redução da duplicação de esforços, fenômeno freqüente em muitas organizações de P\&D. Para tanto, as empresas devem aprender a captar, processar, partilhar e re-utilizar o conhecimento de forma mais eficiente, tanto internamente quanto com colaboradores externos. É necessário que sejam rompidas as barreiras organizacionais, as quais impedem a efetiva colaboração e a partilha do conhecimento. Estas representam condições básicas capazes de minimizar o tempo de chegada ao mercado dos novos produtos.

Lawrence e Lorsch (1973), buscando identificar as características que uma empresa deve ter para enfrentar, com eficiência, as diferentes condições externas, tecnológicas e de mercado, concluíram que para processar todas estas informações em ambientes complexos, as empresas necessitam organizar-se de forma que setores diferenciados interajam com sua área de especialização no ambiente externo, além de criar mecanismos que promovam a integração destas diferentes partes.

Bateman e Snell (1998) apresentam alguns mecanismos que promovem a integração, os quais variam dos mais simples para aqueles mais complexos: contato direto entre administradores que partilham um mesmo problema; papéis de ligação ou cargos especializados para operar as comunicações entre dois departamentos; forças-tarefa ou grupos de representantes de diversos departamentos, reunidos temporariamente para resolver um problema comum; equipes ou grupos interdepartamentais permanentes de tomada de decisão e administradores de programas ou de projetos coordenando grupos inter e multidisciplinares que têm uma tarefa comum a desempenhar.

A capacidade de inovação nas empresas depende de diversos fatores, além dos esforços que têm de empreender para criar novos produtos ou melhorar 
os processos de produção, melhorar a capacitação da mão-de-obra e sua habilidade para aprendizagem, bem como a melhoria geral do ambiente de trabalho (PAPACONSTANTINOU, 1997).

Com base nos resultados de pesquisa realizada na Inglaterra pela Confederation of British Industry - CBI e o Department of Trade and industry DTI, numa amostra de 76 empresas de base tecnológica, que mostrou os fatores de sucesso mais característicos de empresas com boas práticas gerenciais, Neely e Hii (1998) identificaram as três dimensões-chave que ajudam a definir o construto "Capacidade de Inovação". Para estes autores a capacidade de inovação de uma organização pode ser definida como o potencial para gerar uma saída inovativa, sendo este potencial dependente da inter-relação sinérgica da cultura da empresa, dos processos internos e das relações interorganizacionais. Esta caracterização foi feita com base nas seguintes observações:

- Cultura Organizacional: havia uma clara consciência da missão e dos objetivos da empresa; a inovação fazia parte da estratégia; havia uma estrutura organizacional achatada que privilegiava a formação de equipes; havia um encorajamento para tentar novas soluções e assumir riscos, entre outros.

- Processos Internos: havia uma especial preocupação com:

- a geração e captura de idéias e critérios claros para a gestão da carteira de projetos;

- a formulação e implementação da estratégia da empresa; o uso de indicadores de desempenho como forma de controlar a empresa e sua estratégia;

- os procedimentos adotados para assegurar uma melhor contribuição dos profissionais de P\&D para a empresa.

- Relações Interorganizacionais: a rede de relações externas à organização era essencial à habilidade de inovar, uma vez que atuava como veículo para importar conhecimento. Estas relações não se limitavam à aquisição de novas idéias, mas também à partilha de capacidades físicas e intelectuais. 
O construto formado por Neely e Hii (1998) foi utilizado, no presente trabalho, para embasar a análise destes fatores específicos da capacidade de inovação como potenciais vetores na formação de valor em empresas de biotecnologia no Brasil.

\subsection{A cultura organizacional}

A cultura organizacional refere-se à forma pela qual os funcionários percebem características descritivas dos costumes e práticas da empresa (ROBBINS, 2002). Edgar Schein (1985) define cultura como um conjunto de premissas que um grupo aprendeu a aceitar, como resultado da solução de problemas de adaptação ao ambiente e de integração interna. Essas premissas funcionam suficientemente bem para serem consideradas válidas e podem ser ensinadas a novos integrantes como sendo a forma correta de perceber, pensar, e sentir-se em relação a esses problemas de adaptação externa e integração interna.

Esta apreciação da cultura organizacional por parte dos funcionários independe de eles gostarem ou não dela. Trata-se apenas de uma descrição e não de uma avaliação da satisfação com o trabalho. A cultura é derivada da filosofia do fundador ou fundadores da empresa, a qual influencia, por sua vez, os critérios adotados na contratação dos funcionários. A forma como os funcionários serão socializados vai depender tanto do sucesso obtido no processo de seleção, no qual são avaliados os valores dos candidatos, como da preferência dos dirigentes quanto ao método de socialização (ROBBINS, 2002).

Jassawalla e Sashittal (2002, p. 43) definem cultura, no arranjo de inovação de produtos, como "o ambiente social e cognitivo, a visão partilhada da realidade e as crenças coletivas e valores do sistema, refletidos num padrão consistente de comportamento entre os participantes".

A cultura organizacional, além de definir a maneira como os integrantes devem interagir entre si e com o ambiente externo, diferencia uma organização de outra (MAXIMIANO, 2002). 
As pesquisas sobre cultura organizacional têm buscado medir como os funcionários vêem sua organização e, geralmente, buscam responder às seguintes questões: a cultura estimula o trabalho em equipe? Recompensa a inovação? Reprime as iniciativas? Como se realiza a comunicação? (ROBBINS, 2002)

Pesquisa realizada por O'Reilly III, Chatman e Caldwell (1991) sugere que existem sete características básicas que, em seu conjunto, capturam a essência da cultura de uma organização:

1. o grau em que os funcionários são estimulados a serem inovadores e assumirem riscos;

2. o grau em que os funcionários demonstrem precisão, análise e atenção aos detalhes;

3. o grau em que os administradores focalizam os resultados mais que os procedimentos empregados;

4. o grau em que as decisões dos administradores levam em consideração o efeito dos resultados sobre as pessoas dentro da empresa;

5. o grau em que as atividades de trabalho são organizadas estimulando um trabalho de equipe em contraposição a um trabalho individual;

6. o grau em que as pessoas são competitivas em vez de acomodadas; e

7. o grau em que as atividades organizacionais enfatizam o crescimento vis-à-vis a manutenção do status quo.

Robbins (2002), com base no estudo de O'Railly et al. (1991) mostra a cultura organizacional como uma variável interveniente capaz de afetar o desempenho da organização (Figura 3). Os funcionários formam uma percepção geral subjetiva da organização com base em fatores percebidos na forma de histórias, rituais, símbolos e a própria linguagem os quais, por sua vez, formarão a personalidade da organização. Estas percepções favoráveis ou desfavoráveis 
afetam o desempenho e a satisfação dos funcionários, sendo o impacto maior quanto mais forte é a cultura.

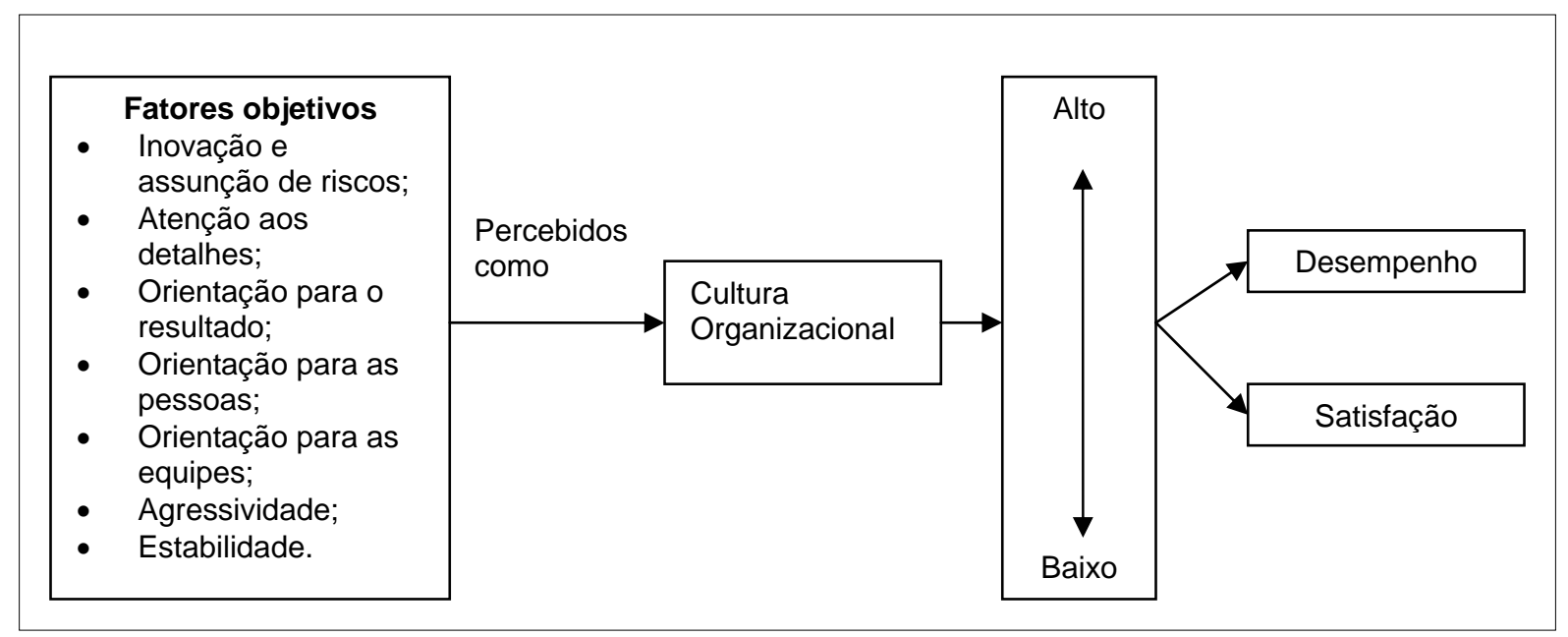

Figura 3: Como a cultura organizacional impacta o desempenho e a satisfação dos funcionários. Fonte: ROBBINS (2000, p. 517)

Subramaniam e Ashkanasy (2001) definem a dimensão inovação na cultura organizacional em termos dos seguintes valores: ser inovadora e com anseio para experimentar novas idéias; ser oportunista; não ser restringida por regulamentos e normas; e ter coragem de assumir riscos. Com estas características, afirmam os autores, os gerentes que percebem a cultura organizacional da empresa como altamente inovadora se sentem confortáveis para realizar projetos que são novidade, não testados e com risco.

Estudo de casos múltiplos realizados por Jassawalla e Sashittal (2002, p. 43) sobre culturas que apóiam processos de inovação de produto levou a resultados que permitiram distinguir dois grupos bem diferenciados de empresas, adotando como variável de saída se os novos produtos, desenvolvidos a partir de novas tecnologias, eram desenvolvidos dentro do cronograma planejado e do orçamento e, além disso, alcançavam sucesso no mercado. Fazendo uso de artifícios observáveis da cultura, como vocabulário, estórias, rituais e símbolos físicos, concluíram que culturas que sustentam processos de inovação de produto apresentam os seguintes elementos:

* Valores, crenças e suposições dos participantes: 
- tomar iniciativa, mostrar criatividade e assumir riscos são importantes e esperados;

- todos os participantes são capazes de serem confiados numa missão cocriativa e são importantes e igualitários "stakeholders";

- todos os participantes (incluindo clientes principais, fornecedores chave e membros de outros grupos funcionais) são 'da casa' e se devem envolver cedo no processo de desenvolvimento de processo;

- as mudanças organizacionais são energéticas e refrescantes. As mudanças deves ser abraçadas em vez de dificultadas.

* Comportamentos

- os participantes falam de um claro senso de controle que eles sentem sobre seus envolvimentos no processo de desenvolvimento de novos produtos;

- os participantes mostram altos níveis de co-criatividade e comportamento colaborativo; e

- os participantes mostram desejos de receber retro-alimentação por parte dos outros.

\subsection{Os processos internos}

Dentre os inúmeros processos internos realizados por qualquer tipo de empresa, alguns se destacam como mais característicos das empresas inovadoras, podendo-se citar: a capacidade de gerar e captar idéias, a gestão da carteira de projetos, a formulação, comunicação e gestão da estratégia empresarial através do uso de indicadores e a capacidade de gerenciar, desenvolver e aproveitar todo o conhecimento apresentado pelos funcionários da empresa. No procedimento de coleta de dados para o presente estudo, pretendeobservar com maior detalhe, em princípio, os processos citados, uma vez que, potencialmente, promovem a inovação.

Empresas inovadoras geram e capturam, constantemente, novas idéias. A busca por inovações começa no momento em que ocorre uma invenção, o que acontece devido à combinação de necessidades práticas, introspecções, tecnologias disponíveis, infra-estrutura, problemas ou possibilidades, e continua quando alguém faz o esforço para obter esse novo conhecimento. Este conhecimento é, então, transformado em novas competências que, posteriormente, se transformarão em novas tecnologias incorporadas nos produtos ou nos processos.

Roussel, et al. (1992) propõem três tipos básicos de P\&D: incremental, radical e fundamental. A P\&D incremental tem como meta os pequenos avanços 
tecnológicos, baseados na aplicação de conhecimentos tecnológicos e de engenharia já estabelecidos. Normalmente, as inovações resultantes deste tipo de P\&D trazem, por exemplo, melhoras no desempenho do produto, na conservação de energia ou, ainda, resultam numa maior eficiência do processo de fabricação. Na P\&D radical, a base de conhecimento técnico e científico por si só é insuficiente para conduzir a um resultado prático desejado. Embora este tipo de P\&D não resulte, na maioria das vezes, em sucesso, oferecem, quando se obtêm êxito, altas margens de lucro para as empresas. Finalmente, a P\&D fundamental visa desenvolver a capacidade de pesquisa em profundidade em campos científicos e tecnológicos nos quais a empresa considera que poderá exercer uma vantagem estratégica no longo prazo.

Miller e Morris (1999) chamam de inovação contínua aquela que acontece a partir do conhecimento já estabelecido. Acontece quando as demandas futuras dos consumidores podem ser obtidas por meio do conhecimento existente, no mercado existente e sem nenhum desafio nas estratégias. A inovação descontínua acontece fora dos mercados e segmentos existentes. Ela se caracteriza pelo pensamento divergente e por conseguir ver além das fronteiras para descobrir os novos conhecimentos relacionados tanto com as necessidades do mercado quanto com a capacitação tecnológica.

De acordo com Martino (1995), seja qual for o tipo de P\&D ou inovação, seu gerenciamento sempre vem acompanhado de um problema: existem mais idéias ou projetos em potencial para serem desenvolvidos que recursos financeiros, humanos e de infra-estrutura física. É preciso selecionar, de alguma forma, os projetos a serem executados dentro de um grande número de projetos propostos. O mesmo autor sentencia que uma falha em selecionar o "melhor" projeto leva a dois custos: o primeiro refere-se aos recursos alocados em projetos pobres e insignificantes; o segundo custo, ainda maior, diz respeito ao custo de oportunidade de projetos vigorosos que poderiam ser bem sucedidos se houvessem recebido em tempo recursos adicionais ou, ainda, aqueles projetos brilhantes que foram preteridos ou simplesmente não desenvolvidos pela falta de recursos. Em síntese, o autor refere-se à gestão da carteira de projetos. 
Cooper, Edgett e Kleinschmidt (1998, p 3) definem a gestão da carteira de projetos como:

[...] o processo dinâmico de decisão no qual uma lista ativa de novos produtos e projetos de $P \& D$ é constantemente atualizada e revisada. Neste processo, novos projetos são avaliados, selecionados e priorizados; projetos existentes podem ser acelerados, interrompidos ou não priorizados; recursos são alocados e re-alocados nos projetos ativos. O processo de decisão da carteira é caracterizado pela incerteza e mudança das informações, dinâmica oportunista, múltiplos objetivos e considerações estratégicas, interdependência entre os projetos e múltiplos tomadores de decisão e locais.

Em suma, pode-se dizer, com base nesta definição, que a gestão da carteira de projetos trata:

1. da alocação de recursos;

2. da hierarquização e seleção de projetos;

3. da operacionalização da estratégia da empresa.

A ênfase em uma ou outra destas atividades vai depender da função, da posição hierárquica e da formação técnica dos observadores e analistas que tomam as decisões na empresa.

Pesquisa realizada nas empresas afiliadas ao Industrial Research Institute (COOPER, et al., 2000, p 18) revelou que a importância e a atenção dada à gestão da carteira de projetos se deve às seguintes razões:

- Maximizar o retorno do investimento em P, D e E;

- Manter a posição competitiva da empresa;

- Alocar apropriadamente os recursos escassos;

- Forjar o vínculo entre a seleção dos projetos e a estratégia da empresa;

- Conseguir um forte foco;

- Obter um balanço entre projetos e investimentos; 
- Comunicar as prioridades de projetos de forma vertical e horizontal dentro da empresa;

- Proporcionar objetividade na seleção de projetos.

Este mesmo trabalho mostrou que, embora a efetiva gestão da carteira de projetos tivesse se convertido em um objetivo per se em muitas empresas, os resultados obtidos com as diversas metodologias de gestão não satisfaziam plenamente os objetivos esperados de cada uma delas. Ou seja, as metodologias conseguiam alinhar bem os investimentos em P\&D com a estratégia da empresa, conseguiam selecionar e impulsionar de forma satisfatória os projetos de alto valor, mas, no entanto, se mostravam insatisfatórias no balanceamento correto da carteira (COOPER et al. opus cit, 2000. p. 19).

As metodologias usadas para a gestão da carteira de projetos podem ser classificadas em categorias, conforme os objetivos propostos e/ou as técnicas analíticas dominantes: (1) hierarquizantes; (2) baseadas na teoria econômica de decisão (simples ou múltiplos estágios); (3) teoria de decisão; (4) otimização da carteira; (5) simulação; (6) modelagem cognitiva e (7) análise de clusters. Cada uma destas categorias gerais engloba várias técnicas (MARTINO, 1995, p. 6).

Os métodos de hierarquização são usados para estabelecer uma ordem nas propostas de projetos. O processo identifica os pontos chave de sucesso e, a partir daí, tenta-se um criar consenso entre os tomadores de decisão. Em princípio, uma vez ordenados os projetos, a gerência procede à distribuição dos recursos orçamentários, físicos ou humanos, de cima para abaixo, até o esgotamento destes recursos. De alguma forma, todos os métodos de hierarquização dependem da comparação entre os pares de projetos (BRENNER, 1994 e MARTINO, 1995).

Há métodos hierarquizantes que desenvolvem índices de hierarquia usando medidas financeiras, indicadores estratégicos de P\&D, indicadores de qualidade, indicadores que medem a capacidade da organização em interagir com o seu ambiente, indicadores de mercado e indicadores de tecnologia ou competência tecnológica (WALSH, 2001). 
Os métodos baseados na teoria econômica de decisão procuram avaliar a contribuição de cada projeto na formação do valor da empresa. Normalmente, levam em consideração o fluxo de caixa envolvido no projeto desde o seu início, passando pelo seu desenvolvimento, até a venda do produto ou até completar o seu ciclo final de vida. As técnicas de análise incluem o valor comercial esperado (VCE), o valor presente líquido (VPL), a taxa interna de retorno (TIR) e o período de retorno (payback). Normalmente, a metodologia requer informação que não pode ser obtida na primeira parte do ciclo de vida do projeto (COOPER et al., 1998).

Os métodos baseados nas teorias de decisão envolvem situações em que os tomadores de decisão se vêem diante de uma série de alternativas e cada uma delas com chances de ocorrência. A probabilidade de ocorrência de cada alternativa pode ser conhecida ou estimada. No final desta seqüência de alternativas e probabilidades de ocorrência, visualizada através de uma árvore de decisões na maioria das vezes, é selecionado o projeto que melhor agrega valor para a empresa (MARTINO, 1995; DAVIS et al., 2001; TRITLE et al., 2000).

Os métodos descritos até agora avaliam os projetos individualmente, sem levar em consideração as potenciais interações entre os projetos e o usos alternativos de recursos entre os mesmos. Por outro lado, os métodos de otimização da carteira de projetos têm como objetivo selecionar, da lista de propostas de projetos, o grupo que oferece o maior retorno ou agrega maior valor para a empresa. Estes métodos podem levar em consideração fatores como a interdependência de recursos, as restrições orçamentárias, a minimização de risco para um dado nível de retorno, as interações técnicas, as interações de mercado, baseando-se nas técnicas de programação linear e na análise de sensitividade (GRAVES et al., 2000).

Outra forma de procurar o balanceamento da carteira de projetos se baseia no emprego de diagramas bidimensionais que utilizam parâmetros considerados chave. Os diagramas visuais têm grande popularidade porque são capazes de representar, de forma simples, a composição da carteira, o que não é possível com os métodos financeiros e de hierarquização (KAUFFMANN et al., 2000; SPRADLIN e KUTOLOSKI, 1999). 
Em muitos casos, pode-se lançar mão de um padrão de decisões, tomadas num número limitado de casos, como modelo para a tomada de decisões futuras. A intenção dos métodos cognitivos é representar esta série de decisões de tal modo que possam ser aplicadas a um número maior de casos. Parte-se da análise de situações de decisões particulares e tenta-se aplicá-las para um universo maior de casos. Este afinamento é realizado com a aplicação de regressão linear, sendo os dados dos casos a variável independente e a seleção ou não seleção do projeto a variável dependente (MARTINO, 1995).

O método de análise de clusters não hierarquiza diretamente os projetos e não se refere a eles pelos seus ganhos ou formação de valor. Entretanto, procura identificar projetos que estão relacionados ou que são similares de alguma forma. Identificados os clusters ou projetos similares, o tomador de decisão aprova projetos nos clusters que mais se identificam com os objetivos da organização. Os clusters são classificados do mais importantes para os menos importantes, de forma a distribuir os recursos entre eles (MARTINO,1995).

Outra função da gestão da carteira de projetos foi apontada como sendo a operacionalização da estratégia da empresa. A missão, a visão e a estratégia do negócio devem estar alinhadas e serem operacionalizadas de forma a determinar onde a empresa aplica o dinheiro (COOPER, EDGETT e KLEINSCHMIDT, 1998). Pesquisa empírica realizada em empresas inovadoras revelou que estas usavam três abordagens para alinhar a carteira de projetos com a estratégia da empresa (COOPER et al., 1998). Primeiramente, uma abordagem de cima para baixo, na qual a visão, os objetivos e a missão da empresa definiam a distribuição de fundos entre os projetos. Numa segunda abordagem, feita de baixo para cima, os critérios eram estabelecidos nas ferramentas usadas para a seleção de projetos, conseguindo-se, desta forma, a adequação com a estratégia através da incorporação de critérios estratégicos nos processos passa/não passa e de métodos de hierarquização. A terceira abordagem constituía uma composição dos dois critérios descritos anteriormente.

Estudo de caso múltiplo realizado por Molina-Palma et al. (2002) para avaliar esta questão na realidade brasileira mostrou haver uma coincidência das práticas adotadas para a gestão da carteira de projetos com aquelas relatadas na 
literatura internacional. A preocupação com a adequação da carteira de projetos à estratégia da empresa se apresentava de forma sutil. Porém, esta preocupação se manifestava com forte evidência na medida em que no comitê de avaliação dos projetos participavam os executivos do mais alto escalão hierárquico das empresas.

A implementação da estratégia é a transformação da estratégia em ação, uma habilidade ausente em muitos executivos, segundo Alfred Chan, diretor da The Hong Kong and China Gás Company, Ltd. (in FREEDMAN, 2003). De acordo com Fischmann (1987), o processo de implementação estratégica é a típica atividade gerencial na qual se dá ou não a conversão do planejado em realidade. Pode-se dizer que implementar uma estratégia é trabalho do dia a dia.

Ao se caracterizar a implementação da estratégia como um problema, um ponto a ser destacado diz respeito à suposição de que o gerenciamento da implementação é apenas uma etapa do processo administrativo e que a decisão de aprovação da estratégia pela alta gerência, a coloca, automaticamente, em operação (MALCOLM, 1965). Purser e Cabana (1997) e Liedtka (2000) afirmam, ainda, que em ambientes empresariais turbulentos, os próprios gerentes estão descobrindo que a abordagem convencional dada ao planejamento estratégico, i.e., elaborada pela alta cúpula e executada pela base da pirâmide organizacional, não é mais viável ou efetiva. Estes gerentes estão aprendendo que o planejamento em ambientes instáveis requer uma aprendizagem organizacional contínua. Freedman (2003) afirma, igualmente, que os presidentes e diretores das grandes empresas reconhecem que é requerida uma verdadeira genialidade para implementar a estratégia e que a disciplina e a habilidade necessárias para a implementação são tão raras quanto às necessárias para a formulação da estratégia. Tais executivos também reconhecem que seu efetivo envolvimento, tanto na formulação quanto na implementação da estratégia, é essencial.

Fischmann (1987) destaca que o planejamento estratégico não é voltado para o habitual e o rotineiro e que é de sua essência lidar com descontinuidades, buscando sempre o melhor ajustamento da organização ao seu ambiente. Ainda segundo o autor, o sucesso da implementação, além de estar intimamente ligado a uma adequada formulação da estratégia, depende de ações efetivas que 
atinjam também a estrutura organizacional, a alocação de recursos, os sistemas de informação, os programas de compensação e a cultura organizacional.

Bourgeois e Brodwin (1984) identificaram cinco modelos de implementação estratégica que podem ser descritos ao considerar seu cenário, suas características e as implicações do modelo. No Quadro 1 estão resumidos estes modelos e a questão estratégica feita pelo principal executivo da empresa para cada um deles.

\begin{tabular}{|c|l|}
\hline Modelo & \multicolumn{1}{|c|}{ Questão estratégica do principal executivo } \\
\hline Comandante & "Como posso formular a estratégia ótima?" \\
\hline Mudança & $\begin{array}{l}\text { "Tenho uma estratégia em mente, agora como posso implementá- } \\
\text { la? }\end{array}$ \\
\hline Colaboração & $\begin{array}{l}\text { "Como posso envolver a alta administração para ter } \\
\text { comprometimento com as estratégias desde a etapa de formulação } \\
\text { da estratégia?" }\end{array}$ \\
\hline Cultural & "Como posso envolver toda a organização na implementação?" \\
\hline In crescendo & $\begin{array}{l}\text { "Como posso encorajar os gerentes a se tornarem defensores de } \\
\text { estratégias sólidas?" }\end{array}$ \\
\hline
\end{tabular}

Quadro 1 Modelo de implementação e o questionamento do principal executivo.

Fonte: Adaptação de Bourgeois e Brodwin (1984, p. 242).

Nesta pesquisa, Bourgeois e Brodwin (1984), levando em conta o esforço global da organização dedicado à formulação e à implementação de estratégias, caracterizam os três primeiros modelos como consumidores de pouco esforço, no que se refere à formulação, e de grande esforço, quando dirigido à implementação. Por outro lado, os modelos "cultural" e "in crescendo", nos quais há um grande dispêndio de energia de muitas pessoas envolvidas na fase de formulação, a implementação da estratégia é quase instantânea.

O modelo cultural toma as características participativas do modelo colaborativo e as leva para o nível operacional da organização como uma resposta à própria pergunta estratégica formulada pelo principal executivo. Neste modelo, o principal executivo guia a organização comunicando e incutindo sua 
visão sobre a missão global da empresa em toda a organização, para então, permitir a cada indivíduo estabelecer seus procedimentos de trabalho coerentes com aquela missão. Quando "as regras do jogo" estão estabelecidas, o principal executivo desempenha um papel equivalente ao de um treinador ou instrutor de equipe esportiva, no qual são dadas as diretrizes gerais, mas encorajada a tomada de decisão individual para determinar os detalhes operacionais do plano de execução.

No modelo "in crescendo" a estratégia é definida na base da organização. O principal executivo estabelece premissas, papel de legislador, e exerce também o papel de juiz. Ou seja, o problema estratégico gira em torno da habilidade do principal executivo em definir o propósito da organização (i.e. estabelecer premissas de decisão - papel de legislador), amplo o suficiente para encorajar a inovação, e em selecionar criteriosamente (i.e. papel de juiz), dentre todos as alternativas estratégicas ou projetos apresentados, aqueles que chamam sua atenção por estarem no escopo da missão da empresa e na visão de longo prazo desta.

Em pesquisa realizada em 91 empresas, Nutt (1986) identificou quatro diferentes táticas de implementação da estratégia utilizadas pelos executivos: táticas por intervenção, por participação, por persuasão e por decreto.

$\mathrm{Na}$ implementação por intervenção, os agentes de mudanças eram gerentes-patrocinadores que assumiam o controle dos processos de mudança planejados. Os implementadores monitoravam cuidadosamente todo o processo de mudança, controlando as situações de índole social e política no momento em que se apresentavam. Propunham novas medidas de desempenho, justificavam estas novas normas e demonstravam como as práticas de trabalho poderiam ser melhoradas.

A implementação por participação parte do princípio que as pessoas reagem mais favoravelmente e se tornam mais compromissadas quando participam do processo de idealização da mudança. Esta tática exige a formação de equipes de força-tarefa que representem os principais grupos de interesse da organização. O gerente-patrocinador, nas empresas analisadas por Nutt (1986), delegava as prerrogativas de desenvolvimento para as equipes de força-tarefa. 
$\mathrm{Na}$ implementação por persuasão os gerentes-patrocinadores delegavam o desenvolvimento a especialistas, que podiam ser consultores externos ou assessores internos. E, finalmente, a implementação por decreto era caracterizada pelo uso de uma ou mais formas de poder (recompensa, legitimidade, reputação técnica, informação e referência) por parte do executivo de mais alto cargo da organização.

Ao relacionar as táticas de implementação à freqüência de ocorrência, ao sucesso relativo e às características dominantes, o autor obteve os dados apresentados no Quadro 2.

\begin{tabular}{|c|c|c|l|}
\hline \multicolumn{1}{|c|}{ Tática } & Freqüência & Sucesso & \multicolumn{1}{|c|}{ Características dominantes } \\
\hline $\begin{array}{l}\text { - Implementação por } \\
\text { intervenção }\end{array}$ & $19 \%$ & $100 \%$ & $\begin{array}{l}\text { Principais executivos justificam } \\
\text { a necessidade de mudança }\end{array}$ \\
\hline $\begin{array}{l}\text { - Implementação por } \\
\text { participação }\end{array}$ & $17 \%$ & $84 \%$ & $\begin{array}{l}\text { Representantes de grupos de } \\
\text { interesse determinam as } \\
\text { características da mudança }\end{array}$ \\
\hline $\begin{array}{c}\text { - Implementação por } \\
\text { persuasão }\end{array}$ & $41 \%$ & $73 \%$ & $\begin{array}{l}\text { Especialistas tentam vender a } \\
\text { mudança que projetaram }\end{array}$ \\
\hline - Implementação por decreto & $23 \%$ & $43 \%$ & $\begin{array}{l}\text { Responsáveis emitem } \\
\text { diretrizes requerendo adoção }\end{array}$ \\
\hline
\end{tabular}

Quadro 2: Caracterização das Táticas de Implementação.

Fonte: Adaptado de Nutt (1986, p. 242 e 253).

Alguns dos problemas que impedem a implementação da estratégia, segundo Freedman (2003) são:

- inércia estratégica - não se consegue dar início à implementação da estratégia devido a uma resistência à mudança por parte dos executivos ou a diferenças de visão para definir as prioridades estratégicas;

- falta de compromisso entre os grupos de interesse - isto é particularmente verdadeiro em relação a gerência média, que normalmente bloqueia o progresso; 
- estratégia sem rumo (não focalizada) - isto acontece muito freqüentemente quando o diretor presidente da empresa ignora 0 processo de implementação;

- enfraquecimento estratégico - embora eventos estejam acontecendo, não há uma clara visão de quem os está liderando. Se na alta cúpula da empresa não há um sentimento de compromisso e apropriação com a estratégia corporativa, quando os membros da equipe retornarem às suas operações, a estratégia não terá a primazia devida;

- isolamento estratégico - caracterizado em situações nas quais ações podem estar acontecendo mas a comunicação é ineficiente;

- falha no entendimento do progresso ou simplesmente na não compreensão do estágio em que se encontra o cumprimento das metas (falta de indicadores de desempenho);

- fadiga na iniciativa - muitas ações em andamento, nenhuma terminada;

- impaciência ou pressa para que as mudanças aconteçam imediatamente. Intelectualmente é sabido que uma estratégia não pode ser implementada de uma hora para outra, mas emocionalmente, o responsável de mais alto cargo na organização pode não ser razoável;

- não reconhecimento do sucesso - falha em reconhecer e premiar o progresso, podendo prejudicar a obtenção do objetivo final.

Parnell, Carraher e Holt (2002) definem a efetividade da difusão da estratégia como o grau no qual uma estratégia é efetivamente implementada e começa a ser aceita como parte da organização. Está implícito nesta definição que não somente a alta gerência, mas também as de nível tático e operacional, determinam, em último caso, o sucesso ou o fracasso de uma estratégia, uma vez que todas têm a capacidade de aceitar ou não a estratégia.

Segundo Parnell (1999), o processo de difusão e comunicação da estratégia pode ser entendido através de um construto formado por três dimensões: envolvimento, entendimento e comprometimento. O envolvimento diz 
respeito ao grau de participação das gerências tática e operacional no processo de elaboração da estratégia. Neste caso, vários processos e técnicas podem ser utilizados desde que demonstrem haver uma consulta ativa e constante entre a alta cúpula da empresa e os demais níveis gerenciais na organização. O fato a ser destacado é que a formulação de estratégias implica no estabelecimento explícito ou implícito de objetivos e, desta forma, o maior envolvimento na formulação da estratégia facilita a sua implementação.

A segunda dimensão - entendimento - sugere que é muito mais fácil implementar uma estratégia quando a gerência tática e a gerência operacional compreendem em profundidade suas partes componentes. De acordo com Parnell (1999), pensar que o entendimento claro e preciso da estratégia, apenas por parte da alta gerência, é o único fato que interessa para a implementação, é uma visão míope deste processo.

A terceira dimensão - comprometimento - representa o grau de determinação das gerências em ver a estratégia efetivamente implementada e sendo parte da organização. Em suma, a difusão e implementação da estratégia é uma função do envolvimento de todos os níveis gerenciais, o entendimento da estratégia pela gerência e seu comprometimento com a efetiva implementação.

Segundo Aughton (1996), o ambiente do planejamento é como um quebracabeça e para ser eficaz é necessário juntar todas as pessoas que tenham conhecimento estratégico da organização e seu ambiente, ou seja, conhecimentos econômicos, técnicos e sociais da organização. Se faltar uma peça do quebra-cabeça, a solução pode ser inadequada ou a implementação do plano pode ser dificultosa.

Em contraposição aos métodos convencionais de planejamento nos quais há uma divisão entre os "grupos pensantes" e os "grupos executores", Purser e Cabana (1997) apresentam a técnica chamada Reunião de Identificação ${ }^{1}$. A Reunião de Identificação é um evento participativo que permite a um grupo grande de funcionários a, coletivamente, criar um plano que eles mesmos

\footnotetext{
${ }^{11}$ Search Conference, no texto original. Pela descrição das atividades desenvolvidas, esta parece ser a melhor tradução.
} 
poderão implementar. As pessoas trabalham durante dois ou três dias planejando tarefas em sessões plenárias em grandes grupos, e neste período desenvolvem a visão estratégica de longo prazo, as metas e o plano de ação concreto. Todo o trabalho é conduzido em equipes autogerenciadas responsáveis por todo o processo de planejamento. O processo desenvolvido na Reunião de Identificação está baseado na participação democrática, na qual o controle sobre o estabelecimento da direção a ser seguida e a elaboração de políticas é dado aos empregados, os quais serão os mais afetados pelas mudanças. O resultado pretendido é estabelecer um grupo de pessoas comprometido e do qual se espera que:

- tenha um profundo entendimento dos desafios a serem confrontados na organização;

- compactue acordos sobre os ideais que a estratégia deve satisfazer;

- consiga alinhamento dos planos de ação com estes ideais;

- saiba conduzir o mecanismo social da participação e o processo de engajamento de todo a organização na implementação da estratégia.

Depois da reunião, todos os que criaram os planos são responsáveis pela implementação.

Os resultados de pesquisas de diferentes autores que abordam as técnicas participativas na formulação e na implementação de estratégias apontam para:

- uma comunicação mais efetiva da estratégia na organização e maior efetividade na tomada de decisões (PARNELL, CARRAHER e HOLT, 2002; STRÖH e JAATINEN, 2001);

- uma relação positiva destas técnicas com a satisfação dos empregados no trabalho, reduzindo o absenteísmo e a rotação da mão-de-obra (KIM, 2002);

- o desenvolvimento do processo de inovação contínua e o desenvolvimento de novos conhecimentos (FORCADELL e GUADAMILLAS, 2002). 
Trabalho realizado por Neely e Hii (1998), tomando como referência pesquisa feita pela Confederation of British Industry e pelo Department of Trade and industry, na Inglaterra, mostrou que o monitoramento dos progressos administrativos através de um conjunto de indicadores de desempenho, estava entre as boas práticas gerenciais. Metas claras eram estabelecidas e indicadores de desempenhos dos concorrentes em áreas como a satisfação do cliente, a tendência de vendas, a participação de mercado e o número de novos produtos introduzidos, eram observados.

Indicadores financeiros e não financeiros estão no centro da descrição de uma estratégia, bem como no desenvolvimento de um único conjunto de medidas de desempenho que comunicam a estratégia claramente e ajudam na sua execução (FRIGO 2002b). As medidas capturam o progresso da estratégia e são utilizadas nos processos gerenciais para sinalizar a qualidade das decisões (KNIGHT, 1998).

Fischmann e Zilber (1999) implementaram, em 1986, nas empresas de energia elétrica de São Paulo um sistema estruturado de indicadores, composto por indicadores financeiros e não-financeiros, com o objetivo de auxiliar a formulação, comunicação e gestão do planejamento estratégico. Mais de uma década depois, com as empresas de energia privatizadas, o mesmo sistema de indicadores apontou diversas falhas operacionais que necessitavam intervenção direta e ações de aperfeiçoamento na gestão estratégica. Chamou a atenção, no caso relatado, a grande disparidade nos resultados. Enquanto os indicadores financeiros exibiam melhoras decorrentes de aumentos tarifários, os indicadores de atendimento ao consumidor, eficiência operacional e de recursos humanos apresentaram deterioração. Este é um exemplo do poder de comunicação e sinalização para a intervenção gerencial de um sistema estruturado de indicadores.

Empresas que dizem adotar estratégias de inovação ou de adicionar valor ao consumidor e escolhem medir seus processos internos através de indicadores centrados somente nos custos e na qualidade das suas operações, dificilmente conseguem implementar estratégias de crescimento. A Companhia 3M é um bom exemplo de como objetivos econômicos, ambientais e desenvolvimento dos 
empregados pode ser atingidos simultaneamente. A inovação é palavra chave que norteia as ações da empresa: $30 \%$ das vendas anuais devem representar produtos introduzidos nos últimos 4 anos (ANDERSON, 1997).

De acordo com Marcovitch e Maximiano (1993), o comportamento dos profissionais relacionados com atividades de P\&D é um dos mais fascinantes e controversos temas no campo da gestão de projetos de P\&D. Sob o ponto de vista gerencial, dizem estes autores, o interesse que o tema suscita está relacionado com o fato de que, para assegurar a melhor contribuição dos profissionais de P\&D para as empresas, é preciso compreendê-los, e entender suas atitudes e suas aspirações de carreira. Algumas das razões apontadas para justificar o fato de haver uma diferença entre administrar pesquisadores e qualquer outro tipo de profissional decorrem das diferenças entre o conjunto peculiar de atitudes desenvolvidas como conseqüência da formação universitária e os requisitos profissionais que as organizações demandam destes profissionais quando entram no mercado de trabalho.

Em tal estudo, no qual procurou-se analisar, especificamente, o comportamento de engenheiros eletrônicos jovens em empresas brasileiras, os autores apresentaram as seguintes proposições:

- Atitudes desenvolvidas na educação técnica

o O mérito técnico do produto é mais valorizado que sua implicação comercial ou de negócio;

o As soluções individuais tendem a ser mais valorizadas;

o Os profissionais são metódicos, analíticos e racionais;

o Os profissionais desenvolvem uma capacidade introspectiva.

- Atitudes demandadas pelas empresas

o Produtos com mérito comercial;

o Solução de problemas em grupo

o Sensitividade com a dimensão emocional do comportamento humano; 
o Intuição, capacidade de expressão e comunicação.

É bastante comum encontrar pessoas de formação técnica ocupando cargos gerenciais, numa carreira apoiada nos méritos obtidos na área técnica. Porém, essa transição do papel técnico para o gerencial não é fácil de ser realizada, devido, entre outros fatores, às seguintes causas:

- Falta de conhecimento das ferramentas gerenciais;

- Medo de perder a identidade técnica (ao ser absorvido pelas atividades gerenciais, o gerente técnico perde contato com o estado da arte na ciência);

- Tentação de participar nos projetos antigos nos quais teve participação como técnico.

Pesquisa realizada por Singh (2002) na indústria norte-americana de Biotecnologia teve como objetivo identificar o grau de importância das habilidades gerenciais à medida que as empresas se movimentavam das atividades de P\&D para as atividades relacionadas com a comercialização dos produtos. Os resultados mostraram que, neste caso, as habilidades associadas com a promoção/marketing e vendas/distribuição passam a ser apontadas internamente como as habilidades mais importantes, seguidas pelas habilidades administrativas relacionadas ao desenvolvimento organizacional/gestão de recursos humanos e gerência geral. A carência destas habilidades nesta fase de atividade empresarial, do desenvolvimento de produto à comercialização, foi apontada também como uma importante barreira à inovação em pesquisa realizada por Hall e Bagchi-Sem (2001).

A pesquisa realizada por Singh (2002) não estava focada nos postos de trabalho, mas na carteira de habilidades críticas necessárias neste estágio específico de desenvolvimento da indústria de Biotecnologia.

Cabe ser lembrado aqui que um dos resultados apresentados por Judice (2001), embora não quantificado, dá a entender que a existência de empresas 
conduzidas por empresários cientistas é significativa no Parque Biotecnológico Brasileiro.

\subsection{As relações interorganizacionais}

Houve o tempo em que as empresas optavam por realizar todas as operações dos seus negócios pois estavam convencidas de poderem obter melhores resultados no desempenho de funções que podiam controlar e usar o seu próprio pessoal. Hoje, as empresas estão descobrindo e se conscientizando da impossibilidade de executar, de maneira adequada, toda e qualquer função, delegando a terceiros as funções para as quais não há competência interna (GALBRAITH et al., 1995).

As empresas formam múltiplas alianças para construir competências ou mesmo para garantir presença global. Como exemplo da dimensão destas múltiplas alianças ou redes, cita-se a aliança formada na indústria espacial entre as empresas Boeing e Airbus, na qual cada uma delas trabalha adicionalmente com mais de cem parceiros, e na aliança estabelecida no negócio de linhas aéreas que resultou na criação da Star Alliance, da qual participam empresas como a United Airlines, a Lufthansa, a Varig, a Thai Airways, entre outras. Estas empresas partilham sistemas de marketing, operações, horários e freqüências de vôo (FREIDHEIM, 1999).

Segundo Amoroso (1994, p. 23) "não existe ainda um consenso na literatura empresarial quanto à definição dos termos alianças e parcerias". Freire (1998) define as alianças estratégicas como um acordo de cooperação no qual se enfoca a complementação das competências como uma forma de alcançar um objetivo comum, partilhando para isto, os custos, os riscos e os benefícios do projeto conjunto. Conforme Devlin e Bleacky (1998) as alianças estratégicas são diferentes dos tradicionais acordos cooperativos, uma vez que levam em consideração as estratégias da companhia e o planejamento de longo prazo. Souza Paula e Gama Alves (2001, p. 17), por sua vez, definem uma aliança como:

[...] um tipo específico de cooperação para a inovação, envolvendo o trabalho conjunto de empresas com interesses 
comuns relativos a certos conhecimentos ou tecnologias que são importantes para a atuação individual de cada uma delas. Em geral, refere-se a acordos que permitem o trabalho conjunto em algumas fases, ou para alguns produtos, mas cada um dos parceiros mantém sua esfera de atividade individual no que se refere aos respectivos produtos e sua comercialização / distribuição final.

Estas diferentes definições apóiam-se nas causas que levam os participantes a estabelecer uma cooperação, porém na última definição as autoras excluem as atividades de comercialização e distribuição final dos produtos.

Kanter (1994) apresenta alguns critérios que devem ser satisfeitos para poder constituir melhores alianças e conseguir o que ela chama de "vantagem colaborativa". São eles:

- Excelência individual: na qual ambos parceiros adicionam valor e seus motivos estão mais relacionados com buscar oportunidades;

- Importância: os parceiros querem que a relação funcione porque isso Ihes ajuda a atingir os objetivos estratégicos de longo prazo;

- Interdependência: deve existir uma necessidade mútua por colaborar e na colaboração cada um atinja sua meta;

- Investimento: os parceiros aplicam na relação recursos financeiros e de outras espécies;

- Informação: há uma comunicação aberta sobre metas, dados técnicos, problemas e situações de mudança;

- Integração: os parceiros desenvolvem formas partilhadas de operação e aprendizagem;

- Institucionalização: a relação é formal e com responsabilidades bem definidas;

- Integridade: ambos parceiros depositam confiança um ao outro. 
Segundo Oliveira (1999) quando uma aliança estratégica é efetuada de maneira otimizada proporciona resultados para as empresas que compõem a parceria, podendo-se assinalar:

- alavancagem na força competitiva de cada uma das organizações envolvidas;

- acesso mais rápido e intenso a vários recursos (tecnológicos, financeiros, comerciais e humanos);

- fortalecimento das operações produtivas através de melhores processos, otimização das instalações e desenvolvimento de padrões operacionais;

- aumento da capacitação tecnológica, alavancando a base tecnológica e a criatividade em P\&D;

- intensificação e consolidação do processo estratégico superando as barreiras de entrada nos vários segmentos de mercado;

- desenvolvimento e consolidação de sinergias que proporcionem resultados interessantes para as partes envolvidas no processo

- estruturação e otimização no processo de controle incluindo ajustes mútuos sistemáticos;

- partilha dos riscos inerentes ao negócio;

- fortalecimento do produto ou serviço com adição de valor, e.g., melhoria no desempenho do produto, redução de custos, criação de novas utilidades no produto, imagem ampliada do produto, etc.

- melhor acesso ao mercado e consolidação de vantagens competitivas;

Fleury e Fleury (2000) afirmam que à medida que as empresas aprendem como organizar seus próprios recursos, podem avaliar as vantagens e desvantagens de buscar novas relações interempresariais. Este processo envolve a criação de relações horizontais, que são as relações de parcerias 
(alianças, joint ventures, fusões), e as relações verticais, estas consubstanciadas na formação de cadeias de fornecimento e/ou distribuição (as chamadas cadeias produtivas).

As empresas de Biotecnologia apresentam um modelo organizacional categorizado como uma 'arquitetura aberta', na medida em que necessidades estratégicas são providas externamente (POWELL, 1999). As empresas de biotecnologia "necessitam, de maneira intensa, de informações e um conjunto de inputs externos para complementação de suas capacidades tecnológicas, mesmo que as atividades de P\&D estejam internalizadas" (JUDICE, 2001, 46). Conseqüentemente, as parcerias e cooperações são vitais ao desenvolvimento do setor.

A realização interna da $P \& D$ é considerada essencial para a geração, assimilação, adaptação e transformação de tecnologias e conhecimentos adquiridos externamente (WALSH, 1993 e JOLY, 1999). Em seu trabalho, Judice (2001) procurou avaliar como o parque brasileiro de Biotecnologia está gerando, absorvendo e transformando os avanços científicos e as novas tecnologias externas, bem como a sua capacidade de realizar cooperações tecnológicas. Foram analisadas, de um lado, a internalização da P\&D por parte das empresas, e, de outro, a existência de cooperações com universidades e centros de pesquisa. Segundo seus resultados, $90 \%$ das empresas pesquisadas realizam seu próprio desenvolvimento tecnológico e 93\% busca incessantemente fontes externas de conhecimento e inovação, mantendo relações formais ou informais com universidades e centros de pesquisa.

O trabalho de Judice (2001) mostra a existência de alianças entre empresas também no setor de Biotecnologia, reafirmando que esta capacidade de formar parcerias significa uma importante forma de aquisição de conhecimentos e informações. A autora não deixa claro, no entanto, quais são as capacidades e as competências partilhadas pelas empresas avaliadas.

Estudos existentes sobre a organização de redes de cooperação no setor de Biotecnologia estão focalizados na transferência e formação de conhecimento técnico entre pesquisadores, grupos de pesquisa e organizações (empresas, institutos de pesquisa, universidades, etc.) (SALLES-FILHO et al., 2001; SOUZA 
PAULA e GAMA ALVES, 2001). O trabalho efetuado de forma conjunta entre pesquisadores e grupos atuantes na fronteira do conhecimento e por firmas que tenham interesse direto na produção e inovação, é visto como um valioso instrumento de avanço científico, de inserção de um grupo ou instituição na comunidade científica e tecnológica internacional e de promoção da inovação (YILMA, 1993 apud SOUZA PAULA e GAMA ALVES, 2001).

\subsection{A formação de valor}

Normalmente, quando se avalia o desempenho de uma empresa, utilizamse indicadores de desempenho financeiro de uso comum no meio empresarial, tais como: receitas/ativo total; lucro/ação; lucro/ativo total; retorno sobre o ativo líquido; lucro/empregado; receitas resultantes sobre novos negócios/receita total, entre outros. Todos estes indicadores são claramente importantes, mas, ao mesmo tempo, apresentam uma apreciação apenas parcial do desempenho da empresa. A mesma limitação ocorre, quando ao avaliarem-se os esforços em inovação, são utilizados indicadores como o número de patentes geradas em um determinado espaço de tempo, o aumento da produtividade da mão-de-obra operacional, a substituição de tecnologias importadas, para citar alguns. Desta forma, segundo Copeland et al. (2000, 21), "o valor é a melhor métrica de desempenho porque é a única que exige informação completa". Usar uma perspectiva de longo prazo, gerenciar os fluxos de caixa tanto da demonstração dos resultados como do balanço patrimonial e saber como comparar os fluxos de caixa de diferentes períodos ajustados por seus riscos, são apenas alguns dos elementos que devem ser levados em conta no processo de criação de valor. Dito de outra forma, o objetivo da estratégia empresarial é produzir retornos que excedam o custo de oportunidade do capital investido (FRIGO, 2002b).

Os resultados de um processo de formação de valor são analisados através da metodologia de avaliação de investimentos. Todo ativo, seja financeiro ou real tem valor. A chave para investir nesses ativos e gerenciá-los com sucesso não reside na compreensão do montante desse valor, mas nas fontes desse valor que são chamadas de value drivers. Qualquer ativo pode ser 
avaliado, mas alguns são mais facilmente avaliados do que outros, e os detalhes da avaliação variam de caso para caso.

Damodaran (1997) alerta sobre alguns mitos desenvolvidos ao longo do tempo a respeito do processo de apreciação de valor e que devem ser esclarecidos antes de interpretar qualquer resultado de uma avaliação. Alguns deles e o argumento para a sua desmistificação são abordados a seguir.

\section{Mito 1: Os modelos de avaliação são quantitativos e por isso a} avaliação é objetiva. A avaliação não é uma ciência exata e nem a busca objetiva do valor verdadeiro. Mesmo que os modelos utilizados na avaliação sejam quantitativos, os dados de entrada deixam margem para apreciações subjetivas.

2. Mito 2: Uma avaliação bem pesquisada e bem feita é eterna. $O$ valor obtido da avaliação é sensível a informações específicas sobre a empresa e o mercado. Isto implica dizer que o valor se modifica toda vez que novas informações sejam recebidas e introduzidas no modelo de avaliação

3. Mito 3: Uma boa avaliação oferece uma estimativa precisa de valor. Por mais detalhada e minuciosa que seja uma avaliação, haverá incertezas quanto ao futuro da empresa e da economia.

4. Mito 4: Quanto mais quantitativo o modelo, melhor a avaliação. A qualidade de uma avaliação será diretamente proporcional ao tempo gasto em reunir dados e ao conhecimento e compreensão da empresa a ser avaliada.

Como a geração de valor é uma medida fundamental de desempenho para a gerência de uma empresa há que se estabelecer uma forma de gerenciar que signifique obter o máximo em termos de criação de valor. Implícita ou explicitamente todas as decisões administrativas baseiam-se em algum modelo de avaliação. O valor de uma empresa é determinado pelos fluxos de caixa futuros descontados e este valor é formado quando as empresas investem com retornos que excedem seu custo de capital (DAMODARAN, 1997; COPELAND et al., 2000; RAPPAPORT, 1998; TVORIK et al., 1998; FRANCIS e MINCHINGTON, 
2000; GRESSLE, 2001). Determinar o valor de uma empresa é uma atividade importante tanto como determinar o valor dos planos da empresa. Para administrar, no entanto, chegar a um valor não é um exercício de mensuração mas de decisões (KNIGHT, 1998).

Knight (1998) Martin e Petty (2000) e Copeland et al. (2000), apresentam uma técnica gerencial, denominada Administração Baseada no Valor (ABV), através da qual o objetivo gerencial passa a ser a formação de valor e não o crescimento periódico do lucro por ação. O valor é estabelecido no presente mas está sempre baseado em expectativas futuras e representam a visão subjetiva dos investidores sobre o prospecto da empresa (KNIGHT, 1998). A Administração Baseada no Valor "é um processo integrador, cujo objetivo é melhorar a tomada de decisões estratégicas e operacionais na organização como um todo, a partir da ênfase atribuída aos principais value drivers da empresa" (COPELAND et al, 2000, p. 87). Os autores reforçam que a ênfase na implementação deste tipo de gestão não deve ser dada à metodologia mas à mudança na cultura da empresa. Frigo (2003) define a administração baseada no valor como o processo usado para identificar os vetores de uma estratégia particular, entender como esses vetores levam à formação de valor, quebrar estes vetores em passos que direcionem a ação ou atividades que podem ser rastreadas através de toda a organização. Condon e Goldstein (1998), por sua vez, definem a $A B V$ como uma filosofia gerencial que utiliza ferramentas e processos analíticos para orientar uma empresa no simples objetivo de criar valor para seus acionistas.

Os chamados value drivers ou vetores de valor são as variáveis que exercem impacto sobre o valor da empresa. Os vetores de valor são os fatores de operação que exercem maior influência nos resultados operacionais e financeiros (KNIGHT, 1998). Uma condição básica para o emprego da técnica de ABV é a necessidade de se ter um profundo conhecimento destas variáveis. Existem dois motivos pelos quais esse conhecimento seja essencial. Primeiro, a empresa não pode atuar diretamente sobre o valor, o que implica dizer que as ações gerenciais são exercidas sobre aquilo que pode influenciar o valor, como a satisfação do cliente, as melhoras nos custos ou os novos investimentos em 
tecnologia. Segundo, é através destes vetores de valor que a gerência aprende a conhecer o restante da empresa. A Figura 4 exemplifica o impacto de alguns vetores de valor no fluxo de caixa do Demonstrativo do Resultado do Exercício.

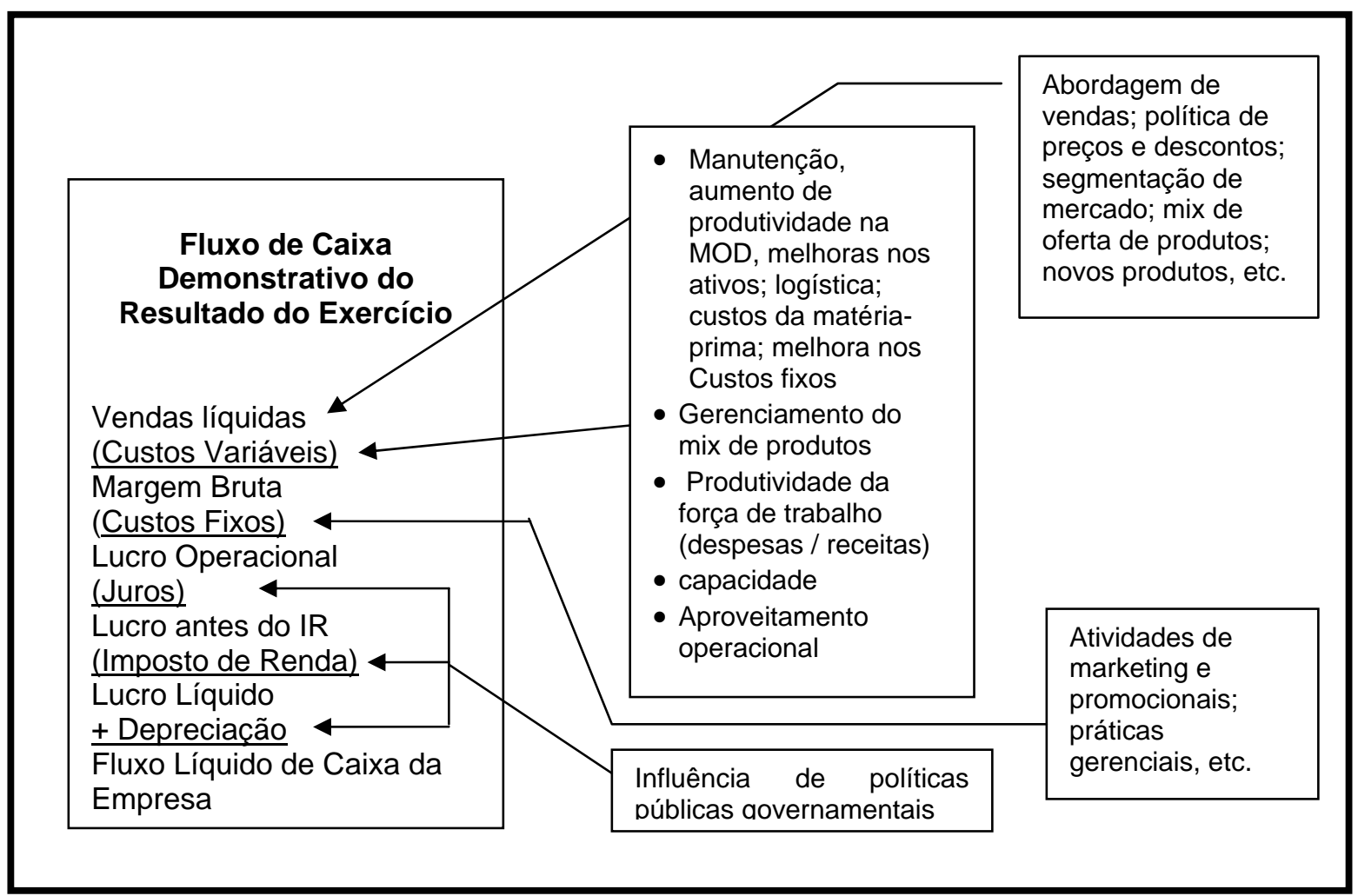

Figura 4: O Fluxo de Caixa Líquido da Empresa e os vetores de valor. Fonte: o autor

Os vetores de valor devem estar alinhados com as variáveis decisórias, as quais devem estar sob controle direto dos gerentes de linha. Essas medidas de valor combinam as três características financeiras essenciais de uma empresa: o fluxo de caixa gerado pela empresa, o capital investido na geração desses fluxos e o custo do capital investido (FRANCIS e MINCHINGTON, 2000). As experiências indicam que os praticantes da administração baseada no valor investem tempo e esforços na identificação dos vetores de valor. Desta forma eles obtêm dois ganhos: ao selecionar os vetores de valor, são focalizadas as atividades dos empregados da base operacional para verificar como elas formam o valor, como segundo ganho, a gerência é obrigada a desenvolver suas estratégias de forma mais clara (HASPESLAGH, NODA e BOULOS, 2001). Um vetor de valor, para uma unidade de atendimento ao cliente, por exemplo, pode 
ser definido como o tempo gasto em responder a chamada e a qualidade da ajuda que o solicitante recebe (HASPESLAGH et al., 2001). A Figura 5 mostra os vetores de valor com relação ao nível em que se encontram na organização.

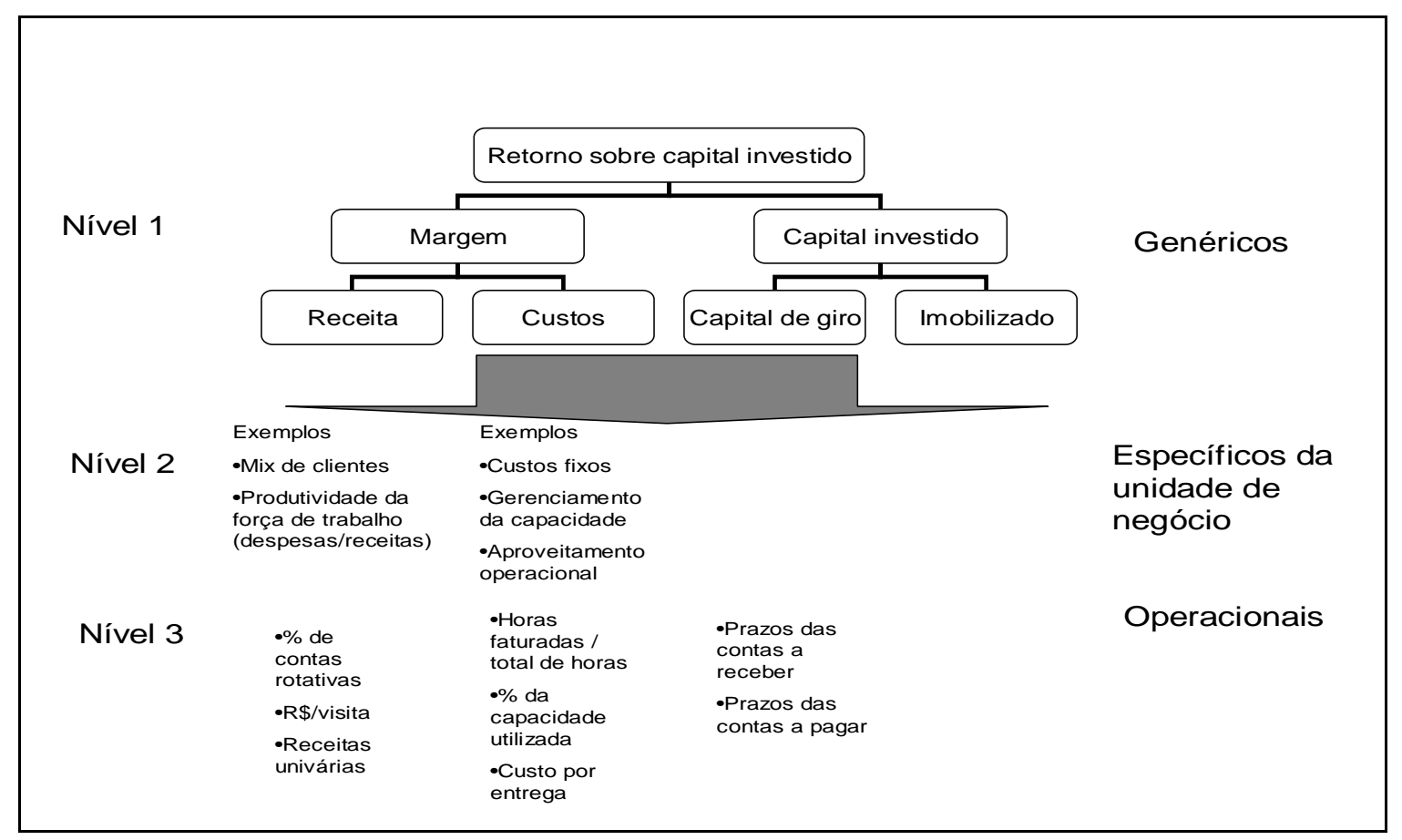

Figura 5: Níveis de identificação de vetores de valor.

Fonte: Adaptado de Copeland et al. (2000, p. 97).

A verdadeira administração baseada no valor cria um alinhamento administrativo ao unir as comumente dispersas atividades de planejamento estratégico, os informes financeiros e o plano de benefícios salariais. A ABV tem sucesso quando as decisões são focadas e conseguem o alinhamento entre a estratégia, as medidas de desempenho e o comportamento das pessoas (DUYCK, 1998).

Brian Pitman (2003), ao relatar o caso mais famoso na literatura sobre a implementação da ABV e, vivido por ele como presidente do Lloyds Bank, afirma que a lição mais importante da $A B V$ é que ela envolve muito mais que implantar um sistema de mensuração de desempenho ou método de contabilidade. Para que as pessoas se concentrem nas atividades que realmente geram valor para a empresa, exige delas uma transformação de suas convicções. Não é o caso de impor uma mentalidade, mas um processo de aprendizagem no qual as pessoas 
são convencidas de que um objetivo vale a pena e, em seguida, aplicam seu talento para atingi-lo.

Haspeslagh et al. (2001), além de reforçar que o sucesso da implementação da $A B V$ depende muito mais da mudança cultural que da mudança no sistema financeiro, advertem que há uma necessidade muito grande de investir tempo, esforço e dinheiro em treinamento envolvendo a maior quantidade possível de funcionários. Pesquisa realizada com 117 empresas praticantes de $A B V$, com vendas anuais superiores a US\$2 bilhões na América do Norte, Europa e Ásia, revelou que 62\% das empresas bem sucedidas com um programa de ABV treinaram mais de $75 \%$ da sua gerência. A Dow Chemical, uma das empresas, treinou 75\% dos seus cerca de 40.000 empregados, incluindo executivos e operários. Conforme sentencia Knight (1998), a estratégia e sua execução será tão boa quanto a habilidade gerencial em comunicá-la de forma que tenham algum significado para toda a equipe encarregada de executá-la.

No presente trabalho não há a intenção de estabelecer qualquer fluxo de caixa ou o montante do capital investido na geração destes fluxos e o custo deste capital. Estas informações são estratégicas e fazem parte do conjunto de informações estritamente sigilosas de qualquer empresa. Busca-se apenas identificar os principais vetores de valor encontrados na "capacidade de inovação", segundo o construto anteriormente formulado, uma vez que a literatura aqui citada aponta para a necessidade de se ter um profundo conhecimento destes vetores. Considera-se necessário, no entanto, mencionar a maneira como o valor das empresas é calculado ao se discorrer sobre a importância dos vetores na formação de valor das empresas.

Na literatura são citadas três abordagens principais para avaliar o valor de uma empresa. São elas, o modelo de avaliação pelo fluxo de caixa líquido da empresa, o método de precificação de opções (DAMODARAN, 1997; COPELAND et al, 2000; RAPPAPORT, 1998) e o modelo de desconto de dividendos (DAMODARAN, 1997; RAPPAPORT, 1998; BREALEY e MYERS, 2000). O modelo de desconto de dividendos e o método de precificação de opções não serão discutidos neste trabalho por não serem adequados para mostrar a importância da identificação dos vetores de valor. 
Os fluxos de caixa livres para a empresa, neste trabalho representado por FC, estão formados pela soma dos fluxos de caixa para todos os detentores de direito da empresa. Tanto os credores quanto os proprietários da empresa esperam ser recompensados pelo custo de oportunidade de se investir em um negócio específico, em lugar de investir em outro negócio com um risco semelhante. O custo médio ponderado de capital - CMPC - é a taxa utilizada para determinar o valor de dinheiro no tempo, convertendo os fluxos de caixa futuro em valor presente para todos os investidores.

O valor da empresa, de uma forma geral, pode ser expresso como o valor presente do FC esperado:

$$
\text { Valor da Empresa }=\sum_{t=1}^{t=\infty} \frac{F C_{t}}{(1+C M P C)^{t}}
$$

em que $\mathrm{FC}_{\mathrm{t}}=\mathrm{FC}$ no ano $\mathrm{t}$

Se a empresa alcançar uma situação de equilíbrio (estado estável) e depois de $\mathrm{n}$ anos começar a crescer a uma taxa de crescimento estável - $\mathrm{g}_{\mathrm{n}}$ - $\mathrm{o}$ valor da empresa poderá ser descrito como:

$$
\text { Valor da Empresa }=\sum_{t=1}^{t=n} \frac{F C_{t}}{(1+C M P C)^{t}}+\frac{F C_{n+1} /\left(C M P C-g_{n}\right)}{(1+C M P C)^{n}}
$$

A finalidade de se avaliar uma empresa tem sempre o propósito de auxiliar a gerência na orientação de certas decisões administrativas ou de investimentos, sejam elas uma aquisição, um desinvestimento ou uma adoção de iniciativas estratégicas internas. Como a maioria das decisões de negócio envolve risco e incerteza, deve-se sempre pensar no valor em termos de cenários e faixas de valor que reflitam essa incerteza. 


\subsection{Síntese e contribuições da literatura para o estudo}

A parte introdutória desta revisão bibliográfica tratou da importância que a inovação tecnológica representa para as empresas atuais. Numa visão contemporânea, a inovação tecnológica constitui uma vantagem competitiva, visto que as empresas podem conseguir privilégios monopolísticos ao ser a primeira a chegar no mercado com produtos protegidos por patentes ou, ainda, sustentar uma vantagem em custos de difícil imitação pelos concorrentes.

O processo de inovação nas indústrias é caracterizado pela sua natureza intangível e a complexidade deste processo ainda não é suficientemente compreendida. O tempo envolvido na inovação tecnológica representa um problema complexo e se constitui num desafio significativo uma vez que existe um descompasso entre o surgimento de uma oportunidade de negócio e a clareza das informações que temos sobre essas oportunidades. A gestão da capacidade de inovação está centrada na gestão do conhecimento relevante de modo tal que sejam percebidos os fracos sinais das oportunidades existentes antes que outras empresas reconheçam essa oportunidade.

Neste estudo, assume-se a capacidade de inovação como o potencial interno de uma empresa para gerar novas idéias, identificar novos mercados e oportunidades tecnológicas, alavancando recursos e competências. Adota-se a premissa que a capacidade de inovação está determinada pelas inter-relações da cultura organizacional, pelos processos internos e pelas relações interorganizacionais. No segundo segmento da revisão bibliográfica discorreu-se sobre a cultura organizacional, de uma forma genérica e, mais especificamente, sobre a cultura organizacional em ambientes inovativos. A cultura organizacional refere-se à forma pela qual os funcionários percebem características descritivas dos costumes e práticas da empresa. Em ambientes que apóiam processos de inovação, os funcionários se sentem encorajados a mostrar criatividade, tomar iniciativas, assumir riscos e a trabalhar em equipe. O clima organizacional favorece um comportamento colaborativo entre todos os funcionários e ainda a que elementos externos à organização, tais como clientes e fornecedores, participem dos processos de inovação da empresa. 
$\mathrm{Na}$ seqüência, dentre os inúmeros processos internos realizados por qualquer tipo de empresa, foram tratados aqueles que se apresentam na literatura como mais característicos das empresas inovadoras. Empresas inovadoras geram e capturam constantemente novas idéias que podem se transformar em novos produtos e novos processos de produção; porém, nenhuma empresa tem recursos financeiros, humanos e infra-estrutura suficiente para desenvolver todas estas idéias. A gestão da carteira de projetos é um processo gerencial que tem como objetivo alocar recursos, selecionar os melhores projetos e, desta forma, operacionalizar a estratégia da empresa. Foram apresentadas as diversas metodologias usadas para a gestão da carteira de projetos. Em primeiro lugar, foram descritas as técnicas que avaliam os projetos individualmente e que são classificadas conforme os objetivos propostos por elas e pelas técnicas analíticas dominantes. Em segundo lugar, foram apresentadas as técnicas que procuram otimizar a carteira como um todo, levando em consideração as potenciais interações entre os projetos e os usos alternativos de recursos entre eles.

A implementação, a comunicação, a execução e o controle da estratégia da empresa é outro processo de suma importância para qualquer tipo de empresa. Neste contexto, foram apresentados os modelos e as táticas de implementação de estratégia e as barreiras mais comuns à sua prática. Foi também desenvolvido o construto que ajuda definir o processo de difusão e comunicação da estratégia, bem como apresentada uma aplicação do modelo participativo, a Reunião de Identificação, e seus resultados. Entre as boas práticas gerencias para monitorar o desempenho administrativo foi citado o uso de indicadores de tendência e indicadores financeiros.

O terceiro processo interno apresentado no estudo está relacionado com a forma de assegurar uma melhor contribuição dos profissionais de P\&D para a empresa, mostrando, para isto, a necessidade de compreender suas atitudes e suas aspirações profissionais. Estudo realizado nos Estados Unidos em empresas de Biotecnologia mostrou que à medida que as empresas se movimentam das atividades de P\&D para a fase de comercialização, há uma maior necessidade de habilidades e conhecimentos gerenciais. Dados de 
trabalho realizado em empresas brasileiras de Biotecnologia sugerem que a existência de empresas conduzidas por empresários cientistas é significativa.

As relações interorganizacionais são vistas como uma forma encontrada pelas empresas para construir competências. Quando as parcerias são realizadas de forma otimizada, seus resultados podem alavancar as forças competitivas de cada uma das organizações envolvidas; proporcionar um acesso mais rápido e intenso a vários recursos (tecnológicos, financeiros, comerciais e humanos); permitir o fortalecimento das operações produtivas, proporcionar aumento da capacitação tecnológica, alavancando a base tecnológica e a criatividade em P\&D, entre outros benefícios.

Finalmente, foi desenvolvido o conceito de formação de valor e justificado o por que este conceito é considerado o melhor indicador de desempenho de uma empresa. O critério de formação de valor é utilizado como valioso instrumento de gestão na técnica denominada Administração Baseada no Valor ( $A B V$ ), na qual todas as decisões gerenciais são analisadas através da metodologia de avaliação de investimentos. Na ABV a ênfase é dada à necessidade de se ter um profundo conhecimento dos vetores de valor, uma vez que não há forma de atuar diretamente sobre o valor e sim sobre as atividades que podem influenciar o valor. O valor é criado quando a empresa investe em atividades que geram fluxos de caixa cujos rendimentos líquidos devem exceder o custo do capital empregado. Não se trata de medir constantemente o valor de uma empresa, mas de identificar as fontes de valor, chamadas de vetores de valor, e administrá-las de forma que sempre se crie valor. No presente estudo limitar-se-á somente à identificação e análise dos principais vetores de valor relacionados à cultura organizacional, aos processos internos acima citados e às relações interorganizacionais, sem a pretensão de estabelecer qualquer parâmetro de ganho no valor das empresas estudadas. 


\section{Capítulo 3}

\section{Metodologia}

\subsection{A natureza da pesquisa e escolha do método}

"A ciência é um empreendimento preocupado exclusivamente com o conhecimento e a compreensão de fenômenos naturais" (KERLINGER, 1980). A pesquisa científica aparece como ferramenta fundamental para a obtenção do conhecimento científico, processo este desencadeado progressivamente e que emerge da coexistência entre teoria e prática (BARROS, 1994). Conforme Barbosa (1978) o trabalho científico é uma tarefa dialética e não metafísica.

"O conhecimento científico é obtido através de um procedimento metódico, o qual mobiliza explicações rigorosas e/ou plausíveis sobre o que se afirma sobre um objeto ou realidade" (BARROS, 1994, p. 10). A escolha de uma metodologia de pesquisa reveste-se, portanto, de elevada importância, uma vez que estabelece os fundamentos teóricos necessários à indagação dos fatos, facilita e orienta as etapas a serem vencidas na investigação da verdade e/ou para alcançar determinado fim. "O objeto das ciências sociais sendo particular e de características sui generis, exige comportamento metodológico especial ajustando o método à sua própria realidade" (BARBOSA, 1978, p.49).

Muitos autores têm buscado organizar uma tipologia para as atividades de pesquisa, a partir de diferentes critérios e enfoques. Esta classificação pode obedecer a interesses, condições, campos, metodologia, situações, objetivos, objetos de estudo, entre outros. Não cabe aqui enumerar todos os aspectos 
que a pesquisa científica possa abordar ou mesmo transcrever todas as classificações já apresentadas por diferentes autores. Porém, vale destacar aquelas classificações que apresentam aspectos pertinentes ao enfoque do presente trabalho e que servirão de suporte para estabelecer o delineamento de todo o estudo.

Gil (1988) classifica as pesquisas de acordo com os objetivos propostos em seu escopo:

- Pesquisas exploratórias: têm por finalidade desenvolver, esclarecer e modificar conceitos e idéias de modo que estas possam servir, em estudos posteriores, para a formulação mais precisa de um problema ou o desenvolvimento de hipóteses para um problema.

De todos os tipos de pesquisa, as pesquisas exploratórias apresentam menor rigidez no planejamento. Este tipo de pesquisa é realizado quando o tema escolhido é pouco explorado, constituindose os seus resultados no ponto de partida para futuras investigações. Selltiz, Wrightsman e Cook (1974) destacam como outra função da pesquisa exploratória o aumento do conhecimento do pesquisador acerca do fenômeno, o esclarecimento de conceitos e o estabelecimento de prioridades para serem investigadas em futuras pesquisas.

- Pesquisas descritivas: têm como objetivo principal a descrição das características de determinada população ou fenômeno ou o estabelecimento de relações entre variáveis.

Selltiz et al. opus cit. enfatizam que neste tipo de pesquisa, as questões de pesquisa pressupõem muitos conhecimentos anteriores do problema a ser pesquisa, contrário do que ocorre com as questões que fundamentam um estudo exploratório. O pesquisador deve ser capaz de definir claramente as variáveis que deseja medir e de identificar métodos adequados para essa mensuração.

- Pesquisas explicativas: "têm como preocupação central identificar os fatores que determinam ou que contribuem para a ocorrência dos 
fenômenos. Este é o tipo de pesquisa que mais aprofunda o conhecimento da realidade, porque explica a razão, o porquê das coisas" (GIL, 1988, p. 48).

Mattar (1994) adverte que a classificação de pesquisa em exploratória ou conclusiva (explicativa) é muito menos precisa do que outras classificações, pois todas as pesquisas têm aspectos exploratórios, e são raras aquelas cujo problema de pesquisa e/ou objetivos estejam tão bem definidos que possam prescindir de pesquisa exploratória.

Um aspecto central relacionado à classificação das pesquisas diz respeito ao seu enfoque qualitativo ou quantitativo. A literatura expõe uma ampla discussão quanto às vantagens e desvantagens de cada um deles e quanto à sua validade e/ou confiabilidade. Com o objetivo de mostrar os aspectos conceituais que diferenciam cada um destes enfoques, o Quadro 3 mostra, de forma condensada, a caracterização de ambos tipos de pesquisa.

\begin{tabular}{|c|c|c|c|}
\hline Pressuposto & Questão & Quantitativa & Qualitativa \\
\hline Ontológico & $\begin{array}{l}\text { Qual é a natureza da } \\
\text { realidade? }\end{array}$ & $\begin{array}{l}\text { A realidade é objetiva e singular, } \\
\text { independente da postura do } \\
\text { pesquisador. }\end{array}$ & $\begin{array}{l}\text { A realidade é múltipla, de acordo } \\
\text { a vivência do pesquisador na } \\
\text { situação pesquisada. }\end{array}$ \\
\hline Epistemológico & $\begin{array}{l}\text { Qual é a relação } \\
\text { entre pesquisador e } \\
\text { assunto pesquisado? }\end{array}$ & $\begin{array}{l}\text { O pesquisador tem uma postura } \\
\text { independente em relação à } \\
\text { situação pesquisada. }\end{array}$ & $\begin{array}{l}\text { O pesquisador interage com o } \\
\text { assunto objeto da pesquisa. }\end{array}$ \\
\hline Axiológico & $\begin{array}{l}\text { Qual é o papel dos } \\
\text { valores? }\end{array}$ & $\begin{array}{l}\text { O valor é de liberdade e de não } \\
\text { influência na postura de } \\
\text { pesquisador. }\end{array}$ & $\begin{array}{l}\text { O valor é carregado e } \\
\text { influenciado pela postura do } \\
\text { pesquisador }\end{array}$ \\
\hline Retórico & $\begin{array}{l}\text { Qual é a linguagem } \\
\text { da pesquisa? }\end{array}$ & $\begin{array}{l}\text { A linguagem é formal e baseada } \\
\text { em definições; a voz é } \\
\text { impessoal; são usados termos } \\
\text { quantitativos. }\end{array}$ & $\begin{array}{l}\text { A linguagem é informal e } \\
\text { abrange decisões; são usados } \\
\text { termos qualitativos. }\end{array}$ \\
\hline Metodológico & $\begin{array}{l}\text { Qual é o processo } \\
\text { da pesquisa? }\end{array}$ & $\begin{array}{l}\text { O processo é dedutivo; busca } \\
\text { relações de causa e efeito; faz } \\
\text { uso de desenho estatístico; } \\
\text { categorias de análise a priori; há } \\
\text { generalização dos resultados; o } \\
\text { cuidado no tratamento é feito } \\
\text { através da validez e da } \\
\text { confiabilidade. }\end{array}$ & $\begin{array}{l}\text { O processo é indutivo; busca } \\
\text { compartilhamento mútuo e } \\
\text { simultâneo de fatores; categorias } \\
\text { de análise a posteriori; os } \\
\text { resultados são limitados ao } \\
\text { contexto; o cuidado e segurança } \\
\text { no tratamento são feitos através } \\
\text { da verificação. }\end{array}$ \\
\hline
\end{tabular}

Quadro 3: Características básicas das pesquisas qualitativas e quantitativas.

Fonte: adaptado de Creswell (1994). 
Fazendo uso dos conceitos apresentados por Creswell (1994), pode-se dizer que as técnicas de pesquisa qualitativa:

- são normalmente exploratórias sem pretender ser diagnósticas;

- envolvem um pequeno número de unidades de observação, sem levar em consideração as técnicas de amostragem em bases estatísticas;

- privilegiam o estudo de assuntos e temas complexos, pois maior será a necessidade de se aprofundar nas informações

Segundo Alves-Mazzotti e Gewandsznajder (1999. p.147),

[...] ao contrário do que ocorre com as pesquisas quantitativas, as investigações qualitativas, por sua diversidade e flexibilidade, não admitem regras precisas, aplicáveis a uma ampla gama de casos. Além disso, as pesquisas qualitativas diferem bastante quanto ao grau de estruturação prévia, isto é, quanto aos aspectos que podem ser definidos já no projeto.

Há controvérsias quanto ao grau de estruturação prévia necessária nos projetos de pesquisa qualitativa. Lincoln e Guba (1990) apresentam alguns argumentos para defender uma mínima estruturação:

a) o foco e o modelo do estudo não podem ser definidos a priori, visto que a realidade é múltipla, não se podendo, portanto, apreender seu significado se a aprisionarmos em dimensões e categorias de maneira arbitrária e precoce; sendo assim, o foco e o modelo devem emergir do conhecimento do contexto.

b) os fenômenos sociais são de natureza idiográfica (fatos considerados únicos) e holística (exige a visão da totalidade), não sendo nenhuma teoria selecionada a priori capaz, portanto, de dar conta dessa realidade em sua especificidade e globalidade.

c) a visão do pesquisador pode ser turvada pela focalização prematura do problema e pela adoção de um quadro teórico, levando-o a desconsiderar aspectos importantes que não se encaixam na teoria e a fazer interpretações distorcidas dos fenômenos estudados. 
Marshall e Rossmann (1995) e Miles e Huberman (1994) destacam, por outro lado, alguns argumentos a favor de um maior grau de estruturação dos projetos, destacando-se:

a) um pesquisador inicia seu trabalho partindo de uma base teórica que norteia seus pontos de observação;

b) ao escolher um determinado problema a ser pesquisado, qualquer pesquisador tem um objetivo e algumas questões em mente; estes podem ser explicitados no início do projeto, mesmo que sujeitos a reajustes futuros.

c) o foco e a adoção de critérios para a coleta de dados evita excesso de dados, facilita sua interpretação e evita perda de tempo.

Argumentos contra e a favor da estruturação podem ser válidos dependendo da situação estudada. Projetos menos estruturados são mais adequados para estudo de realidades muito complexas e/ou pouco conhecidas.

Entre as situações em que a técnica de pesquisa qualitativa pode ser recomendada, de acordo com Woncester (1991), destacam-se as seguintes:

- quando não há nenhum conhecimento quanto ao problema em questão;

- para identificar padrões de comportamento relevantes, crenças, opiniões, atitudes, motivações, dentre outros;

- para obter dados que possam alimentar estudos de análise multivariada;

- para elucidar pontos que serão abordados na condução de investigações posteriores, de modo a não repetir o trabalho exploratório;

- para avaliar a compreensão de questionários.

Julga-se adequado, ainda, ressaltar os parâmetros que determinam a escolha do método qualitativo para a realização de uma pesquisa, conforme Reis (1994, p.12): 
- a abrangência do fenômeno: "quanto maior a abrangência do que se quer estudar, mais adequado é o método qualitativo, devido às suas características holísticas, sua orientação para a orientação e descrição dos fenômenos."

- A quantidade de informação disponível: "quanto menos informação se tem sobre o assunto, maior a dificuldade de se usar medidas controladas, característica dos métodos quantitativos".

- A complexidade do fenômeno a ser estudado: "quanto mais complexo é o assunto da investigação, maior a necessidade de se obter profundidade nas informações, e isso é melhor obtido por meio da metodologia qualitativa".

- O tempo e os recursos disponíveis para a pesquisa: "quanto menor a disponibilidade de tempo e recursos para a pesquisa, mais adequado o uso da pesquisa qualitativa, desde que o objeto da pesquisa seja compreender o fenômeno e não medir a sua ocorrência"

Com base nas considerações até aqui apresentadas, o presente projeto, que visa estudar a capacidade de inovação como formadora de valor, pode ser enquadrado no tipo de pesquisa exploratória. A inserção do trabalho nesta classificação é justificada pelas características inerentes ao tema escolhido, como a alta complexidade do fenômeno, o fato de não pretender ser um estudo definitivo, mas de buscar caminhos para o desenvolvimento de futuras pesquisas e, finalmente, a pouca familiaridade do pesquisador com o assunto a ser abordado na realidade empresarial.

Ainda com relação à categoria de pesquisa escolhida, o presente estudo pode ser também caracterizado como uma pesquisa qualitativa. Será adotado o método de estudo de casos, o qual, segundo Gil (1988, 59), "é um estudo profundo e exaustivo de um ou poucos fenômenos [de estudo], de maneira que permita o seu amplo e detalhado conhecimento". 
Yin $(1994,13)$ define estudo de caso como "uma pesquisa empírica na qual se investiga um fenômeno contemporâneo no seu contexto real no qual os limites entre o fenômeno e o contexto não são claramente evidentes". Do ponto de vista técnico, continua o autor, a pesquisa através do uso de estudo de casos,

\begin{abstract}
[...] depara-se com situações tecnicamente distintivas nas quais se encontrarão muito mais variáveis de interesse do que dados pontuais, como um resultado; baseia-se em fontes múltiplas de evidência, com dados que necessariamente devem convergir de uma forma triangular, como um outro resultado; beneficia-se de um desenvolvimento prévio de proposições teóricas que guiarão a coleta de dados e sua análise.
\end{abstract}

A maior utilidade do estudo de casos, assinala Gil (1987), é verificada nas pesquisas exploratórias. Por sua flexibilidade, é recomendável nas fases iniciais de um estudo sobre temas complexos, como é a proposta deste estudo, para a construção de hipóteses ou reformulação de um problema.

As principais características de um estudo de caso são sintetizadas por Ludke e Andre (1988) da seguinte forma:

- Visam à descoberta. Todo pesquisador, de forma lógica, parte de uma base teórica, para fazer uma investigação, devendo adotar uma postura aberta e flexível a novos elementos que possam surgir durante a pesquisa. Portanto, o conhecimento teórico inicial será o esqueleto a ser complementado por novas dimensões durante o avanço da pesquisa.

- Enfatizam a interpretação no contexto. A pesquisa se contextualiza na unidade ou objeto de estudo, podendo-se compreender melhor as diversas e complexas inter-relações dos indivíduos e/ou empresas e seu ambiente específico, em razão de percepções, comportamentos e interações.

- Buscam a realidade de forma completa e profunda. Pretendem revelar as diversas dimensões naturais de uma determinada situação. 
- Usam variadas fontes de informação. Os dados são coletados em diferentes momentos, em variadas condições e com diferentes informantes, através do emprego de diferentes técnicas.

- Utilizam linguagem mais acessível se comparados a outros relatórios de pesquisa. Imprime-se um estilo narrativo informal ilustrado por figuras de linguagem, citações, exemplos e descrições.

De acordo, portanto, com as colocações destes autores (YIN, 1994; GIL, 1987; LUDKE e ANDRE, 1988), reforça-se que a técnica de estudo de caso mostra-se a mais adequada para estudar a capacidade de inovação como formadora de valor. Ao não existir um entendimento do fenômeno a ser estudado, a técnica favorece a adoção de variáveis não contempladas inicialmente e que possam surgir no decorrer do estudo. Além disso, o fenômeno é complexo, exigindo um nível maior de detalhamento das relações dentro da organização, a interpretação dos fatos está intimamente ligada ao contexto empresarial e, finalmente, o método favorece o uso de diferentes técnicas de coleta de dados.

\subsection{Modelo de pesquisa}

Entende-se por modelo de pesquisa o sistema de conceitos representativos dos fatos, fenômenos e variáveis considerados como objeto de pesquisa (BARBOSA, 1978). Qualquer tipo de pesquisa empírica tem um modelo de pesquisa implícito. No seu sentido mais elementar, o modelo é a lógica que une os dados a serem coletados (e as conclusões a serem desenhadas) às perguntas iniciais do estudo (YIN, 1994). Seu principal propósito, continua o autor, é ajudar a evitar a situação na qual a evidência não esteja direcionada às perguntas iniciais de pesquisa; ou seja, o modelo de pesquisa lida com um problema lógico e não com um problema logístico. O modelo ajuda a não perder o foco do trabalho.

Yin (1994) considera cinco componentes do modelo de pesquisa como especialmente importantes no estudo de casos:

1. a pergunta de pesquisa; 
2. suas proposições, se houver;

3. sua(s) unidade(s) de análise;

4. a lógica que liga os dados às proposições; e

5. os critérios para interpretação dos resultados.

Cada um destes componentes é detalhado pelo autor, sendo sua vinculação com o desenvolvimento do presente trabalho, apresentada a seguir.

Acredita-se que para responder à pergunta de pesquisa proposta neste estudo - "Como determinados aspectos da capacidade de inovação propiciam a formação de valor das empresas?" - possa-se lançar mão da estratégia de estudo de caso, uma vez que há na literatura uma indicação de que esta técnica é mais apropriada para responder a perguntas do tipo "como" e "por que" (YIN, 1994).

As proposições têm como função direcionar e limitar a atenção para algo que deverá ser examinado no escopo do estudo. Na proposta deste projeto elaborou-se o construto "capacidade de inovação" como sendo a proposição do trabalho, o qual é composto pela cultura organizacional, os processos internos e as relações interorganizacionais. Este construto delimitará o foco das atenções no desenvolvimento deste estudo.

O terceiro componente do modelo, a unidade de análise, está relacionado com o problema fundamental de definir o que é o caso. No trabalho a ser desenvolvido, a unidade de análise será a empresa de Biotecnologia. Como mais de uma empresa será analisada, o modelo caracteriza-se como estudo de casos múltiplos. "As evidências obtidas de estudos de casos múltiplos são consideradas mais fortes, o que faz com que o conjunto do estudo seja considerado mais robusto" (HERRIOTT e FIRESTONE, 1983 apud YIN, 1994, p. 45). Uma decisão derivada da alternativa de realizar um estudo de casos múltiplos está relacionada com a escolha do número estimado de casos necessários ou suficientes para o estudo. 
O quarto e o quinto componente do modelo de pesquisa, a vinculação dos dados às proposições e os critérios para interpretar os resultados, são, segundo YIN (1994) os componentes que menos têm se desenvolvido nos estudos de casos. Estes componentes representam os passos na análise dos dados em pesquisas que usam estudo de casos e o modelo de pesquisa deve ser o alicerce que esta análise possa ser realizada. O autor sugere que sejam usadas algumas proposições teóricas da literatura para vincular os dados às proposições usadas no estudo de casos. Este cuidado foi levado em consideração ao fazer a revisão da literatura pertinente.

A figura 6 mostra, de forma esquemática, o modelo de pesquisa definido para este trabalho. Por tratar-se de um estudo qualitativo, as variáveis apresentadas não representam relações de causa e efeito, característica destacada por CRESWELL (1994) como distintiva entre os estudos qualitativos e quantitativos. Devem ser vistas, portanto, apenas como variáveis contribuintes, ou seja, não necessárias e nem suficientes, mas passíveis de serem associadas com o fenômeno "formação de valor" a ser estudado.

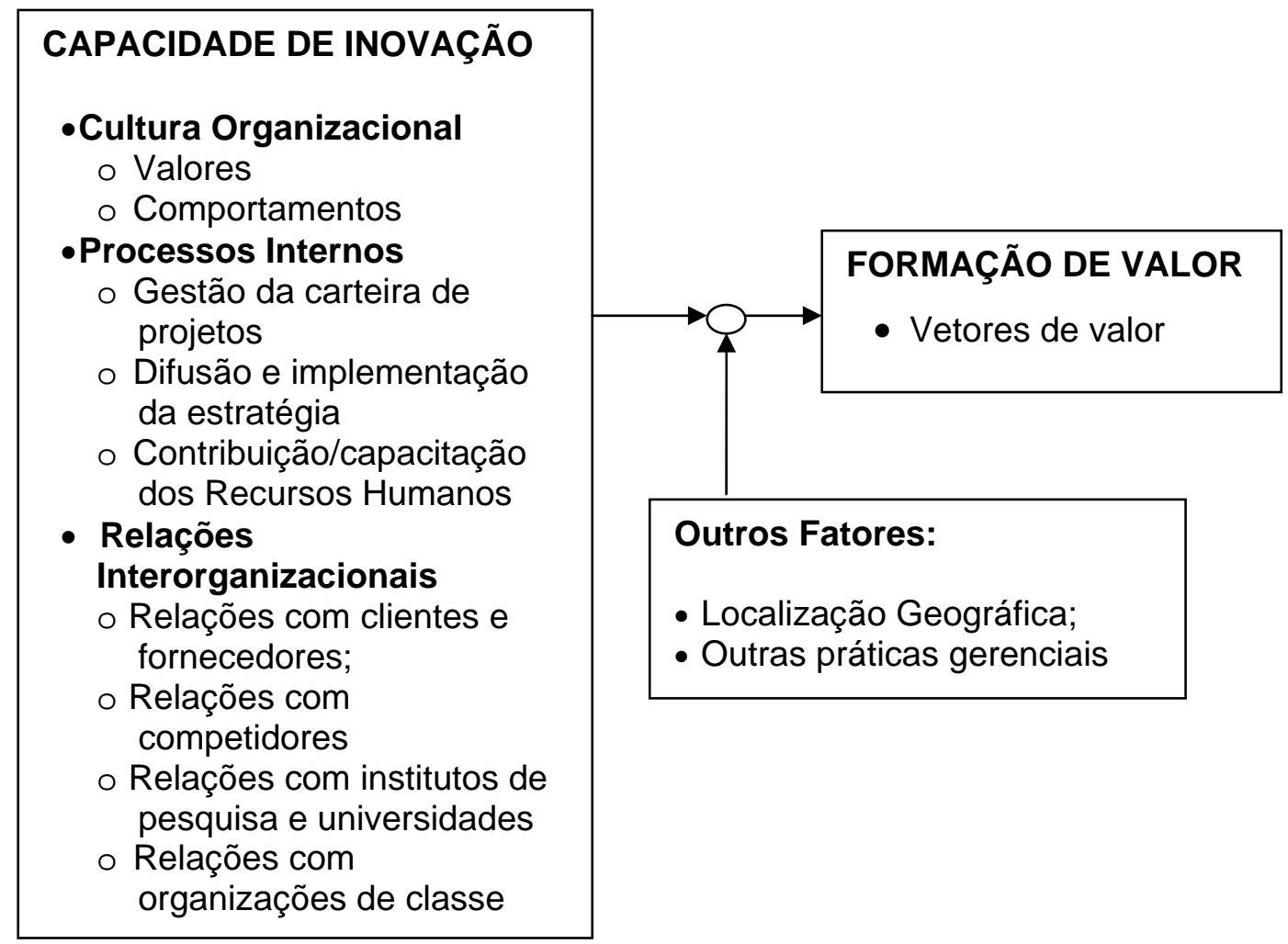

Figura 6: Modelo de pesquisa proposto. 


\subsection{Definição das variáveis}

Ao ser realizada uma pesquisa quantitativa, o pesquisador isola e define variáveis e as classifica em categorias. Essas variáveis são relacionadas para formular hipóteses e, com muita freqüência, isto é feito antes que os dados sejam coletados, sendo, então, essas hipóteses testadas contra os dados. Em contraste, a pesquisa qualitativa começa definindo conceitos muito gerais, os quais, no decorrer da pesquisa, sofrem modificações. Na pesquisa quantitativa, as variáveis são os veículos ou os meios para realizar a análise; na pesquisa qualitativa, as variáveis podem constituir o produto ou resultado da pesquisa. Numa visão abrangente, o pesquisador "qualitativo" busca padrões de interrelacionamento entre um conjunto de conceitos previamente não especificados, enquanto o pesquisador "quantitativo" procura através de uma lente estreita um conjunto específico de variáveis (BRANNEN, 1995).

O Quadro 4 apresenta as variáveis contribuintes a serem consideradas no estudo.

\begin{tabular}{|l|l|}
\hline \multicolumn{1}{|c|}{ VARIÁVEL } & \multicolumn{1}{c|}{ DEFINIÇÃo } \\
\hline $\begin{array}{l}\text { CULTURA ORGANIZACIONAL. Conceitos desenvolvidos por JASSAWALLA e SASHITTAL } \\
\text { (2002) como característicos das culturas que apóiam processos inovativos. }\end{array}$ \\
\hline Cultura & $\begin{array}{l}\text { Compreende o ambiente social e cognitivo, a visão partilhada da } \\
\text { realidade, o sistema coletivo de crenças e valores refletido num } \\
\text { consistente padrão de comportamentos entre os participantes. } \\
>\text { A cultura é estudada através de artifícios observáveis, tais como o } \\
\text { vocabulário utilizado nas narrativas sobre a empresa, as estórias } \\
\text { repassadas por seus funcionários, os rituais e símbolos físicos, etc. }\end{array}$ \\
\hline Valores & $\begin{array}{l}\text { São convicções básicas de que um modo específico de conduta é } \\
\text { preferível a um outro oposto. Compreendem crenças, preconceitos, } \\
\text { ideologias e todos os tipos de julgamentos compartilhados pelos } \\
\text { integrantes de uma organização. } \\
>\text { É analisada pela observação da presença/ausência destes } \\
\text { valores na empresa. Em empresas inovativas são valores } \\
\text { característicos: } \\
\text { - O estímulo a tomarem iniciativas e a assumirem riscos } \\
\text { - A abertura da empresa para que clientes e fornecedores } \\
\text { participem do processo de inovação } \\
\text { Orientação para o trabalho em equipe } \\
\text { Pouca resistência à mudança organizacional }\end{array}$ \\
\hline
\end{tabular}

Quadro 4: Definição das variáveis contribuintes (continua) 


\begin{tabular}{|c|c|}
\hline Comportamentos & $\begin{array}{l}\text { Níveis de participação dos funcionários no processo de } \\
\text { desenvolvimento de novos produtos; receptividade para receber } \\
\text { retroalimentação. }\end{array}$ \\
\hline \multicolumn{2}{|l|}{ PROCESSOS INTERNOS } \\
\hline $\begin{array}{l}\text { Gestão da carteira de } \\
\text { projetos }\end{array}$ & $\begin{array}{l}\text { Processo dinâmico de decisão preocupado com priorizar, distribuir } \\
\text { recursos e operacionalizar a estratégia da empresa (COOPER et al., } \\
2000 \text { ). } \\
\text { D Observado através dos critérios adotados no processo de } \\
\text { decisão. }\end{array}$ \\
\hline $\begin{array}{l}\text { Comunicação da } \\
\text { estratégia }\end{array}$ & $\begin{array}{l}\text { Forma pela qual todos os funcionários adquirem um conhecimento } \\
\text { claro dos objetivos de longo prazo da empresa e conseguem } \\
\text { compreender o papel que sua atividade representa na consecução } \\
\text { desse objetivo. } \\
\text { D A observação é através de formas convencionais de comunicação } \\
\text { oral e escrita (conversas informais, palestras, seminários } \\
\text { participativos, cartazes, manuais, etc.) }\end{array}$ \\
\hline $\begin{array}{l}\text { Contribuição / capacitação } \\
\text { dos Recursos humanos }\end{array}$ & $\begin{array}{l}\text { Compreensão dos conhecimentos, atitudes e habilidades } \\
\text { necessárias para sustentar o processo de inovação. } \\
\text { D Observado através das atitudes em resposta às demandas da } \\
\text { empresa }\end{array}$ \\
\hline \multicolumn{2}{|c|}{ RELAÇÕES INTERORGANIZACIONAIS } \\
\hline $\begin{array}{l}\text { Relações com clientes e } \\
\text { fornecedores }\end{array}$ & $\begin{array}{l}\text { Grau em que a empresa faz uso de informações ou até da própria } \\
\text { participação de clientes e fornecedores no desenvolvimento de } \\
\text { novos produtos e processos. }\end{array}$ \\
\hline $\begin{array}{l}\text { Relações com } \\
\text { competidores }\end{array}$ & $\begin{array}{l}\text { Grau em que as atividades dos competidores são monitoradas, } \\
\text { muitas vezes através de redes de informação informais. }\end{array}$ \\
\hline $\begin{array}{l}\text { Relações com institutos de } \\
\text { pesquisa e universidades }\end{array}$ & $\begin{array}{l}\text { Nível de interação da empresa com grupos de pesquisa em } \\
\text { universidades e centros de pesquisa. }\end{array}$ \\
\hline $\begin{array}{l}\text { Relações com } \\
\text { organizações de classe }\end{array}$ & $\begin{array}{l}\text { Participação dos funcionários da empresa em congressos, } \\
\text { workshops e encontros promovidos pelas associações de classe } \\
\text { com vistas a adquirir novos conhecimentos e novas oportunidades } \\
\text { de negócio. }\end{array}$ \\
\hline \multicolumn{2}{|c|}{ FORMAÇÃO DE VALOR (KNIGHT, 1998) } \\
\hline Vetores de valor & $\begin{array}{l}\text { Fatores de operação que exercem maior influência nos resultados } \\
\text { operacionais e financeiros. }\end{array}$ \\
\hline
\end{tabular}

Quadro 4: Definição das variáveis contribuintes (continuação) 


\subsection{Identificação da amostra, critérios e procedimentos de seleção}

Yin (1994) é enfático ao distinguir a generalização estatística da generalização analítica. Na generalização estatística, uma inferência sobre a população ou universo é feita a partir dos dados empíricos obtidos através de uma amostra. Um erro fatal na interpretação de estudos de casos é considerar como válido os resultados de um caso e realizar inferências sobre a população. Os casos não são amostras e não devem ser escolhidos no estudo por esta razão. Os estudos de caso múltiplos devem ser considerados da mesma forma que o pesquisador de laboratório considera uma repetição do experimento.

Na generalização analítica, uma teoria previamente desenvolvida é usada como modelo para comparar os resultados empíricos do estudo de caso. Se dois ou mais casos parecem suportar a mesma teoria, uma réplica pode ser necessária. Os resultados empíricos podem ser considerados ainda mais fortes se dois ou mais casos dão suporte a mesma teoria mas não dão suporte a uma teoria rival igualmente plausível.

Em dezembro de 2001 a Fundação BIOMINAS divulgou os resultados do estudo empírico, denominado "Parque Nacional de Empresas de Biotecnologia", solicitado pelo Ministério de Ciência e Tecnologia. O estudo, de caráter exploratório, tomou como base o Diretório Nacional de Empresas de Biotecnologia/2001, Versão BIOMINAS, que identificara 304 empresas como atuantes em Biotecnologia no Brasil. Seu objetivo foi o de auxiliar o planejamento de investimentos públicos no setor, assim como conhecer o universo das empresas atuantes em Biotecnologia no Brasil, identificando os principais problemas e gargalos à realização do potencial gerador de riquezas (Tabelas $1 \mathrm{e}$ 2) (JUDICE, 2001). 
Tabela 1: Diretório Nacional de Empresas de Biotecnologia 2001:

Distribuição total e percentual por estados brasileiros e o DF.

\begin{tabular}{|c|c|c|}
\hline \multirow[t]{2}{*}{ Regiões / Estadas } & \multicolumn{2}{|c|}{$\begin{array}{l}\text { Empresas identificadas no Diretório } \\
\qquad(\mathrm{N}=304)\end{array}$} \\
\hline & Número & $\%$ \\
\hline SUDESTE & 246 & 81 \\
\hline Minas Gerais & 89 & 29 \\
\hline São Paulo & 129 & 42 \\
\hline Rio de Janeiro & 28 & 9 \\
\hline Sul & 27 & 9 \\
\hline Paraná & 16 & 5 \\
\hline Santa Catarina & 3 & 1 \\
\hline Rio Grande do Sul & 8 & 3 \\
\hline Centro Oeste & 16 & 5 \\
\hline Brasília & 10 & 3 \\
\hline \multicolumn{3}{|l|}{ Sul } \\
\hline Norte e Nordeste & 9 & 3 \\
\hline Pernambuco & 5 & 1.7 \\
\hline Bahia & 2 & 0,7 \\
\hline Paraíba & 1 & 0,3 \\
\hline Pará & 1 & 0,3 \\
\hline $\begin{array}{l}\text { Empresas sem informação } \\
\text { completa }\end{array}$ & 6 & 2 \\
\hline TOTAL & 304 & 100 \\
\hline
\end{tabular}

Fonte: BIOMINAS (2001) apud Judice (2001, p. 15). 
Tabela 2: Diretório Nacional de Empresas de Biotecnologia 2001: Distribuição das empresas por segmentos de mercado e percentuais gerais de participação por segmento em estados de maior concentração.

\begin{tabular}{|c|c|c|c|c|c|c|c|c|}
\hline \multirow[b]{2}{*}{ Segmentos de Mercado } & \multicolumn{3}{|c|}{$\begin{array}{c}\text { Diretório de } \\
\text { Empresas } \\
(\mathrm{N}=304)\end{array}$} & \multicolumn{5}{|c|}{$\begin{array}{c}\text { Diretório de Empresas } \\
\text { Estados de maior concentração } \\
n=272(90 \% \text { de } N)\end{array}$} \\
\hline & $\begin{array}{l}\mathrm{N}^{0} \\
\text { Total }\end{array}$ & $\begin{array}{c}\% \\
\text { Total }\end{array}$ & $\begin{array}{c}\% \\
\text { só } \\
\text { SP e } \\
\text { MG }\end{array}$ & $\begin{array}{c}\mathrm{SP} \\
\mathrm{n}=129 \\
\% \mathrm{~s}\end{array}$ & $\begin{array}{c}\text { MG } \\
\mathrm{n}= \\
89 \\
\text { bre o }\end{array}$ & $\begin{array}{c}\mathrm{RJ} \\
\mathrm{n}=28 \\
\text { total } \mathrm{p}\end{array}$ & $\begin{array}{c}\text { PR } \\
n=16 \\
\text { ra o } \mathrm{Br}\end{array}$ & $\begin{array}{c}\text { DF } \\
n=10\end{array}$ \\
\hline Saúde humana (1) & 74 & 24 & 72 & 27 & 45 & 16 & 5 & - \\
\hline Saúde Hum., Anim. e Veg. (2) & 14 & 4 & 79 & 36 & 43 & - & - & 14 \\
\hline Saúde animal (3) & 14 & 4 & 64 & 21 & 43 & - & 7 & - \\
\hline Agronegócio (4) & 37 & 12 & 57 & 35 & 22 & 8 & 13,5 & 13,5 \\
\hline Meio Ambiente (5) & 14 & 4 & 78 & 14 & 64 & 14 & - & 7 \\
\hline Instrumental complementar (6) & 11 & 3 & 63 & 45 & 18 & - & 9 & 9 \\
\hline Química fina / enzimas (7) & 18 & 6 & 63 & 28 & 5,5 & - & 5,5 & - \\
\hline Em sinergia (8) & 15 & 5 & 73 & 13 & 6 & 7 & - & - \\
\hline Fornecedores (9) & 51 & 17 & 92 & 76 & 16 & 2 & 2 & - \\
\hline MNC, públicas, fármacos, genéricos, & 66 & 22 & 64 & 53 & 11 & 14 & 4 & 1,5 \\
\hline TOTAL & 304 & 100 & 71 & 42 & 29 & 9 & 5 & 3 \\
\hline
\end{tabular}

Fonte: BIOMINAS (2001) apud Judice (2001, p.18).

(1) Diagnósticos, fármacos, fitofármacos, vacinas, soros e biodiversidade

(2) Identificação genética, análise e transgênicos

(3) Veterinária, reprodução animal, pet, vacinas, probióticos, aqüicultura

(4) Melhoramento de plantas, transgênicos, produtos florestais, plantas ornamentais e medicinais, bioinseticidas, biofertilizantes, inoculantes, flores

(5) Biorremediação, tratamento de resíduos, análise

(6) Softwares, Internet, bioinformática, e-commerce, P\&D

(7) Química fina, enzimas

(8) Biomateriais, biomedicina, consultoria em biotecnologia

(9) Equipamentos, insumos, suprimentos

Uma das constatações do estudo é o surgimento e o crescimento do parque biotecnológico brasileiro a partir de 1994, tendo sido criadas após este período, aproximadamente, 50\% das empresas hoje existentes no setor (JUDICE, 2001, 37). Este crescimento tardio do parque biotecnológico brasileiro, mais de 20 anos depois do uso industrial das técnicas de engenharia genética nos Estados Unidos, deixa estas empresas numa situação vulnerável, uma vez que os projetos de biotecnologia possuem longos períodos de maturação. Se comparados com a indústria de informática, e.g., as empresas de biotecnologia são consideradas "lentas" em sua consolidação no mercado. Uma empresa de biotecnologia na área farmacêutica leva 12 anos, em média, para o desenvolvimento de um medicamento e o seu lançamento no mercado. Uma das características que marcadamente diferenciam a indústria de Biotecnologia de 
outras indústrias de alta tecnologia é a relativa intensidade de P\&D e o tempo necessário para que uma inovação chegue ao mercado (HALL e BAGACHI-SEM, 2001). Esta característica obriga estas empresas a ter estratégias robustas, mas flexíveis, para a inovação, o crescimento e sua sobrevivência.

Ainda segundo os dados obtidos pela Fundação BIOMINAS, considerando um número de 50 empresas em uma amostragem intencional, 8\% destas não tinham faturado, até o ano 2000 , nem um centavo. Um faturamento de até $\mathrm{R} \$ 500$ mil/ano foi alcançado por 30\% das empresas estudadas, tendo $18 \%$ delas atingido um faturamento anual máximo de R\$2 milhões (JUDICE, 2001, p. 41).

Mesmo quando têm mercado para seus produtos e serviços, as empresas de Biotecnologia podem se tornar o próprio produto de venda, como é fato comum no mercado mundial neste setor.

Em síntese, a escolha da indústria de Biotecnologia como arena para realizar este trabalho de pesquisa se deve aos seguintes motivos:

- é uma indústria de desenvolvimento embrionário no país, se comparado com o estágio de desenvolvimento em outros países;

- $\quad$ as próprias empresas podem ser o produto de venda;

- o desenvolvimento de produtos e processos é lento se comparado com outras indústrias de alta tecnologia, como a informática;

- o desenvolvimento da biotecnologia, tanto como ciência quanto setor industrial, é considerado de importância estratégica para o Brasil.

- $\quad$ pelo próprio fato de ser uma indústria nova, há uma necessidade por estudos que atendam a realidade brasileira e que ajudem a formular políticas dirigidas ao fortalecimento do setor.

- identificação pessoal do pesquisador, em razão de experiências de trabalho passadas, com relação ao desenvolvimento da Biotecnologia como ciência e um envolvimento e preocupação com relação às políticas públicas para o setor. 
De acordo com Yin (1994), a definição dos casos a serem estudados deve ser feita de forma a possibilitar que a pesquisa alcance tanto o problema quanto $o$ seu contexto, revelando as variáveis potencialmente relevantes e possibilitando, conseqüentemente, um quadro de entendimento da questão e a posterior replicação da pesquisa. Cada caso deve ser selecionado de modo que produza os resultados previstos (uma réplica) ou leve a produzir resultados contrastantes, mas por razões previsíveis (uma replicação teórica). Sabino apud Gil (1987) indica alguns critérios para selecionar casos:

a) Procurar casos típicos: explorar unidades de análise que, em função de informações anteriores, constituam uma expressão do tipo representativo da categoria;

b) Selecionar casos extremos: apresenta a vantagem de mostrar, mesmo que sutilmente, os limites dentro dos quais as variáveis podem oscilar;

c) Escolher casos marginais: trata-se de encontrar casos atípicos ou anormais para, por contraste, conhecer as pautas dos casos normais e as possíveis causas de desvio.

Stake (1994) sugere que a escolha dos casos seja feita assegurando variedade, mas não, necessariamente, representatividade, sem nenhum forte argumento para a tipificação. O que se deve procurar, segundo este autor, é um balanceamento de considerações como acessibilidade e receptividade para colaborar com a pesquisa. O principal critério que deve nortear a escolha é a oportunidade de aprender.

Seguindo as recomendações destes autores e procurando resultados robustos, a escolha dos casos levou em consideração a natureza dos produtos, a localização, o tamanho da empresa, a idade e a predisposição em participar e colaborar com a pesquisa. Desta forma, a escolha dos casos estudados é de caráter intencional.

Seguindo a classificação das empresas por segmentos de mercado mostrada na Tabela 2, dez empresas foram escolhidas, entre os meses de julho e 
agosto de 2003, entre as empresas cadastradas nas páginas WEB da Fundação BIOMINAS (www.biominas.org.br), Fundação BIORIO (www.biorio.org.br) e ABRABI - Associação Brasileira de Empresas de Biotecnologia (www.abrabi.org.br) e por indicações de pesquisadores na área de biotecnologia da Universidade Estadual do Norte Fluminense - UENF, em Campos dos Goytacazes. Foi realizado um contato telefônico para identificar o principal executivo responsável pelo desenvolvimento tecnológico, verificar se a empresa estava em operação e se haveria disposição para participar deste trabalho de pesquisa. A partir das informações levantadas, foram selecionadas cinco empresas atuantes nos seguintes segmentos:

1. Saúde Humana: uma empresa que se dedica à identificação de novas moléculas ativas contra doenças específicas na biodiversidade brasileira, doravante denominada de Empresa 1.

2. Saúde Vegetal: uma empresa de pesquisa e desenvolvimento em genômica aplicada à área vegetal com objetivo de solucionar problemas economicamente importantes em fitopatologia, doravante denominada de Empresa 2.

3. Saúde Animal: uma empresa produtora de vacinas e medicamentos de uso veterinário, doravante denominada de Empresa 3.

4. Agronegócio: uma empresa de melhoramento de plantas pela técnica de cultura de tecidos vegetais in vitro visando à obtenção de mudas em larga escala e em processo de cultivo rigorosamente controlado de plantas com características superiores, doravante denominada de Empresa 4.

5. Multinacional: uma empresa de insumos químicos produzidos por via fermentativa, doravante denominada de Empresa 5.

\subsection{Coleta de dados}

Segundo Pereira (2001, p. 21) "o dado qualitativo é a representação simbólica atribuída a manifestações de um evento qualitativo". É uma forma de representar e reconhecer um fenômeno aparentemente imponderável que, 
fixando premissas de natureza semântica, instrumentaliza o reconhecimento do evento, a análise do seu comportamento e suas relações com outros eventos.

As pesquisas qualitativas, dentro das quais os estudos de casos, usam uma grande variedade de procedimentos e instrumentos de coleta de dados, sendo, caracteristicamente, multimetodológicas. As técnicas de observação de fatos, comportamentos e cenários; de entrevista e de análise de documentos são as mais utilizadas (ALVES-MAZZOTTI e GEWANDSZNAJDER, 1999) O uso concomitante destas fontes favorece a análise crítica de cada informação recebida ou percebida.

A observação é uma técnica de coleta de dados que se vale dos sentidos com vistas a adquirir os conhecimentos necessários sobre determinados aspectos da realidade (GIL, 1987; LAKATOS e MARCONI, 1991). A técnica não consiste somente em ver e ouvir, mas também examinar os fatos e os fenômenos que se desejam estudar. "A observação ajuda o pesquisador a identificar e a obter provas a respeito de objetivos sobre os quais os indivíduos não têm consciência, mas que orientam seu comportamento" (LAKATOS e MARCONI, 1982, p.65).

Segundo Selltiz et al. (1974, p. 225) a observação se torna um instrumento científico na medida que:

1. serve a um objetivo formulado de pesquisa;

2. é sistematicamente planejada;

3. é sistematicamente registrada e ligada a proposições mais gerais, em vez de ser apresentada como conjunto de curiosidades interessantes;

4. é submetida a verificações e controles de validade e precisão

A grande vantagem da técnica de observação direta é o fato de permitir o registro do comportamento tal e qual este ocorre, sem qualquer intermediação. Alves-Mazzotti e Gewandsznajder (1999) apresentam algumas vantagens que costumam ser atribuídas à observação, dentre as quais podem ser citadas: a) independência do nível do conhecimento ou da capacidade verbal dos sujeitos observados; b) possibilidade do pesquisador verificar a consistência de certas respostas; c) identificação de comportamentos não intencionais ou inconsistentes 
e d) exploração de tópicos que os informantes não se sentem à vontade para discutir.

Quanto ao grau de flexibilidade da sua estrutura, as observações podem ser classificadas como sistemáticas (ou estruturadas) e assistemáticas (ou não estruturadas) (SELLTIZ et al., 1974). Nas observações estruturadas, os comportamentos a serem observados, bem como a forma de registro, são preestabelecidos. São usadas quando o pesquisador trabalha com um quadro teórico a priori que lhe permite propor questões mais precisas. Este tipo de observação é muito usado para identificar práticas indicadas na literatura como sendo eficazes e, eventualmente, permite usar alguma forma de quantificação através de sinais, registro de freqüência ou escalas.. Na observação não estruturada os comportamentos a serem observados não são pré-determinados e são relatados da forma como ocorrem, com o objetivo de descrever $\mathrm{e}$ compreender o que está acontecendo num dado momento (Alves-Mazzotti e Gewandsznajder, 1999). Segundo estes últimos autores este é o tipo de observação característico dos estudos qualitativos. No entanto, Selltiz et al. (1974) afirmam que no emprego de técnicas mais formais de observação, como nos estudos mais sistemáticos, o pesquisador sabe quais os aspectos são significativos para os objetivos da pesquisa e, portanto, pode criar um plano específico antes da coleta de dados para a realização e o registro de observações.

A entrevista constitui uma ferramenta básica em todo processo de levantamento de dados, especialmente em estudos do tipo qualitativo, nos quais a temática engloba conceitos de relações humanas ou práticas gerenciais, como é o caso da análise da capacidade de inovação, objeto deste estudo. Por sua natureza interativa, a entrevista permite tratar de temas complexos que dificilmente poderiam ser investigados adequadamente através de questionários, explorando-os em profundidade.

Selltis et al. (1974, p. 273-286) apresentam razões que constituem os objetivos principais das entrevistas, tendo como base os padrões de seu conteúdo: 
1. Conteúdo dirigido principalmente para a verificação de fatos: descobrir se as pessoas que têm acesso à informação são capazes de compreendê-la, se são motivados a adquiri-la, e se assim o quiserem, podem dar ao pesquisador as descrições de muitos fatos interessantes e valiosos.

2. Conteúdo dirigido principalmente à verificação de crenças quanto aos fatos: conhecer aquilo que as pessoas pensam ou julgam que os fatos sejam.

3. Conteúdo dirigido principalmente à verificação de sentimentos: compreender a conduta de alguém em razão de seus sentimentos e anseios.

4. Conteúdo dirigido principalmente à descoberta de padrões de ação: descobrir, por meio das definições individuais dadas, qual é a conduta adequada para determinadas situações, a fim de prever qual será a do observador. As definições adequadas de ação apresentam em geral dois componentes: os padrões éticos do que "deveria" ter sido feito e considerações práticas do que é "possível" fazer.

5. Conteúdo dirigido principalmente ao comportamento presente ou passado: a maneira pela qual uma pessoa se comportou anteriormente, em determinado tipo de situação, é, na ausência de provas contrárias, uma indicação de seu comportamento futuro em situações semelhantes.

6. Conteúdo dirigido principalmente a razões conscientes de crenças, sentimentos, orientações ou comportamento: descobrir quais fatores podem influenciar opiniões, sentimentos e condutas e por que motivo.

No caso específico deste estudo, se optou pela elaboração de um roteiro padronizado ou estruturado de entrevista, procurando garantir a abrangência de todas as variáveis pretendidas (Apêndice). Como instrumento auxiliar à 
realização da entrevista e com a anuência do entrevistado, foi utilizado um microgravador.

No Quadro 5 são apresentadas as variáveis do estudo e as questões do questionário referentes a cada uma delas, sendo as variáveis agrupadas de acordo com os elementos do construto capacidade de inovação. No Quadro 6 são apresentados os indicadores de resultado e as questões formuladas do questionário para cada um deles.

\begin{tabular}{|l|c|}
\hline \multicolumn{1}{|c|}{ VARIÁVEL } & QUESTÕES \\
\hline \multicolumn{2}{|c|}{ RELIONADAS COM A CULTURA ORGANIZACIONAL } \\
\hline Compromisso da Gerência com a inovação & 4 \\
\hline Compromisso dos funcionários com a inovação & 5 \\
\hline Ambiente para assumir riscos & 6 \\
\hline Prêmios por desempenho & 8 \\
\hline Estímulo à geração de idéias & 11 \\
\hline Trabalho em equipe & 20 e 21 \\
\hline \multicolumn{2}{|c|}{ RELCIONADAS COM OS PROCESSOS INTERNOS } \\
\hline Inovação como elemento da estratégia & 1 e 2 \\
\hline Difusão e comunicação da estratégia & 3 e 7 \\
\hline Recursos financeiros para inovação & 9 \\
\hline Critérios para hierarquizar projetos & 10 \\
\hline Habilidades necessárias para a inovação & 12 \\
\hline Infra-estrutura para a inovação & 14 \\
\hline Processo de obtenção de novas idéias & 16 \\
\hline Gestão da carteira de projetos & 17 \\
\hline Mecanismos para conseguir informação de mercado & 18 \\
\hline Mecanismos para conseguir conhecimento tecnológico & 19 \\
\hline \multicolumn{2}{|c|}{ RELACIONADAS COM AS RELAÇÕES INTERORGANIZACIONAIS } \\
\hline Sub contrataçães & 13 e 15 \\
\hline Consumidores como parceiros na inovação & 22 \\
\hline Fornecedores como parceiros na inovação & 23 \\
\hline Monitoramento da concorrência & 24 \\
\hline Contratos externos e alianças & 25 \\
\hline Relações com universidades & 26 \\
\hline Outras fontes de informação & 27 \\
\hline
\end{tabular}

Quadro 5: Relação das variáveis do estudo e das questões formuladas no instrumento auxiliar de coleta de dados para cada uma delas. Fonte: o autor. 


\begin{tabular}{|l|c|}
\hline \multicolumn{2}{|c|}{ INDICADORES DE RESULTADO } \\
\hline Inovação de produtos & 28 e 29 \\
\hline Inovação de processos & 28 e 30 \\
\hline Inovações organizacionais & 28 e 31 \\
\hline Redução em custos & 32 \\
\hline $\begin{array}{l}\text { Outros indicadores de desempenho empresarial e informações da } \\
\text { empresa }\end{array}$ & 33 \\
\hline
\end{tabular}

Quadro 6: Relação dos indicadores de resultado e das questões formuladas no instrumento auxiliar de coleta de dados para cada um deles. Fonte: o autor.

São considerados documentos qualquer registro escrito que possa ser usado como fonte de informação, tais como regulamentos, atas de reunião, relatórios, pareceres, etc. Qualquer que seja a forma de utilização dos documentos, o pesquisador precisa conhecer algumas informações sobre eles, e.g., por quem foram criados, que fontes e procedimentos foram utilizados e que motivos levaram à criação do documento (ALVES-MAZZOTTI e GEWANDSZNAJDER, 1999). Os documentos devem ser cuidadosamente utilizados e não devem ser aceitos como um registro inequívoco dos eventos que já aconteceram - eles podem ser apenas uma interpretação dos fatos, por parte da empresa, ou a forma que a empresa deseja que sejam vistos. Se as evidências dos documentos são contraditórias em vez de confirmatórias, há razões para que o pesquisador verifique profundamente o motivo dessa diferença com outro meio.

Destacam-se dois aspectos importantes referentes ao processo de levantamento de dados: a realização de um pré-teste que visa verificar a compreensão e o alcance das perguntas por parte dos entrevistados, e certificação de que os entrevistados sejam pessoas com conhecimento e informação suficientes para responder com precisão às perguntas formuladas na entrevista (Selltiz et al., 1974). Neste contexto, no presente trabalho, optou-se pela realização um pré-teste, feito na primeira empresa a ser estudada, no sentido de empregá-lo como modelo para a realização dos ajustes necessários quanto à identificação e solução de problemas não previstos no questionário. O pré-teste mostrou a necessidade de incluir novas perguntas, reformular algumas perguntas 
já contempladas, de modo a permitir seu melhor entendimento, e eliminar as perguntas relacionadas aos resultados financeiros e de custo de capital, consideradas pelo entrevistado como estratégicas e de caráter sigiloso. Em segundo lugar, ao selecionar as empresas, as pessoas mais indicadas para responder ao questionário foram, também, concomitantemente identificadas. Em três, das cinco empresas escolhidas, a entrevista foi realizada com os fundadores/diretores técnicos ou científicos. Nas outras duas empresas, os entrevistados foram gerentes das áreas mais pertinentes com os assuntos de inovação e que, além disso, tinham dez ou mais anos no cargo. O Quadro 7 sintetiza as qualificações dos entrevistados e a duração da entrevista.

\begin{tabular}{|c|c|l|l|l|l|}
\hline Empresa & $\begin{array}{c}\text { Ano de } \\
\text { Fundação }\end{array}$ & $\begin{array}{c}\text { Cargo do } \\
\text { Entrevistado }\end{array}$ & $\begin{array}{l}\text { Experiência } \\
\text { no cargo }\end{array}$ & Formação & $\begin{array}{c}\text { Duração } \\
\text { da } \\
\text { entrevista }\end{array}$ \\
\hline $\begin{array}{c}\text { Empresa 1 } \\
\text { Saúde } \\
\text { Humana }\end{array}$ & 1998 & $\begin{array}{l}\text { Diretor de } \\
\text { Desenvolvimento } \\
\text { Tecnológico }\end{array}$ & $\begin{array}{l}\text { Fundador da } \\
\text { empresa }\end{array}$ & $\begin{array}{l}\text { Ph.D em } \\
\text { Química } \\
\text { Orgânica }\end{array}$ & $\begin{array}{l}2 \text { horas e } \\
30 \text { minutos }\end{array}$ \\
\hline $\begin{array}{c}\text { Empresa 2 } \\
\text { Saúde }\end{array}$ & 2002 & Diretor & $\begin{array}{l}\text { Fundador da } \\
\text { empresa }\end{array}$ & $\begin{array}{l}\text { Ph.D em } \\
\text { Bioquímica }\end{array}$ & $\begin{array}{l}2 \text { horas e } \\
\text { 30 minutos }\end{array}$ \\
\hline $\begin{array}{c}\text { Empresa 3 } \\
\text { Saúde Animal }\end{array}$ & 1961 & $\begin{array}{l}\text { Gerente de } \\
\text { Administração } \\
\text { de Projetos }\end{array}$ & Dez anos & $\begin{array}{l}\text { M.Sc. em } \\
\text { Escrobiologia; em } \\
\text { Administração }\end{array}$ & 3 horas \\
\hline Empresa 4 \\
Agronegócio
\end{tabular}

Quadro 7: Qualificação dos Entrevistados e tempo de entrevista. Fonte: o autor

\subsection{Método de análise dos dados}

As pesquisas qualitativas tipicamente geram um enorme volume de dados que precisam ser organizados e compreendidos. Lofland e Lofland (1984) 
apontam para a crença errônea de muitos pesquisadores que imaginam a coleta de dados como uma fase do trabalho e a análise dos dados como uma outra fase. Esta divisão de esforços costuma levar ao fracasso prévio no desenvolvimento de qualquer tipo de análise e até comprometer a coleta de dados. Os autores recomendam que a coleta e a análise de dados sejam realizadas de forma simultânea na maior parte do tempo gasto no projeto e, no estágio final de análise, depois que a coleta de dados tenha terminado, haja um período para ordenar as idéias desenvolvidas anteriormente.

Ponderação semelhante é feita por Alves-Mazzotti e Gewandsznajder (1999, p. 170) que caracterizam a análise de dados como "um processo complexo, não linear, que implica um trabalho de redução, organização e interpretação de dados que se inicia já na fase exploratória e acompanha toda a investigação". À medida que os dados vão sendo coletados, recomendam os autores, o pesquisador deve identificar temas e relações, mesmo de forma tentativa, construir interpretações e gerar novas questões e/ou aperfeiçoar as anteriores. Desta forma, o pesquisador é levado a buscar novos dados, complementares ou mais específicos, que testem suas interpretações e as afinem, num processo que vai até a análise final.

Yin (1994) apresenta quatro técnicas analíticas dominantes para analisar estudos de casos. A primeira técnica é denominada de "comparação de padrões", na qual se compara o padrão empírico com o esperado, de acordo com uma teoria. Se os padrões coincidem, os resultados podem ajudar a fortalecer a validade interna do estudo de casos.

A segunda técnica analítica é denominada de "construção da explicação" que é, de fato, um tipo especial de "comparação de padrões", porém um pouco mais complexo. Seu objetivo é analisar os dados do caso construindo uma explicação do mesmo. Explicar um fenômeno é estipular um conjunto de ligações casuais entre variáveis. Este tipo de explicação é construído de forma narrativa, mas pode ter representação gráfica, como no caso dos Mapas Cognitivos. Este procedimento é principalmente relevante em estudos explicativos. Procedimento similar é usado em estudos exploratórios, como é a proposta deste trabalho, não 
havendo, porém, a intenção de ser conclusivo, mas de desenvolver idéias para estudos posteriores.

A terceira e quarta técnicas, "Análise de Séries-Temporais" e "Modelos de Programação Lógica", respectivamente, são técnicas não aplicáveis ao objeto deste estudo, uma vez que ambas fazem uso de observações ao longo do tempo e, desta forma, não serão exploradas nesta revisão.

Para Eden (in press), o termo Mapa Cognitivo é a representação gráfica da forma de pensar de uma pessoa com relação a um problema ou assunto. Já Novak (2003) define o termo como uma ferramenta para organizar e representar o conhecimento. EDEN et al. (1992) explicam que os mapas são uma rede de nodos e setas que os conectam, nos quais a direção da seta implica numa suposta causalidade. Mais especificamente, na sua representação, um Mapa Cognitivo é desenhado a partir de fragmentos de texto (conceitos) unidos por setas unidirecionais. De forma geral, o fragmento de texto que está na origem da seta é tido como o fato causador, aquele que implica na afirmação contida no fragmento de texto presente na outra extremidade da seta. Os Mapas Cognitivos são usualmente derivados de entrevistas e, desta forma, buscam representar o mundo subjetivo do entrevistado. Quando um Mapa Cognitivo é desenhado fica relativamente fácil ver como cada um dos conceitos e suas relações causais se relacionam entre si, e como está estruturada a situação global narrada pelo entrevistado.

As bases teóricas para a construção dos Mapas Cognitivos derivam da Teoria do Construto Pessoal de Kelly (1955), que propõe um entendimento de como o homem "interpreta" o mundo ao seu redor ao procurar conduzí-lo e controlá-lo. Segundo Eden e Ackermann (2004), ao fazer uso da técnica de Mapas Cognitivos o pesquisador procura elucidar, seja através de entrevista e/ou análise e decodificação de documentos, as crenças, os valores e a habilidades técnicas e opiniões do tomador de decisão, que são relevantes para o tema tratado. Estes conceitos são, então, capturados como um modelo do sistema do construto e representado numa forma esquemática denominada Mapa Cognitivo ou Mapa Conceitual. Os mapas não são apenas uma descrição gráfica do que é dito, mas uma interpretação do que é significativo para o entrevistado. 
$\mathrm{Na}$ elaboração dos Mapas Cognitivos resultantes dos dados coletados em campo, foi utilizado, no presente trabalho, o programa de software livre Concept Map Tools, versão 3.3, do Institute for Human Machine Cognition da University of West Florida.

Eden e Ackermann (1992) afirmam que os mapas cognitivos podem ser codificados seguindo diferentes convenções e, por este motivo, é argüível a não existência de uma abordagem geral para sua análise. Ou seja, a interpretação dos mapas deve ser feita levando-se em consideração tanto o propósito da pesquisa quanto as bases teóricas que fundamentam a forma da representação a ser analisada. Dadas estas reservas, os autores apresentam algumas técnicas para a análise dos mapas cognitivos. Com relação a sua natureza, estes são caracterizados por terem uma estrutura hierárquica na forma de gráfico de meios I fins com um objetivo colocado no topo da hierarquia. Embora a forma hierárquica do mapa seja, às vezes, destruída por uma circularidade, na qual uma cadeia de meios e fins volta a si mesma, os elementos compreendidos nesta estrutura circular têm o mesmo status hierárquico, sendo a forma geral do mapa ainda entendida como hierárquica. A existência de uma circularidade pode ser explicada, em primeiro lugar, por um acidente de codificação que necessita correção. Em segundo lugar, a circularidade pode resultar da existência de um sistema dinâmico, na forma de retroalimentação, o qual pode representar um papel importante na solução de problemas.

Ao ser analisado um mapa cognitivo, observa-se, em primeiro lugar, a sua complexidade. Esta é função do número de nodos e do número de conectores existentes na sua estrutura. Em segundo lugar, procura-se verificar a existência da centralidade cognitiva de um nodo em particular.

A análise inicial sugere que quanto mais nodos houver em um mapa, mais complexo é o mapa. Neste caso, o método de elucidação dos fatos é crucial para determinar a validade de tal medida. Numa entrevista estruturada, o número de construtos (nodos) é significativamente afetado pela própria estrutura da entrevista; na entrevista não-estrutura, este é afetado pela falta de habilidade do entrevistador. Eden e Ackermann (1992) afirmam que o número de construtos elucidados numa entrevista é dependente, sobretudo, da duração da entrevista e 
da habilidade do entrevistador. Desta forma, qualquer análise que dependa do número de nodos deve ser tratada com grande cuidado.

Uma forma alternativa à contagem absoluta do número de nodos é o estabelecimento da relação entre conectores e nodos. Uma alta razão indica um mapa densamente conectado e, supostamente, um alto nível de complexidade. Novamente, a robustez da análise é dependente da habilidade de codificação de quem está fazendo o mapa. Mapas elaborados por Eden e Ackermann (1992) mostram razões entre 1,15 e 1,20. Para os autores, este intervalo de variação não permite identificar diferenças significativas na complexidade cognitiva dos mapas.

A segunda análise é geralmente conhecida como "análise de domínio" ou "conceito dominante". Esta analisa e leva em consideração o número total de setas que chegam e de setas que saem de um nodo ou conceito, ou seja, seu domínio imediato. Os nodos cujos domínios imediatos são mais complexos compreendem, supostamente, aqueles cognitivamente mais centrais. Esta não é uma medida da complexidade cognitiva geral do mapa, mas sim da complexidade local de um nodo em particular. No entanto, a análise indica a riqueza do significado de cada construto em particular e esta característica é utilizada como um método para isolar "construtos importantes" e que serão utilizados para produzir uma visão geral do mapa.

Em alguns mapas é possível detectar nodos mais conectados entre si, os quais podem ser identificados e separados do mapa formando agrupamentos ou clusters. Os clusters são formados quando nodos similares ou fortemente conectados (influenciados) podem ser separados num mesmo agrupamento, até que um nível de dissimilaridade seja atingido e os vínculos com o restante do mapa sejam mínimos. Esta análise identifica as partes "robustas" do mapa cognitivo, ou seja, aquelas que são relativamente insensíveis a pequenas mudanças na estrutura global do mapa. Cada cluster formado e a inter-relação entre clusters mostram uma síntese das características do mapa como um todo. A análise de clusters pode dar uma noção do grau de complexidade de um mapa: mapas que podem ser fragmentados em pequenos clusters desconectados apresentam menor complexidade que aqueles nos quais a separação de clusters 
é de difícil execução. Eden e Ackermann (in press) ressaltam que na pesquisa operacional, o propósito da análise de cluster está na identificação do "sistema de problemas" que direciona os pontos de atenção e para os quais há que buscar uma solução.

\subsection{Limitações}

Como mencionado anteriormente, uma das grandes limitações da pesquisa através do uso de estudo de casos é a incapacidade de extrapolar seus resultados para a população. O propósito da presente pesquisa é simplesmente exploratório, e desta forma, tem o intuito de conhecer a natureza de um fenômeno empresarial no seu próprio contexto e dar subsídios ou indicativos para o desenvolvimento de outras pesquisas sobre o assunto.

Cada uma das técnicas utilizadas para o levantamento dos dados do estudo apresenta limitações particulares. $O$ principal inconveniente da observação reside no fato de que a presença do pesquisador pode provocar alterações no comportamento dos observados, inibindo a espontaneidade dos mesmos e produzindo resultados pouco confiáveis. As técnicas de observação apresentam uma série de limitações, das quais Lakatos e Marconi (1991) destacam algumas que, especificamente, poderiam afetar o estudo proposto:

- a tendência do observado em criar impressões favoráveis ou desfavoráveis ao observador;

- a possibilidade de fatores imprevistos interferir na tarefa do pesquisador;

- a dificuldade para ter acesso aos aspectos da vida cotidiana, particular, da empresa.

Por sua vez, Gil (1987) apresenta algumas limitações que podem comprometer a qualidade de uma entrevista. São elas:

- a falta de motivação do entrevistado para responder às perguntas formuladas; 
- a dificuldade de compreensão da pergunta pelo entrevistado;

- possibilidade de respostas falsas e/ou retenção de alguns dados importantes, determinadas por razões conscientes ou inconscientes ou por receio de que sua identidade seja revelada;

- inabilidade ou mesmo incapacidade do entrevistado para responder adequadamente as questões, em decorrência de insuficiência de vocabulário;

- possibilidade de influência do pesquisador sobre o entrevistado;

- possibilidade de influência das opiniões pessoais do entrevistador sobre as respostas do entrevistado.

Todavia, em função da flexibilidade própria da técnica de entrevista, muitas das dificuldades citadas podem ser contornadas.

Além das limitações técnicas impostas pela metodologia e pelas técnicas de levantamento de dados, é preciso considerar, ainda, as limitações físicas e financeiras, uma vez que as empresas de Biotecnologia se encontram geograficamente dispersas. Porém, a riqueza do estudo de casos múltiplos está associada, especificamente em relação ao presente estudo, à possibilidade de observar o fenômeno formação de valor em empresas de Biotecnologia que produzam produtos de diferentes naturezas e que estejam localizadas em diferentes regiões do país. 


\section{Capítulo 4}

\section{Resultados}

Segundo Frigo (2003) a administração baseada no valor envolve o processo de identificação dos vetores de uma determinada estratégia e a compreensão do modo como esses vetores levam à formação de valor, o que só pode ser alcançado com o desmembramento destes vetores em ações ou atividades que podem ser rastreadas através de toda a organização.

De modo a melhor demonstrar como determinados aspectos da capacidade de inovação propiciam a formação de valor e de que forma estes se inter-relacionam, os resultados da análise dos dados de cada uma das cinco empresas avaliadas no presente trabalho são apresentados separadamente, sendo cada diagnóstico organizado em três partes distintas. Na primeira parte, a empresa é caracterizada através de um breve histórico sobre a atividade empresarial desenvolvida. $\mathrm{Na}$ segunda, são apresentados os fatores determinantes da capacidade de inovação, bem como o mapa cognitivo que mostra a forma pela qual estes se relacionam. Neste caso, os fatores serão agrupados, conforme mostra o modelo de pesquisa apresentado na Figura 6, da seguinte forma: cultura organizacional, processos internos, relações interorganizacionais e outros fatores condicionantes. Na terceira parte, é feito especificamente o exame dos vetores de maior influência sobre a formação de valor. 


\subsection{Empresa 1 - Empresa de Saúde Humana}

\subsubsection{Histórico}

A Empresa 1 foi criada em 1998 como uma empresa de capital limitado, iniciando suas atividades comerciais em 1999. Está localizada próxima a instituições de pesquisa consideradas de excelência na área de atuação da empresa. Trata-se, hoje, de uma empresa de capital aberto que almeja acessar, catalogar e analisar substâncias químicas derivadas da biodiversidade brasileira aplicáveis principalmente na indústria farmacêutica e na agroquímica para o controle de doenças e pragas.

Segundo informações da empresa, o Brasil detém uma posição potencialmente competitiva na descoberta de novas drogas naturais. Aqui se encontram representadas $70 \%$ da biodiversidade do Planeta, sendo que cerca de $21 \%$ dessas espécies, raças e variedades são encontradas apenas no território nacional. Para que esse potencial químico-farmacêutico possa ser explorado, é necessário estruturar o acesso à biodiversidade, não apenas como atividade exploratória de cunho científico, mas também como atividade econômica que permita o desenvolvimento sustentável.

A estratégia da empresa está centrada em duas atividades distintas. A primeira envolve o estabelecimento e a organização de uma coleção ou biblioteca de produtos naturais que represente a diversidade química do país. A segunda, se refere a disponibilização desta vasta coleção de moléculas a empresas que tenham alvos biológicos específicos, por exemplo uma doença humana ou o extermínio de uma praga agrícola, o que é feito após a triagem da atividade biológica das moléculas isoladas. Desta forma a empresa promove o desenvolvimento de produtos inovadores passíveis de proteção intelectual em acordo com as diretrizes da Convenção de Diversidade Biológica (BRASIL, 2000) e da legislação brasileira relacionada ao Acesso à Biodiversidade e a Lei de Propriedade Intelectual.

O número de funcionários tem variado em função do estágio em que se encontram os projetos em desenvolvimento, chegando a um número máximo de 48 , dos quais $58 \%$ tinham título de doutor ou mestre, 38\% eram bacharéis e 
técnicos e duas pessoas cuidando da administração. A maior parte dos funcionários em nível de doutorado fazem parte do quadro permanente da empresa.

\subsubsection{A capacidade de inovação}

O Mapa Cognitivo mostrando os vetores de valor da capacidade de inovação da Empresa 1, bem como a forma como estes se relacionam entre si, é mostrado na Figura 7. A organização da análise de cada um dos fatores contribuintes para a formação de valor foi feita de modo que a linha de raciocínio seja acompanhada com o auxilio do mapa cognitivo.

\subsubsection{A Cultura Organizacional}

É uma empresa orientada para o resultado e toda a sua atividade está voltada para o desenvolvimento de projetos contratados.

Toda a alta gerência está comprometida com a inovação, uma vez que esta é a essência da estratégia corporativa ou, conforme expresso na entrevista, "a inovação é a única estratégia da empresa". Em função deste compromisso, outros valores são derivados tais como o estímulo à criatividade, a orientação à formação de equipes e o encorajamento para que os funcionários tenham um compromisso com a inovação.

O estímulo à criatividade é afetado por um outro valor, no qual os erros de um funcionário, ao experimentar novas idéias voltadas para os projetos, sejam vistos como experiências para a sua aprendizagem, o que coincide com observação feita por Jassavalla e Sashittal (2002). Como a empresa é organizada por projetos contratados por clientes, um rigoroso cronograma de tarefas e resultados esperados é seguido e controlado por todos os indivíduos envolvidos no projeto, incluindo a diretoria e o cliente. Segundo Bubshait e Farooq (2001) um projeto é o resultado de um esforço integrado de diferentes disciplinas, alcançado usando os recursos disponíveis dentro de restrições de custos, tempo e qualidade. 


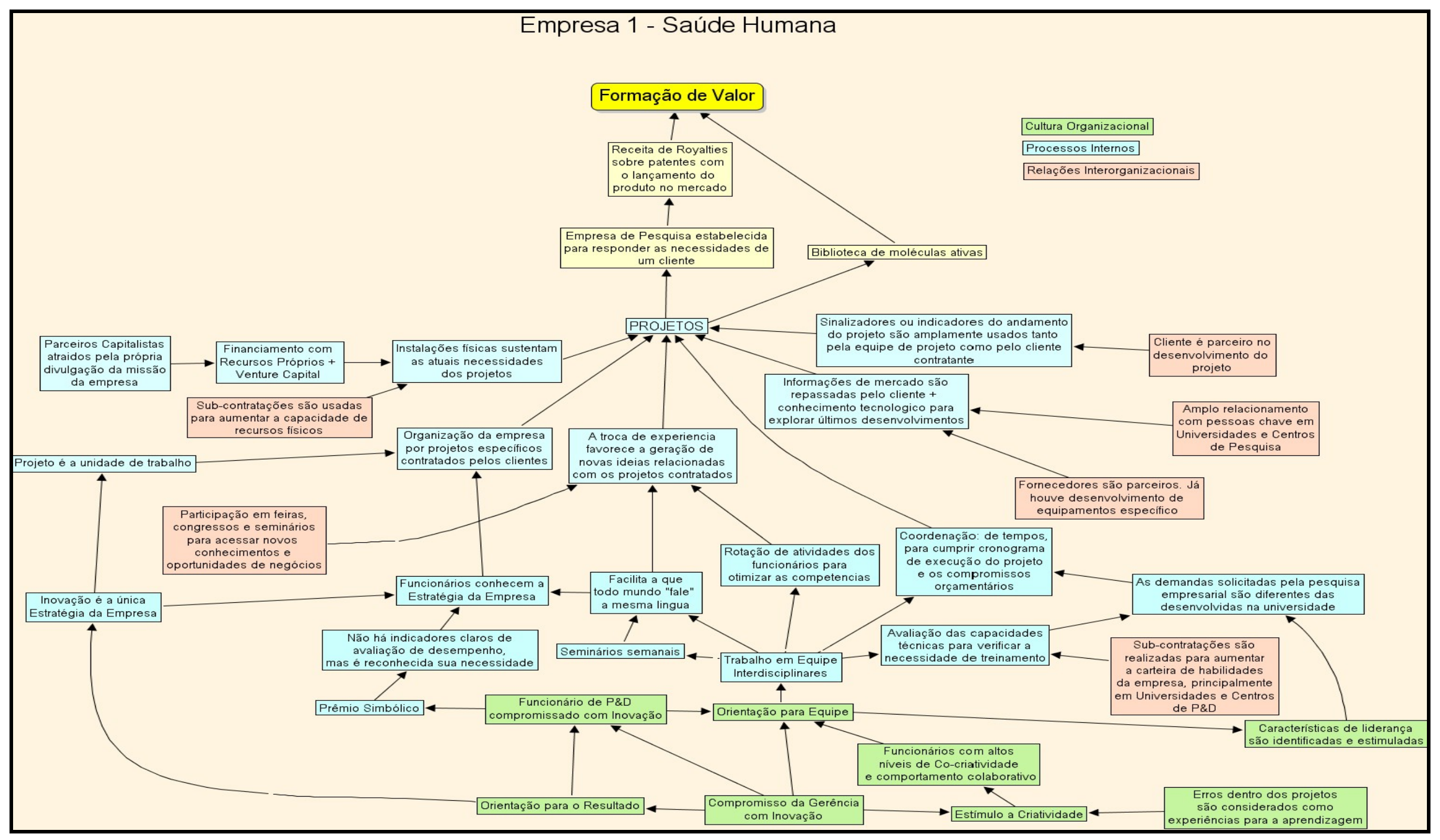

Figura 7: Vetores de valor da Capacidade de Inovação da Empresa 1Fonte: o autor. 
Verificou-se que na Empresa 1 a experimentação de novas idéias sobre determinados procedimentos é permitida e estimulada desde que exista a folga no cronograma. O estímulo à criatividade provoca, por sua vez, um ambiente que favorece o comportamento colaborativo e a co-criatividade.

Para se ter um ambiente no qual o funcionário se sinta compromissado com a inovação, é necessário que ele perceba o compromisso da alta gerência com a inovação e a existência de uma orientação para o resultado, este último funcionando como um sinalizador de foco. Para reforçar o comportamento de compromisso com a inovação, a empresa adota a concessão de prêmios simbólicos aos funcionários em função dos resultados alcançados.

Bubshait e Farooq (2001) enumeram seis elementos necessários para a formação de uma equipe de trabalho: (1) o respeito e a consideração mútua e a compreensão de que todos os membros são valiosos na formação da equipe; (2) o estabelecimento das responsabilidades de cada um em relação às tarefas e dos padrões de desempenho esperados; (3) a comunicação como indivíduos e como grupo; (4) o estabelecimento de objetivos individuais e de grupo; (6) a recompensa ao trabalho em equipe e a prática e encorajamento de lealdade para com a equipe. Na empresa em estudo, todas as considerações sobre a cultura e o clima empresarial levam a uma orientação para a formação de equipes de trabalho, que por sua vez leva à prática de estimular e identificar características de lideranças entre os componentes do grupo.

\subsubsection{Os Processos Internos}

A Empresa 1 é organizada por projetos encomendados por clientes. $\mathrm{Na}$ busca de soluções para os alvos específicos estabelecidos pelos clientes, formase uma biblioteca de moléculas bioativas, sendo disponibilizadas para a empresa contratante aquelas efetivamente eficazes para seus alvos. O restante da coleção, isto é, o acervo que não interessa ao cliente contratante, pode ser negociado com outros clientes através de contrato. Não faz parte do escopo da Empresa 1 o desenvolvimento do produto nem o processo de fabricação do mesmo. Na Figura 7 são mostrados os processos internos observados na empresa. 
O conceito de inovação é entendido, no contexto da empresa, como uma solução nova para os alvos específicos determinados pelo cliente, diferente das soluções compreendidas no estado da arte. Esta solução é dada a partir de um potencial ainda não descoberto na biodiversidade e que possa ser transformado em produto e, efetivamente, dar retorno financeiro. A característica de ser uma solução desconhecida até o momento é uma condição para que seja concedido o direito de propriedade intelectual. As patentes decorrentes são licenciadas para serem exploradas comercialmente pelos clientes, sendo os royalties oriundos da futura venda dos produtos produzidos com a tecnologia gerada a partir das moléculas isoladas, a principal fonte de receita da Empresa 1. A outra fonte de receita refere-se ao pagamento pela execução do contrato de risco relacionado à execução dos projetos na busca das novas moléculas. O gerenciamento da carteira de projetos envolve uma situação diferente daquela apontada por Martino (1995), segundo o qual o problema enfrentado pelas empresas é ter mais projetos em potencial para ser desenvolvido que recursos financeiros, humanos e de infraestrutura física. Na Empresa 1, uma vez que os clientes pagam pela execução dos projetos de risco, estes recursos são garantidos a partir da assinatura do contrato.

As atuais instalações físicas da empresa sustentam as necessidades requeridas pelos projetos em andamento, todas elas financiadas com recursos próprios e capital de risco. Caso seja necessário, subcontratações são usadas para aumentar a capacidade física.

Os projetos em andamento são controlados e acompanhados por um sofisticado sistema computadorizado que permite, através do uso de senhas privativas em diversos níveis de acesso, que a diretoria técnica, o gerente do projeto, os membros da equipe e o próprio cliente monitorem o andamento do projeto e o cumprimento das metas através de sinalizadores ou indicadores de desempenho. Os projetos têm uma duração média de quatro anos.

Conforme mencionado anteriormente, a diretoria da Empresa 1 considera a inovação como "a única estratégia da empresa". O conceito de inovação como algo que não está contemplado no estado da arte da ciência é inerente aos 
projetos a serem executados e, por sua vez, constitui-se em um desafio que deve ser assumido por todos os funcionários dentro da empresa.

A formulação e a implementação da estratégia na empresa avaliada apresenta características do modelo cultural descrito por Bourgeois e Brodwin (1986), no qual as informações são obtidas dos executivos que estão na base operacional da empresa, o que permite a exatidão das informações prestadas. Neste modelo, a estratégia é negociada entre indivíduos com pontos de vista distintos e até mesmo objetivos individuais diferentes. Este modelo começa a ser mais apropriado em ambientes complexos e menos estáveis, nos quais pode ser difícil, para a alta administração da empresa, assimilar e compreender a totalidade das atividades desenvolvidas e seus detalhes.

O papel desempenhado pela Diretoria de Desenvolvimento Tecnológico coincide com o papel descrito por Bourgeois e Brodwin (1986) para cargo de hierarquia semelhante, no qual a visão e a missão da empresa é amplamente comunicada pelo principal executivo, de modo que a permitir a participação de cada indivíduo no estabelecimento de seus próprios procedimentos de trabalho, desde que em consonância com a missão e a visão da empresa.

Pode-se ver no Mapa Cognitivo (Figura 7), que o modelo cultural, assim como proposto por Bourgeois e Brodwin (1986), se apóia num ambiente no qual predomina a orientação para o trabalho em equipe, como forma de coordenação, e que a estrutura do trabalho em equipe é capaz de caracterizar a organização da empresa como um todo.

A Empresa 1 está organizada em equipes de projetos interdisciplinares. Não se trata, portanto, de uma organização matricial de equipes multidisciplinares de projetos, na qual participam, além dos especialistas das áreas técnicas, especialistas das áreas funcionais da empresa, conforme descrito por Clark e Wheelwright (1992), Maximiano, Sbragia e Kroner (1997) e Sbragia (2000). Tratase de uma empresa pequena com apenas dois funcionários tipicamente administrativos, os quais realizam as funções de controle financeiro e de pessoal. Estas pessoas não participam diretamente na gestão dos projetos. As funções de relacionamento com clientes para a discussão de assuntos pertinentes aos 
projetos, bem como a divulgação da empresa, são ainda exercidas pelos seus diretores, que também realizam tarefas científicas.

A consolidação das equipes de projetos e o compromisso dos funcionários com a empresa devem-se principalmente ao fato de todos acreditarem na missão da empresa. No começo das atividades da empresa, eram realizadas reuniões semanais para que cada área técnica apresentasse um seminário visando a que todos conhecessem tanto o andamento da atividade desenvolvida quanto os questionamentos formulados dentro das equipes. Esta é considerada uma ferramenta de integração que, por sua vez, facilita a comunicação entre as diversas áreas técnicas, contribuindo para que todos "falem a mesma língua", como foi expresso pelo entrevistado. As reuniões também ajudam a promover o clima de que não existe uma tarefa mais importante que a outra, mas tarefas complementares e necessárias à conclusão do projeto. Nestas reuniões, no momento em que é discutido o andamento dos projetos, é feita também uma adequação dos tempos de trabalho das diversas equipes, a fim de evitar a ociosidade da mão-de-obra. Estas reuniões são realizadas de forma mais espaçadas atualmente e são feitas para a discussão de projetos específicos, com as equipes correspondentes. Embora não tenha sido previsto neste trabalho, a observação das redes informais como um fenômeno de comunicação, assim como sua importância estratégica, não pode ser menosprezada, conforme observam Cross, Borgatti e Parker (2002).

Uma prática adotada na empresa é a rotação de pessoal técnico na execução das diversas tarefas o que, além de otimizar a utilização de pessoal, desenvolve novas competências e conhecimentos.

Existe na diretoria uma preocupação com relação às atitudes e aspirações de carreira dos profissionais de P\&D, além da preocupação em assegurar uma melhor contribuição destes funcionários para os projetos em desenvolvimento, o que está de acordo com Marcovitch e Maximiano (1993). Também é constatada uma alta rotatividade do pessoal de mais alta graduação, explicada principalmente por não encontrarem no ambiente empresarial o mesmo ambiente existente nas universidades ou centros de pesquisa, onde foram treinados tecnicamente. Nestas instituições não existe uma cobrança rígida dos tempos 
para a apresentação de resultados técnicos, há amplo espaço para pesquisar assuntos não contemplados no projeto original, o resultado é uma contribuição individual e não há necessidade de uma coordenação com o trabalho de outros grupos de pesquisa. O trabalho no ambiente empresarial exige o compromisso da obtenção de resultados num dado tempo e dentro do orçamento negociado, desafio para o qual o pesquisador não foi preparado. Espera-se que o funcionário seja criativo e original e encontre suas próprias respostas. Estes compromissos somente são assumidos quando se trabalha em equipe e em contato com outras equipes. Pressupõe-se a existência de uma liderança dentro de uma cultura de equipe. No caso da Empresa 1, os gerentes que melhor se adaptaram ao trabalho tiveram experiência em indústria em algum instante da vida acadêmica, seja através de estágios, envolvimento com programas de qualidade total ou até trabalho em nível de pós-doutorado. Existe um bom entendimento sobre as habilidades requeridas para desenvolver os projetos e planos de treinamento se houver horizonte de tempo disponível.

Ainda não há na empresa um sistema de medidas aplicável à avaliação de desempenho, mas este assunto está sendo discutido em razão de um pedido de vários dos sócios corporativos que desejam a implementação de incentivos baseados em participação de lucros ou bônus.

\subsubsection{As Relações Interorganizacionais}

Como típica empresa de biotecnologia, a Empresa 1 apresenta uma arquitetura aberta, na qual as necessidades estratégicas são providas externamente (POWELL, 1999; JUDICE, 2001). A própria existência da empresa está fundamentada na prestação de serviço numa área do conhecimento em que a empresa contratante não tem competência nem deseja ter, ou ainda por ser uma atividade onerosa, o que caracteriza uma aliança, em conformidade com as definições de Galbraith et al. (1995) e Souza Paula e Gama Alves (2001).

Entre os clientes atuais da Empresa 1, são observados todos os critérios apresentados por Kanter (1994) como necessários para conseguir uma "vantagem colaborativa". Já houve o caso do cliente participar no treinamento de funcionários para o ensinamento de metodologias científicas essenciais para o 
desenvolvimento técnico do projeto, as quais não estavam compreendidas entre as habilidades da casa. O cliente ganha ao dar um impulso no andamento do projeto e, por outro lado, a empresa também ganha ao poder contar com uma nova habilidade técnica e experiência que pode ser aplicada e adaptada para ser utilizada em outros projetos.

Caso seja necessário, a carteira de habilidades é aumentada através da terceirização feita pala contratação de consultores em universidades, centros de pesquisa e mesmo em empresas fora do Brasil, via a realização de sub-projetos ou prestação de serviço com contrato específico de sigilo. Está muito clara para a diretoria a idéia de que se o conhecimento existe e que há que buscá-lo onde ele estiver.

Os fornecedores são vistos como parceiros no desenvolvimento dos projetos, tendo havido um caso em que um deles desenvolveu, espontaneamente, um equipamento com características específicas para atender uma necessidade técnica em particular. O fornecedor ganha com isso a inclusão de mais um item em sua carteira de produtos.

Poucos são os concorrentes brasileiros da Empresa 1, mas seus diretores acreditam que essa concorrência tem aspectos benéficos, uma vez que auxilia 0 acesso e o intercâmbio de moléculas entre as bibliotecas de moléculas bioativas estabelecidas pelas diferentes empresas.

\subsubsection{Análise}

Explica Eden (in press), um especialista em pesquisa operacional, que, para o pesquisador, a principal utilidade do mapa cognitivo, como modelo, encontra-se no conforto que ele permite para a análise do modelo. Esta análise poderá explicitar variáveis não previstas na concepção do problema em estudo, trazendo indicativos para um trabalho posterior no mesmo tema, ao mesmo tempo em que identifica características do contexto que não seriam identificadas com segurança sem o modelo conceitual e sua análise.

Quando um mapa é relativamente complexo, há a necessidade de uma representação gráfica que seja de fácil leitura e que leve à visualização de um 
padrão ou forma. Com este objetivo, os nódulos ou conceitos são colocados e movidos no mapa de modo que as relações entre eles e a leitura do próprio mapa sejam de fácil compreensão num marco bidimensional. A estrutura do mapa ajuda a indicar características emergentes, simplesmente pela maneira como é montado o melhor desenho das atividades em duas dimensões, i.e., apresentando juntos conceitos relacionados, mantendo o mínimo de conectores entrecruzando e orientando as setas para o objetivo maior, o qual está localizado na extremidade superior do mapa. Desta forma, o conceito que se mostra central no mapa é significativo para a interpretação do assunto estudado.

A estrutura do mapa cognitivo da Capacidade de Inovação desenhado com os dados da Empresa 1 (Figura 7) leva a duas análises complementares: a análise do conceito dominante e a formação de clusters ou agregados. A Figura 8, feita a partir da Figura 7, tem o objetivo de facilitar tais análises. A análise mais simples para identificar o conceito dominante se faz observando o total de setas que apontam para um conceito e as setas que saem do mesmo (EDEN, in press). Isto fornece uma idéia do grau de riqueza e a significância que este conceito, em particular, tem para o mapa.

No mapa da Empresa 1, o conceito dominante é identificado como o trabalho em equipes interdisciplinares, encontrando-se bem próximo da base do mapa, e sendo também chave na caracterização do cluster. O trabalho em equipes interdisciplinares está influenciado por um dos valores cultivados na empresa, um fator característico da cultura organizacional, que é a orientação para a formação de equipes.

O trabalho em equipes favorece a existência de uma uniformidade de linguagem que, por sua vez, é necessária para que se conheça a própria estratégia da empresa. Como apontado por Freedman (2003), quando equipes participam da formulação e implementação da estratégia da empresa, evita-se que se perca o compromisso com ela e que aconteça uma perda de foco nos objetivos. 


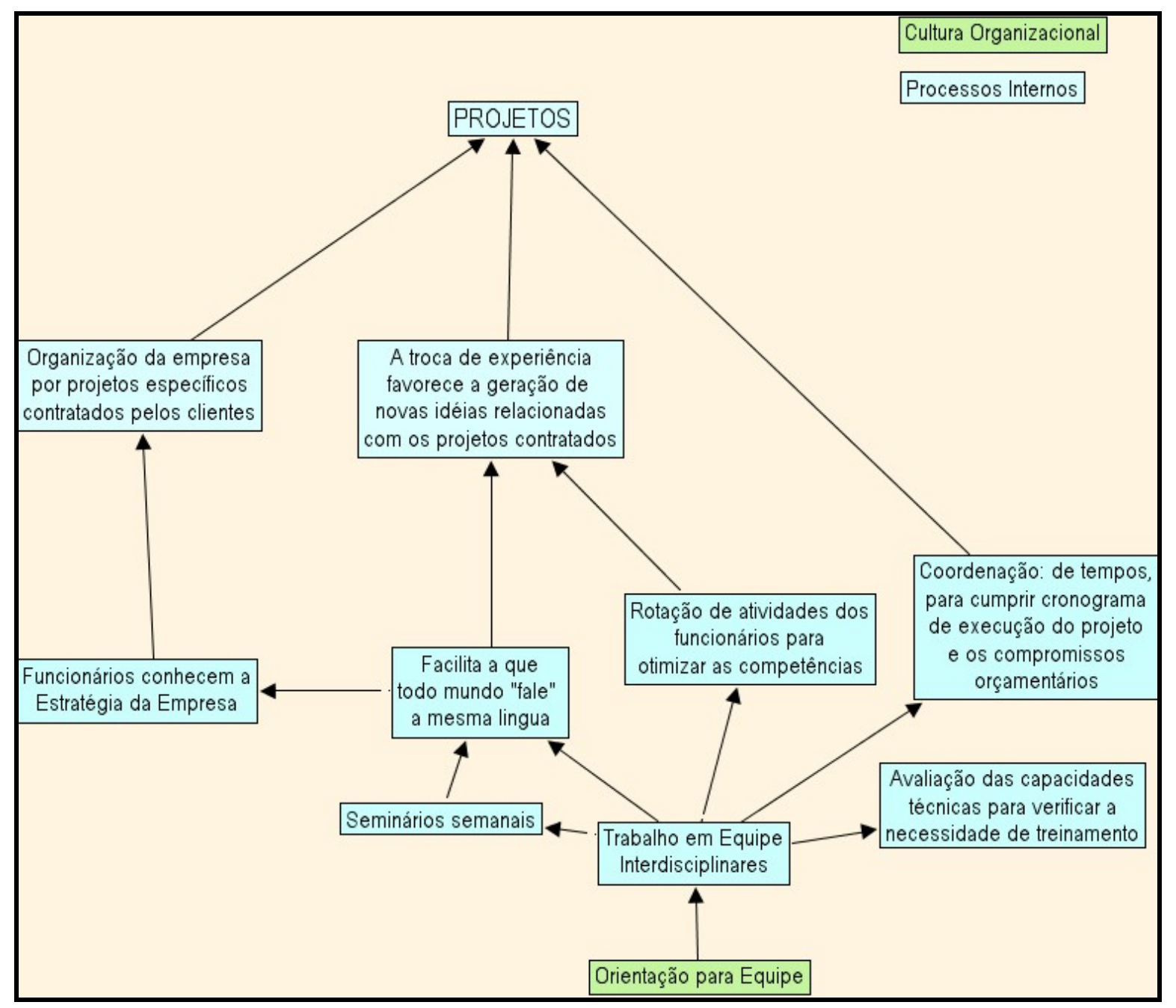

Figura 8: Análise do conceito dominante e de cluster no Mapa Cognitivo da Capacidade de Inovação da Empresa 1. Fonte: o autor

A Empresa 1 trabalha com projetos que desafiam a própria fronteira do conhecimento. Segundo Sotirlou e Wittmer (2001) projetos desafiadores constituem o fator motivacional mais importante para os membros de uma equipe. No entanto, na Empresa 1, foi apontado como problema a alta rotatividade entre os profissionais de mais alto grau de formação. Os diretores atribuem este problema à pressão resultante da necessidade de obtenção de resultados em tempo pré-determinado e de acordo com o orçamento estabelecido no contrato.

Thamhain (1995) enumera dezesseis necessidades específicas que, se satisfeitas, podem proporcionar um desempenho superior dos membros de uma equipe de projeto. A incapacidade, por parte da empresa, em satisfazer estas necessidades pode criar uma barreira para o melhor desempenho da equipe no projeto. São elas: 
1. ser um trabalho interessante e desafiador; esta característica conduz a uma motivação intrínseca dos indivíduos e ajuda a integrar objetivos pessoais com objetivos organizacionais;

2. ambiente de trabalho profissionalmente estimulante; isto proporciona um envolvimento profissional, estimula a criatividade e serve como suporte para a interdisciplinaridade;

3. crescimento profissional; medido através de promoções, ganhos salariais, aprendizado de novas técnicas e habilidades e o reconhecimento profissional;

4. liderança; isto envolve capacitação técnica, habilidade no processamento das informações, comunicação efetiva e habilidades para a tomada de decisão;

5. registros tangíveis do histórico dos funcionários na empresa; registros dos aumentos salariais, incentivos, promoções, reconhecimentos, oportunidades educacionais;

6. perícia técnica; a equipe deve ser composta com profissionais com todas as habilidades interdisciplinares necessárias à execução do projeto, o que não sendo possível na prática, pressupõe abertura para a busca de competências fora da empresa;

7. assistência na solução de problemas; refere-se à facilidade para dar suporte na solução de problemas técnicos, administrativos e pessoais;

8. objetivos claramente definidos para todas as pessoas envolvidas;

9. controle gerencial; a gerência deve compreender as interações das variáveis organizacionais e comportamentais;

10. garantia do emprego; esta é uma das necessidades mais fundamentais e deve ser satisfeita antes de considerar as necessidades de crescimento profissional;

11. suporte da alta gerência no sentido de prover recursos financeiros e instalações físicas, além de assegurar a cooperação das áreas de apoio;

12. boas relações interpessoais; condição sine qua non para o trabalho em equipe, uma vez que proporciona um ambiente estimulante de trabalho, com baixa ocorrência de conflitos e alta produtividade;

13. planejamento apropriado; o que requer habilidades de comunicação e de processamento da informação para definir as necessidades requeridas de recursos e o suporte administrativo necessário;

14. definição clara de papéis; necessário para minimizar conflitos e lutas pelo poder entre os membros da equipe e/ou as unidades de suporte;

15. comunicação aberta; a fim de satisfazer a necessidade de se obter um fluxo livre de informação tanto horizontal como vertical; 
16. mínima ocorrência de mudanças; embora o ambiente empresarial imponha uma tolerância às mudanças, estas devem ser minimizadas através de um planejamento avançado e uma comunicação apropriada, o que ajudará a atenuar seus impactos negativos.

Muitas das necessidades apontadas por Thamhain (1995) como importantes para o bom funcionamento de uma estrutura de equipe aparecem no Mapa Cognitivo da Figura 8. Conforme sugerido por Kaplan e Norton (1997), Duyck (1998) e Haspeslagh, Noda e Boulos (2001), indicadores de tendência e financeiros poderiam ser atribuídos às diferentes atividades relacionadas à estrutura de equipe, visto esta ser o grande motor na formação de valor da Empresa 1.

\subsection{Empresa 2 - Empresa de Saúde Vegetal}

\subsubsection{Histórico}

A Empresa 2 é uma empresa de Pesquisa e Desenvolvimento em Genômica Aplicada. Foi fundada e iniciou suas atividades comerciais em princípios de 2002. Está localizada próxima a clientes potenciais, a universidades e a centros de pesquisa públicos e privados reconhecidos como referência nacional e internacional. Foi constituída como empresa de capital aberto, recebendo financiamento unicamente de empresas de capital de risco. Seu objetivo é utilizar informações já decifradas do genoma de espécies vegetais e de agentes fitopatogênicos, que se encontram disponíveis em bancos de genes de domínio público ou que tenham sido geradas internamente, para o entendimento e a busca de solução para importantes enfermidades que atacam culturas vegetais de interesse agrícola, a fim de melhorar a produtividade das mesmas e a qualidade dos produtos derivados.

De acordo com a concepção do diretor entrevistado, no âmbito de sua empresa uma inovação é uma nova idéia, completamente distinta das alternativas até então utilizadas para o controle de problemas fitosanitários, e que será trabalhada para se tornar uma nova opção de tratamento de tais doenças. Esta definição coincide com a definição de inovação descontínua apresentada por 
Miller e Morris (1999). Por outro lado, de acordo com o mesmo entrevistado, trabalhar uma idéia existente no escopo da ciência é considerado um desenvolvimento. Com base neste conceito de inovação, o entrevistado caracteriza a Empresa 2 como uma empresa de inovação tecnológica.

Os fundadores da Empresa 2, todos cientistas, foram ativos participantes dos projetos realizados para o seqüenciamento do genoma de bactérias causadoras de doenças em plantas e, também, para o seqüenciamento dos transcriptomas de culturas economicamente importantes para o Brasil.

A empresa conta hoje com um corpo técnico formado por 70 funcionários, dos quais 20 são doutores, incluindo pós-doutores, 15 mestres, 35 bacharéis, tecnólogos e técnicos, e 5 funcionários administrativos.

\subsubsection{A Capacidade de Inovação}

A Figura 9 apresenta o Mapa Cognitivo com os vetores de valor da capacidade de inovação da Empresa 2 e a forma como estes se relacionam.

\subsubsection{A Cultura Organizacional}

Todos os diretores fundadores da empresa são cientistas atuantes em suas áreas de competência e manifestam compromisso com a inovação. Há uma consciente orientação para o resultado, que se torna visível no esforço realizado para atingir a solução dos problemas propostos nos projetos em andamento. Para todos os funcionários há um claro entendimento de que qualquer atividade inovadora deve ser orientada para atingir resultados específicos.

Uma vez que a empresa trabalha na expansão da fronteira do conhecimento, há a preocupação para que exista um ambiente no qual seja estimulada a criatividade. Tratando de inovação, Subramaniam e Ashkanasy (2001) definem a dimensão da cultura organizacional em termos dos seguintes 


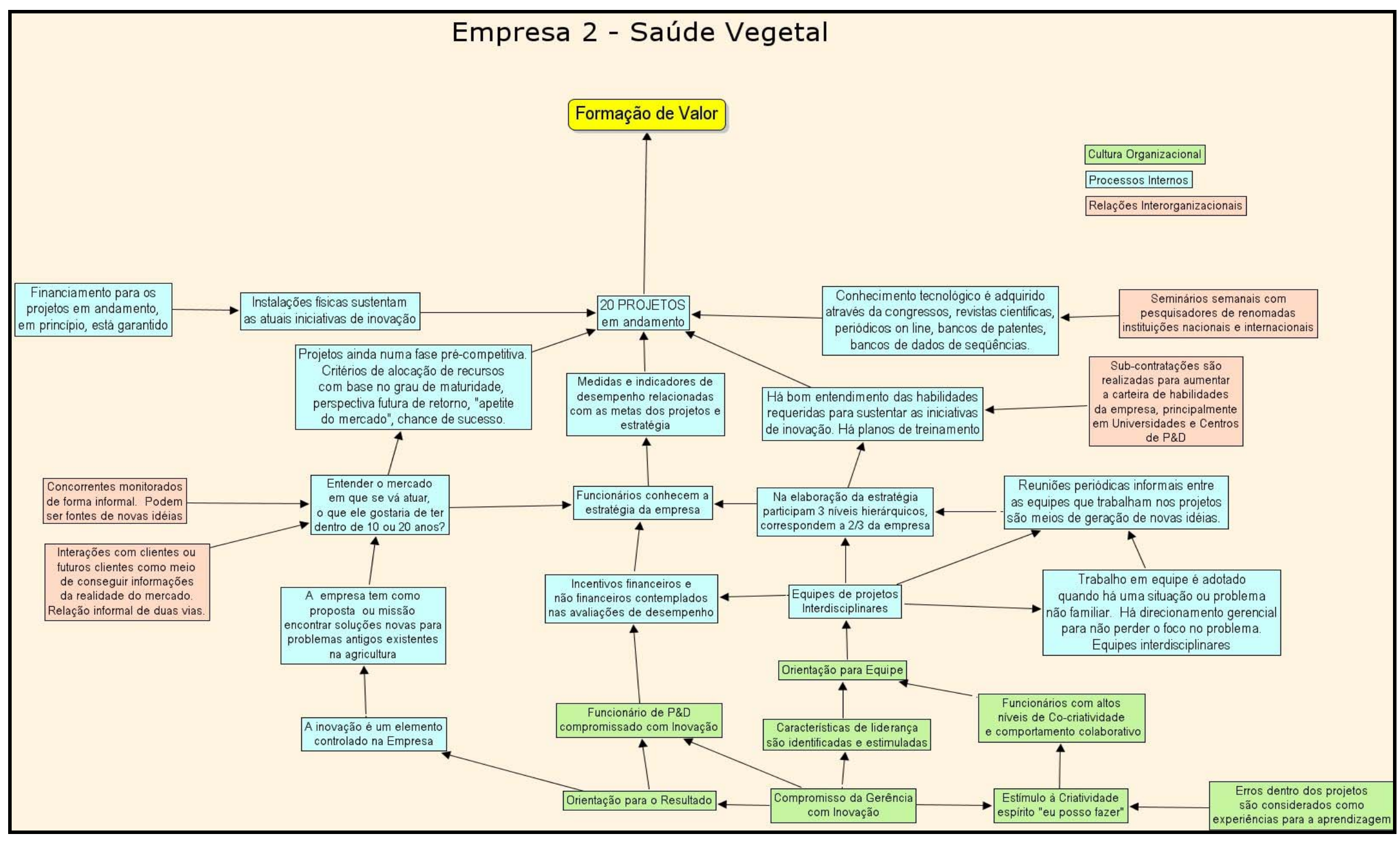

Figura 9: Vetores de valor da Capacidade de Inovação da Empresa 2. Fonte: o autor 
valores, muito dos quais são encontrados na Empresa 2: ser inovativa e disposta a experimentar novas idéias, ser oportunista, não estar restringida por muitas regras e ter predisposição para assumir riscos.

Na Empresa 2 o ambiente para a inovação é fortalecido na medida em que erros, devidamente controlados e documentados, são considerados como experiências para a aprendizagem, valor também ressaltado por Jassavalla e Sashittal (2002).

Espera-se dos funcionários uma atitude pró-ativa com relação ao processo de inovação. A identificação de características de liderança nos funcionários não é feita ainda no processo de seleção, mas têm sido identificadas no contato cotidiano e estimuladas ao longo do tempo. Isto é possível pelo fato de ser uma empresa pequena na qual é fácil conhecer e ter contato mais próximo entre todas as pessoas. O diretor entrevistado se refere aos indivíduos que apresentam características de liderança como líderes ou como gestores de inovação, em síntese, "gente que faz", conforme suas próprias palavras.

Há um entendimento geral de que o trabalho desenvolvido na empresa só é possível de ser realizado através de equipes interdisciplinares. Existe uma clara orientação para a formação de equipes.

\subsubsection{Os Processos Internos}

A empresa tem como missão encontrar soluções novas para antigos problemas existentes na agricultura, propondo-se a empregar ferramentas nunca antes utilizadas para tal finalidade: técnicas de biologia molecular e engenharia genética. Trata-se de tecnologias avançadas, de desenvolvimento recente e constante, em estudo em diversos laboratórios do mundo todo e que visam à compreensão e solução de inúmeros problemas agrícolas.

A inovação é um processo contemplado e controlado na estratégia da empresa. Desta forma, é fundamental um bom entendimento do mercado de atuação, o qual é determinado pelos problemas fitosanitários de maior impacto para o setor agrícola, e ainda a visão daquilo que este mercado necessitará em 10 ou 20 anos. Algumas das pesquisas em andamento na Empresa 2, além de 
direcionadas aos alvos específicos, geram algumas vezes, em paralelo, subprojetos motivados pela ciência. Este fato coincide com um dos resultados do estudo realizado por Hall e Bagch-Sem (2001) na indústria de biotecnologia dos Estados Unidos, que verificaram que inovações orientadas pela ciência (science push) e inovações orientadas pelas necessidades do mercado (demand-pull) não são mutuamente excludentes e podem ser desenvolvidas na mesma empresa através de diversos tipos de arranjos com clientes, universidades e centros de P\&D.,

A estratégia da Empresa 2 é conhecida por seus funcionários. Na sua elaboração participam, de forma democrática, aproximadamente $60 \%$ do corpo de funcionários (diretoria, gerência e pesquisadores), ficando de fora só o pessoal de nível técnico, menos graduado. Estes últimos tomam conhecimento da estratégia através de reuniões com gerentes e pesquisadores que participaram das discussões. Esta forma de participação está afinada com algumas das características da Reunião de Identificação apresentadas por Purser e Cabana (1997). Segundo o entrevistado, a participação dos funcionários neste processo depende muito de sua própria atitude e da decisão de participar ou não das discussões. Todos são convidados, mas há quem demonstre não ter vontade de tomar parte do processo. Desta forma, este funcionário passa a não ser convidado a participar de futuras reuniões.

O envolvimento da grande maioria dos funcionários na elaboração da estratégia favorece um bom entendimento das habilidades requeridas para sustentar as iniciativas de inovação e, ainda, beneficia o direcionamento dos programas de treinamento e capacitação. Ademais, medidas e indicadores de desempenho atrelados às metas dos projetos, discutidos e negociados entre todas as partes interessadas, ajudam a compor o sistema de controle da estratégia global da Empresa 2. Incentivos financeiros e não financeiros são contemplados nas avaliações de desempenho.

$\mathrm{Na}$ Empresa 2, assim como na Empresa 1, o trabalho em equipes interdisciplinares exerce um papel preponderante na formulação da estratégia e sua implementação, esta última refletida na execução dos projetos per se. O trabalho em equipes é também adotado toda vez que surge uma situação ou 
problema não familiar, sempre com direcionamento de um líder que auxilia na manutenção do foco no problema. É característica na ciência da genômica esta forma de organização do trabalho, mesmo com a dispersão geográfica dos diferentes grupos de pesquisa envolvidos num determinado projeto. Para citar um exemplo, no "Projeto Genoma da Xyllela fastidiosa", que visou decifrar o genoma da bactéria responsável pela praga do amarelinho, doença que ataca laranjais, participaram em rede 207 pesquisadores pertencentes a 34 laboratórios de biologia e um centro de bioinformática, todos do Brasil (UNICAMP, 2000). Vale ressaltar que o progresso da ciência da genômica tem sido fortemente favorecido pelos avanços da ciência da computação, pela velocidade e qualidade dos meios de comunicação e seu fácil acesso.

As reuniões informais são constantes e o contato entre todos é facilitado inclusive durante as refeições, feitas no próprio refeitório da empresa. Este tipo de relação promove a formação de redes informais entre os indivíduos da empresa, simplesmente por permitir a descoberta de afinidades mútuas. Cross, Borgatti e Parker (2002) verificaram que redes informais contribuem para a satisfação no trabalho e para o desempenho dos funcionários. Afirmam estes autores que, embora estas redes informais, não descritas nos organogramas, perpassem processos de trabalho centrais ou iniciativas de desenvolvimento de novos produtos, proporcionam flexibilidade organizacional, inovação, eficiência e qualidade nos produtos e serviços, simplesmente por constituírem uma coligação de habilidades diferentes.

O financiamento para os 20 projetos em desenvolvimento na Empresa 2 está, em princípio, garantido. A infra-estrutura já instalada (instalações físicas e equipamentos) sustenta as atuais iniciativas de inovação. O início do desenvolvimento de tais projetos marcou igualmente o início das atividades da empresa, sendo considerado, mesmo após dois anos, que estes projetos estão apenas começando. Acredita a diretoria que, somente ao esgotar as iniciativas em andamento, a empresa avaliará novos projetos, o que, calculam eles, ocorrerá dentro de, aproximadamente, 10 anos. Segundo a diretoria, nesta área de pesquisa, um projeto entra em processo de maturação entre 5 e 10 anos. 
Como os projetos em andamento são considerados, hoje, como estando em estágio embrionário, a escolha dos temas pesquisados e a alocação de recursos é quase uma aposta no futuro. Acredita-se que, num futuro próximo, no processo de gestão da carteira de projetos, a alocação de recursos seja realizada de forma a hierarquizar os projetos. Os critérios a serem adotados, neste caso, seriam o grau de maturidade e velocidade no andamento dos projetos, a perspectiva futura de retorno, o "apetite do mercado", conforme palavras do próprio entrevistado, e a chance de sucesso. Este procedimento é semelhante ao descrito nas metodologias hierarquizantes por Brenner (1994 e Martino (1995).

A complementação e atualização dos conhecimentos tecnológicos necessários às operações da empresa é feita através da participação em eventos científicos, revistas especializadas, bancos de patentes e bancos de dados de seqüências genômicas.

\subsubsection{As Relações Interorganizacionais}

A aquisição e/ou atualização do conhecimento tecnológico é também incrementada com a realização de seminários semanais na sede da empresa, para os quais são convidados destacados cientistas de universidades e centros de pesquisa nacionais e internacionais. Como não é possível reunir todas as competências técnicas dentro da organização, as necessidades pontuais são supridas por subcontratações feitas, freqüentemente, em universidades e centros de pesquisa.

Há na empresa a prática de se manter um contato contínuo com futuros clientes, sem que isto seja, necessariamente, caracterizado como uma perspectiva de futuro contrato formal de trabalho. Este relacionamento é utilizado principalmente como uma maneira de não perder o contato com a realidade vivida pelo setor agrícola.

Não ocorre nenhum tipo de participação dos fornecedores de equipamentos ou de materiais de consumo no desenvolvimento dos projetos.

São poucos os concorrentes da Empresa 2 no Brasil, mas a concorrência pode vir de empresas do exterior. O fato de haver uma pequena concorrência 
interna não impede, porém, que suas atividades sejam monitoradas pela Empresa 2, assim como são aquelas desenvolvidas fora do país. Este monitoramento é feito, certamente, de forma discreta e pela observação de pequenos sinais, requerendo perspicácia e vigilância constante por parte dos pesquisadores. A participação em congressos, por exemplo, é uma oportunidade para ver o que um certo pesquisador, vinculado a determinado grupo de pesquisa ou empresa, está estudando, o que pode fornecer elementos inclusive sobre metodologias e abordagens adotados no desenvolvimento do projeto.

Não foi verificada a formação de alianças estratégicas para a complementação de competências na busca de alcançar objetivos comuns, o que permitiria partilha de custos, de riscos e de benefícios, conforme Freire (1998) e Souza Paula e Gama Alves (2001). As relações externas se restringem a parcerias e cooperações que visam complementar habilidades tecnológicas vitais para o desenvolvimento dos projetos da empresa, dado este em consonância com as observações de Judice (2001).

\subsubsection{Análise}

A estrutura de equipes interdisciplinares como elemento principal da capacidade de inovação apresenta-se na Empresa 2, assim como observado na Empresa 1. Segundo Robbins (2002), há evidências de que a estruturação das empresas em equipes permite um melhor desempenho dos indivíduos quando uma tarefa requer múltiplas habilidades, julgamentos e experiências, resultando em um melhor aproveitamento do talento dos seus funcionários.

Segundo Robbins (2002), as equipes interdisciplinares podem ser definidas como equipes de trabalho autogerenciadas, caracterizadas por um grupo de funcionários que realizam trabalhos muito relacionados ou interdependentes e que assumem responsabilidades que incluem:

- o planejamento e o cronograma de trabalho;

- a delegação de tarefa aos membros;

- o controle coletivo sobre o andamento do trabalho;

- a tomada de decisões operacionais; e 
- a implementação de ações para solucionar os problemas.

Estas características do trabalho em equipe parecem estar evidentes nas equipes de trabalho da Empresa 2, em virtude do tipo de tarefas que realizam, principalmente em relação ao seu envolvimento na elaboração do planejamento estratégico e sua implementação, conforme é mostrado na Figura 10, extraída do mapa cognitivo da capacidade de inovação da Empresa 2 (Fig. 9).

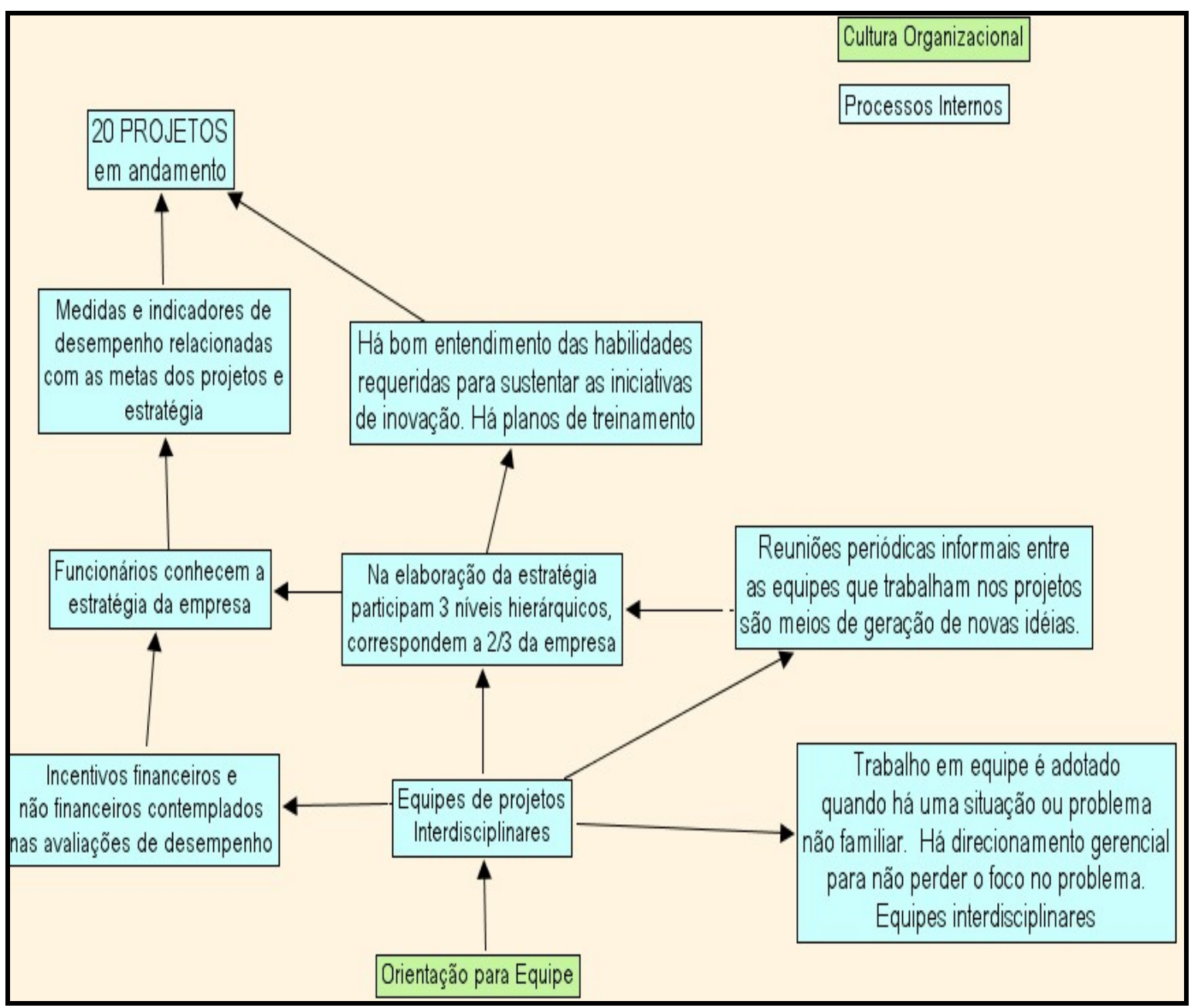

Figura 10: Análise do conceito dominante e de cluster no Mapa Cognitivo da Capacidade de Inovação da Empresa 2. Fonte: o autor

O processo de elaboração, difusão e comunicação da estratégia é, segundo Parnell (1999), composto por três dimensões: envolvimento, entendimento e comprometimento. Na Empresa 2, estas são claramente 
observadas: envolvimento, uma vez que $60 \%$ dos funcionários, todos eles com responsabilidades-chave, participam na elaboração e implementação da estratégia; entendimento, pois se obtém uma compreensão em profundidade da estratégia e suas implicações; e, finalmente, comprometimento, já que estão imbuídos do propósito de alcançar os objetivos estabelecidos e reconhecem a estratégia como parte ativa da organização.

\subsection{Empresa 3 - Saúde Animal}

\subsubsection{Histórico}

A Empresa 3 é uma grande empresa nacional de capital aberto, fundada há mais de 40 anos. Tem hoje aproximadamente 500 funcionários e um faturamento anual da ordem de $\mathrm{R} \$ 115$ milhões. Sua unidade fabril, bem como a quase totalidade das unidades de pesquisa científica, está localizada em um parque industrial em uma cidade do interior que, para atrair novos investimentos e iniciativas produtivas, oferece benefícios fiscais. Apesar de estar geograficamente distante dos centros de pesquisa de interesse, a cidade conta com infra-estrutura de transporte terrestre e aéreo para as principais capitais do país. A empresa atua no ramo veterinário, dedicando-se à produção de vacinas, antiparasitários, suplementos e terapêuticos para animais de grande porte.

Segundo o entrevistado, o conceito de inovação é compreendido na empresa "como a capacidade da empresa em colocar um produto no mercado, de forma a atender uma demanda que o consumidor final não consegue explicitar, mas que existe como uma necessidade real". Outra forma de inovar seria "a incorporação de produtos, já existentes no mercado, na atual linha de produção da empresa, uma vez que se reconhece que estes produtos são importantes para alavancar uma estratégia de penetração em novos mercados". O grande esforço de inovação realizado pela Empresa 3 se identifica com a primeira definição. 


\subsubsection{A Capacidade de Inovação}

A Figura 11 apresenta o Mapa Cognitivo com os vetores de valor da capacidade de inovação da Empresa 3 e a forma como estes se relacionam.

\subsubsection{A Cultura Organizacional}

A alta gerência manifesta compromisso com a inovação em todas as suas atividades, e esta preocupação em procurar surpreender o mercado com novos produtos permeia todas as áreas funcionais da organização. Especial atenção é dada para que os funcionários vinculados com as áreas de P\&D, responsáveis finais para que as inovações em produtos e processos aconteçam, vivam o compromisso com a inovação. Se, para sustentar este compromisso, são necessárias mudanças organizacionais, estas são trabalhadas de forma a que sejam assimiladas como eventos positivos e indispensáveis para impulsionar a empresa na consecução de seus objetivos.

Há uma clara orientação para o resultado, visto estar compreendido que ser inovador é uma garantia do sucesso da empresa e uma sustentação para sua própria sobrevivência. O clima para a geração de idéias é fortemente estimulado com campanhas em toda a empresa, feitas através de cartazes e folhetos que indicam como deve ser realizado o processo de encaminhamento das idéias e como serão realizadas as fases de estudo das mesmas. Os funcionários são estimulados a assumir riscos controlados sempre que uma nova situação chama para a experimentação.

A orientação para a realização do trabalho em equipe é um valor que caracteriza a empresa e espera-se que os funcionários desenvolvam altos níveis de comportamento colaborativo e criatividade. As características citadas coincidem com os fatores da cultura organizacional encontrados por O'Railly, Chatman e Caldwell (1991) que caracterizam a cultura organizacional como uma variável interveniente capaz de afetar o desempenho da organização. 


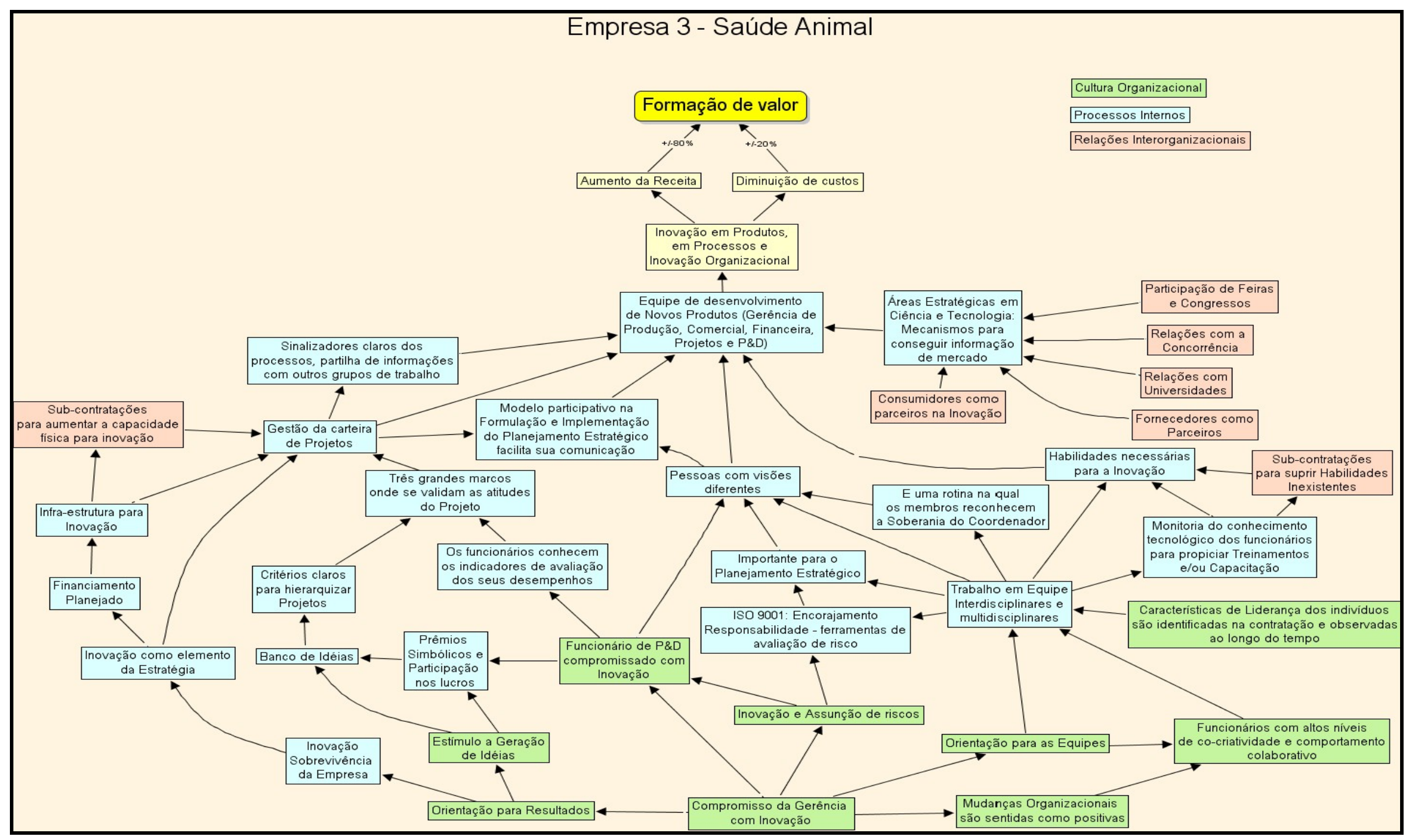

Figura 11: Vetores de valor da Capacidade de Inovação da Empresa 3. Fonte: o autor. 


\subsubsection{Os Processos Internos}

A inovação, entendida como o desenvolvimento de novos produtos que venham suprir necessidades que o próprio mercado não consegue explicitar, é um desafio que se encontra no centro da estratégia empresarial. Sua importância é tamanha que recebe a mesma atenção que outras áreas fundamentais da empresa para a formação de valor, como vendas, marketing e produção.

Contínuos e planejados investimentos têm sido realizados para ampliar as pesquisas no setor e para adequar suas instalações laboratoriais de modo a fazer uso das mais modernas tecnologias científicas disponíveis e aplicáveis à parasitologia, à tecnologia de fermentação, à recuperação e purificação de produtos e à tecnologia farmacêutica.

$\mathrm{Na}$ realização do orçamento anual são estabelecidas as rubricas de financiamento para sustentar cada um dos projetos em andamento. Atividades não orçadas no escopo do projeto e validadas pela equipe de projeto como necessárias, devem ser justificadas e negociadas com a Diretoria.

Uma das formas utilizadas pela Empresa 3 para se manter inovadora compreende a realização de campanhas de incentivo à participação voluntária de todos os funcionários na geração de novas idéias para incrementar o banco de idéias. Trata-se de um processo contínuo, no qual o funcionário preenche um cadastro para formalizar a idéia e enviá-la à Gerência de Administração de Projetos. Feito este processo, a idéia será submetida a três fases de avaliação que visam validar a consistência da idéia como candidata a compor a carteira de projetos. Nesta análise participam pessoas das áreas de produção, mercado e $P \& D$, todas com conhecimento das tecnologias disponíveis na empresa. Estas fases são assim descritas:

1. Seleção prévia. Consiste na triagem de todas as idéias que, em princípio, são coerentes com o direcionamento estratégico adotado pela empresa. Isto inclui o potencial de mercado, o complemento à linha de produtos da empresa, o domínio do processo e o espectro de espécies animais a serem atendidas pelo novo produto; 
2. Hierarquização das idéias mediante critérios estratégicos, técnicos, comerciais e financeiros. Nesta fase são avaliadas tanto as oportunidades quanto as ameaças que possam surgir no mercado. Os critérios mais relevantes são a disponibilidade de matéria-prima, o investimento necessário para eventuais modificações na planta industrial, a facilidade de terceirização, o prazo de lançamento, o faturamento anual estimado, o orçamento do investimento total e as taxas de retorno financeiro;

3. Análise do conjunto das idéias para o balanceamento da carteira de projetos. É utilizada a metodologia do Diagrama de Bolhas proposto por Roussel et al. (1992). O objetivo é agregar os projetos em um só contexto e comparar seus pontos críticos a fim de selecionar o conjunto de acordo com seu potencial de sucesso e seu valor agregado, bem como o balanceamento entre projetos de desenvolvimento a longo e curto prazo e de projetos destinados às diferentes linhas de produto e faixas orçamentárias.

As idéias aprovadas nesta análise serão imediatamente transformadas em Propostas Preliminares de Projetos que, por sua vez, serão levadas para apreciação e aprovação pela diretoria para que sejam efetivamente convertidas em Projetos.

Um outro tipo de campanha é feito semestralmente através da divulgação de um Edital Interno, que difere do anterior pela característica de direcionar as idéias para temas pré-estabelecidos pela diretoria, como por exemplo mercados, espécies de animais e linhas de produtos. A carteira de projetos assim formada é continuamente avaliada pelos mesmos critérios utilizados para a transformação das Propostas Preliminares de Projetos em Projetos em Desenvolvimento.

Os procedimentos adotados pela Empresa 3 para a seleção das idéias do Banco de Idéias e sua transformação em projeto e a própria gestão da carteira de projetos seguem as recomendações de Cooper et al (2000), Brenner (1994), Martino (995), Walsh (2001), Kauffmann et al. (2000) e Spradlin e Kutoloski (1999). Estes mesmos autores recomendam também o uso simultâneo de várias 
técnicas e critérios para uma maior segurança na tomada de decisão, procedimento também adotado na Empresa 3. Todos os projetos, individualmente, têm seu desenvolvimento monitorado através de indicadores de desenvolvimento, que por sua vez estão relacionados com metas e objetivos da estratégia (COOPER, EDGETT e KLEINSCHMIDT, 1998).

O trabalho de funcionários cujas idéias causaram impacto no desenvolvimento de determinado projeto é contemplado com prêmios simbólicos, o que também é feito em relação às equipes de projetos cujos indicadores de desempenho foram destaque. É realizado um cerimonial anual, com a participação da alta diretoria da empresa e todos os funcionários envolvidos com o processo de inovação, onde é feita a entrega de placas e reconhecimento público pelo trabalho. Se os produtos lançados no ano atingirem as metas de venda esperadas, uma premiação complementar de participação nos lucros, proporcional ao salário e abrangendo todos os funcionários, é proporcionada.

É adotado um sistema compreensível de medidas e indicadores de desempenho atrelado à estratégia da empresa, sendo este do conhecimento de todos os funcionários. Este sistema inclui tanto medidas de desempenho individual e da equipe quanto medidas e indicadores de acompanhamento dos projetos em andamento. Existem indicadores globais, de maior interesse no nível tático da organização, para avaliar aspectos mais amplos, e.g., investimento em P\&D em relação ao faturamento de novos produtos nos últimos 5 anos. Outros indicadores são mais operacionais, e.g., tarefas realizadas no período decorrido entre a última reunião e a atual. Todos estes indicadores são bem concretos e, ao serem de conhecimento geral, exigem que o funcionário se sinta comprometido com todo o processo de inovação.

Na Empresa 3, o trabalho em equipes interdisciplinares e multidisciplinares é uma rotina que permeia não só as atividades de $P \& D$, mas todas as atividades da empresa, funcionado como uma equipe de força-tarefa, uma vez que permite que pessoas com diferentes formações e experiências realizem avaliações sobre determinado fenômeno e colaborem com diferentes pontos de vista. Vale ressaltar novamente que o "valor inovação" é um elemento muito forte na cultura organizacional. 
Maximiano, Sbragia e Kroner (1997) explicam de forma simplificada as alternativas para organizar projetos de criação, melhoria e desenvolvimento de produtos numa empresa típica. São elas:

- Organização funcional, na qual cada segmento do projeto fica sob a responsabilidade de uma unidade funcional, mas não há definição de uma autoridade central.

- Organização de projetos (projetos autônomos), caracterizada pela formação de uma equipe temporária, afastada fisicamente da organização; este tipo de organização é mais apropriada para projetos de grande porte, de alto grau de complexidade tecnológica e, por ser um modelo dispendioso, pressupõe disponibilidade de alto montante de recursos financeiros.

- Organização matricial, cuja principal característica é a combinação de uma estrutura funcional com uma organização de projeto. Levando em consideração a bidimensionalidade desta estrutura, é possível sub-classificá-la em função da distribuição de autoridade:

o Matriz funcional - a autoridade é exercida pelos gerentes funcionais;

o Matriz projetos - a autoridade é exercida pelo gerente de projeto;

o Matriz balanceada - há um equilíbrio de autoridade entre os gerentes funcionais e os gerentes de projeto.

$\mathrm{Na}$ Empresa 3, os funcionários das áreas de marketing, finanças, produção, compras ou mesmo da gerência administrativa de projetos, para mencionar alguns, não são considerados "administrativos", mas membros integrantes da equipe de P\&D para um projeto determinado. A Gerência "Administrativa" de Projetos tem ciência, em qualquer momento, do andamento de todos os projetos e exerce um papel de suporte administrativo para os mesmos. O grau de participação de indivíduos das demais áreas funcionais varia muito ao longo do desenvolvimento do projeto. A intensidade é muito grande no começo, 
quando são necessárias considerações de mercado, produção, custo da matériaprima, retorno financeiro, e torna-se esporádica no decorrer do desenvolvimento do projeto. Pode acontecer, por exemplo, que uma variação no preço mundial de um insumo seja tão elevada que inviabilize o projeto ou provoque sua suspensão temporária. Esse tipo de informação é acessado, elaborado e discutido por membros da equipe de projeto oriundos das áreas funcionais. A estrutura de P\&D, contando a estrutura de apoio administrativo, é composta de 43 pessoas. Com a participação das áreas funcionais nos projetos, o número chega a um total de 57 a 60 pessoas.

A autoridade é prerrogativa do gerente de projeto. As características de liderança são identificadas no processo de seleção dos funcionários e trabalhadas ao longo do tempo. A cultura do trabalho em equipe é tão forte que a soberania e autoridade do líder do projeto ou da pessoa delegada para liderar uma forçatarefa é considerada uma rotina. Pode acontecer que um coordenador de projeto de apenas 26 anos e recém formado esteja liderando uma equipe de projeto da qual participa um funcionário com cargo de gerência e 20 anos de empresa. Conflitos ocorrem e é papel da Gerência Administrativa de Projetos ou da Diretoria de P\&D intervir para resolver ou amenizar as diversas situações problema.

O trabalho em equipe facilita a que seja feito um monitoramento mais próximo das habilidades necessárias para o desenvolvimento do projeto e para que possam ser tomadas decisões com relação a necessidades de treinamento ou capacitação.

Os funcionários são encorajados a assumir riscos controlados sempre que uma nova situação chama para a experimentação de novas soluções. Existe na empresa um processo de desenvolvimento ISO 9001 que, além do encorajamento ou de dar espaço para a experimentação, chama também para a responsabilidade. Este processo disponibiliza diferentes ferramentas de avaliação de risco, de modo que quando um funcionário vai colocar em prática uma nova idéia conhecerá todos os procedimentos e cuidados necessários e pelos quais será responsabilizado. 
A introdução contínua de produtos inovadores no mercado é uma atividade que comanda a estratégia empresarial, vista sua importância para o crescimento e a sobrevivência da empresa. Para crescer não basta somente aumentar a parcela de mercado com os produtos existentes, mas também ganhar mercado com produtos que se diferenciem dos concorrentes e satisfaçam necessidades até então inexploradas. A equipe de Desenvolvimento de Novos Produtos é integrada pelas gerências de Produção, Comercial, Financeira, Projetos e P\&D, sempre com o intuito de promover distintos pontos de vista, conseqüência das diferenças de experiência e conhecimentos técnicos sobre um mesmo assunto. São estes gerentes os que, em última instância, acabarão avaliando todas as iniciativas de inovação.

A empresa adota, ainda, a prática de realizar fóruns que reúnem entre 40 e 50 pessoas, incluindo a participação do Presidente, da alta diretoria, da equipe de Desenvolvimento de Novos Produtos e das equipes de P\&D. Nestas oportunidades é possível a manifestação espontânea de idéias e de sugestões que podem mudar o rumo de um projeto ou as características de um produto.

Todo o processo de formulação de estratégia é participativo e é feito em um evento denominado Ciclo de Administração Estratégica, que acontece fora da empresa e conta com a participação de todas as gerências e líderes de projetos, e ainda com a mediação de um consultor externo. A reunião é desenvolvida durante dois ou três dias, cumprindo um cronograma de tarefas semelhante à Reunião de Identificação descrita por Purser e Cabana (1997). Este tipo de reunião permite juntar todas as pessoas que detenham os conhecimentos econômicos, comerciais, técnicos e sociais da organização e, em conjunto, traçar o melhor caminho para atingir os objetivos e metas da empresa e tornar fácil a implementação da estratégia, conforme justificado por Aughton (1996).

A Empresa 3 mantém uma base de dados denominada Áreas Estratégicas em Ciência e Tecnologia - AECTs, que atua como uma central de informações para a inovação. O sistema é alimentado com informações acerca do mercado, fornecedores, pesquisadores que detêm conhecimento científico de interesse e sua localização no Brasil ou no exterior, artigos científicos e tecnológicos, depósito de patentes e legislação pertinente. Segunda a empresa, as tecnologias 
são classificadas como: tecnologias de base, aquelas dominadas pela empresa; tecnologias-chave, aquelas que se dominadas permitirão obter vantagem competitiva; e tecnologias emergentes, aquelas que a empresa não tem, mas o avanço da ciência tornam-nas uma realidade e a movimentação da concorrência para a sua utilização é um indicativo de sua importância. Esta forma de classificação serve para planejar programas de treinamento e capacitação dos funcionários, entre outras possibilidades. Todo funcionário que tiver informação importante para o desenvolvimento ou avaliação de projetos é solicitado a alimentar periodicamente esta base de dados. Todas as pessoas que trabalham nos projetos em desenvolvimento ou que participam nos processos de avaliação dos projetos têm acesso a esta base de dados.

\subsubsection{As Relações Interorganizacionais}

Todas as formas de relações interorganizacionais são encontradas na Empresa 3. As parcerias e subcontratações são usadas não só para aumentar a carteira de habilidades da empresa, mas também quando, mesmo tendo internamente o domínio da ciência, há a necessidade de ganhar tempo no desenvolvimento de um projeto. Este mesmo princípio é adotado com relação às parcerias feitas para aumentar a capacidade física da empresa. Na contratação de espaço físico externo, a empresa considera como se estivesse trabalhando numa extensão de seu próprio laboratório, com uma equipe de pesquisadores, consultores ou mesmo bolsistas do CNPq, neste caso pesquisadores do Programa RHAE (Recursos Humanos em Áreas Estratégicas). Também há a mobilização de recursos humanos da empresa para o laboratório contratado, tanto como mão-de-obra quanto para aperfeiçoamento em novas técnicas.

Os clientes ou consumidores são vistos como parceiros na organização. As informações dos consumidores, e.g., as objeções ou opiniões sobre determinado produto, são intensamente trabalhadas e levadas em consideração quando são desenvolvidos novos produtos e processos. Estes são vistos como importantes formadores de opinião. Não participam do desenvolvimento em si nos laboratórios da empresa, mas alguns deles colocam à disposição a infraestrutura de suas fazendas, em diferentes localidades do Brasil, para a realização 
de testes clínicos de campo. Como contra-partida, a empresa fornece gratuitamente alguns de seus produtos e o cliente ganha também com a "consultoria" dada pelos veterinários da empresa. É comum que um cliente chame informalmente um dos veterinários para, em determinado momento, assistir um animal com algum problema.

A parceria com fornecedores é fato, mas requer cuidados especiais relacionados com contratos de sigilo. Os fornecedores são considerados fontes de geração de novas idéias para produtos e processo. Existem igualmente relações com concorrentes e estas são consideradas saudáveis. Há um pacto entre todos, com regras bem estabelecidas, para partilhar informações de mercado. Não haveria uma outra forma de estabelecer o tamanho de mercado para as diversas linhas de produto, nem a participação de cada uma das empresas em cada linha de produto. A parceria para desenvolvimento tecnológico com uma empresa concorrente, tipo de pesquisa cooperativa, é mais difícil de acontecer.

Há uma procura ativa por contatos externos através de consultorias para realização de co-desenvolvimento de projetos com centros de pesquisa brasileiros e do exterior. Pessoas-chave em todas as áreas da ciência pertinentes aos produtos em desenvolvimento estão bem identificadas e são consultadas constantemente, promovendo a aquisição de novos conhecimentos técnicos, comerciais e gerenciais.

Em todos os congressos científicos e feiras importantes no ramo do negócio há a participação de funcionários da empresa, entendida como forma de aquisição de novos conhecimentos técnicos e de observação das tendências científicas e de mercado.

\subsubsection{Análise}

A estrutura de equipes interdisciplinares e multidisciplinares permeia a estrutura organizacional da Empresa 3, conforme pode ser observado na Figura 12. Dado o tamanho da empresa e o alto grau de diferenciação de todas as atividades, a estrutura matricial adotada pela empresa funciona como tática 
integradora destas atividades, o que está de acordo Lawrence \& Lorsch (1973) em sua Teoria da Contingência. Esta prática proporciona flexibilidade suficiente para que a empresa possa competir no mercado e conseguir a vantagem competitiva que sua competência técnica lhe permite.Nos últimos três anos foram introduzidos 20 novos produtos no mercado, realizada 01 inovação de importância significativa nos processos de produção e a adotadas 03 novas práticas de trabalho ou mudanças organizacionais.

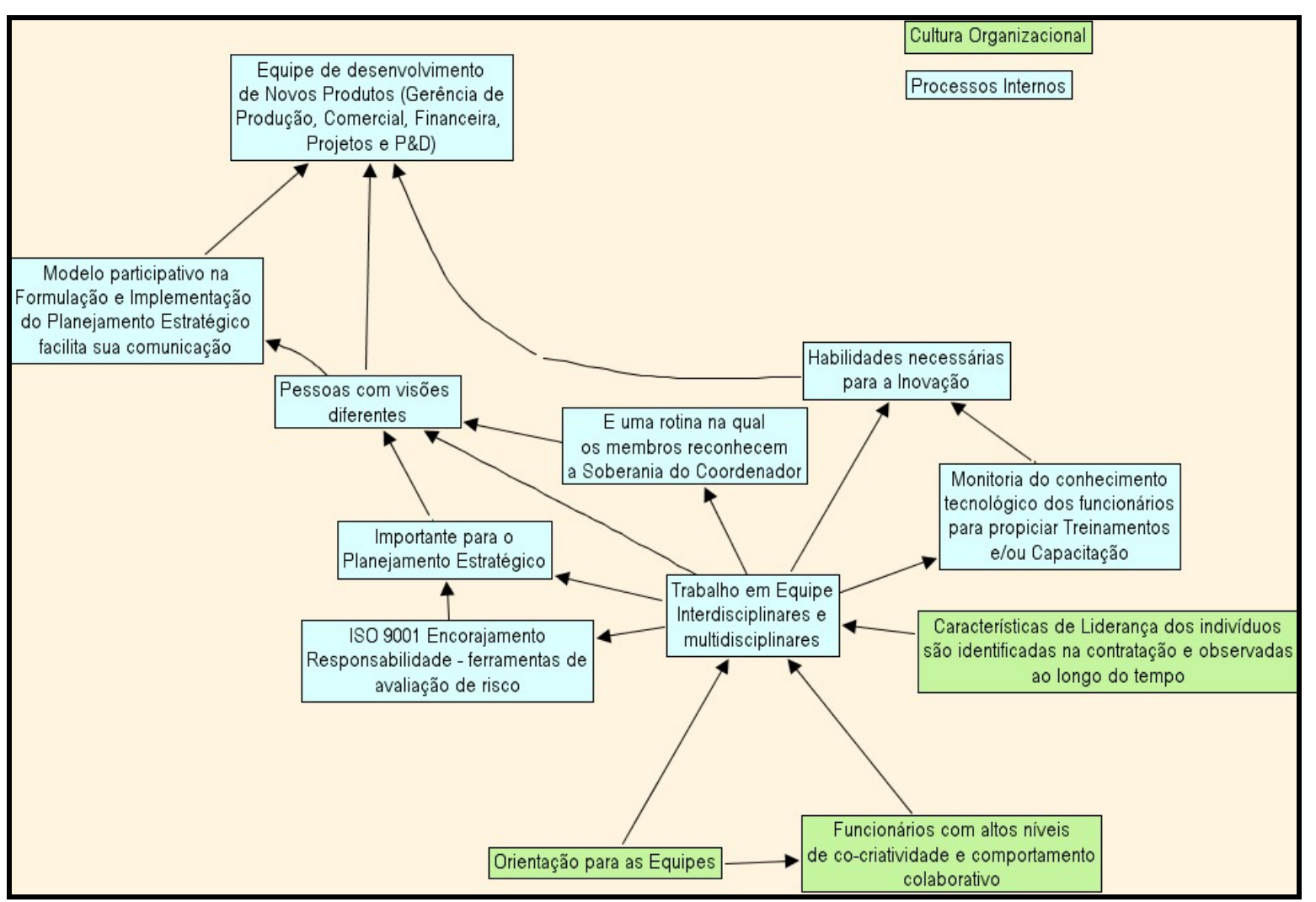

Figura 12: Análise do conceito dominante e de cluster no Mapa Cognitivo da Capacidade de Inovação da Empresa 3. Fonte: o autor

\subsection{Empresa 4 - Agronegócio}

\subsubsection{Histórico}

A Empresa 4 é um empreendimento nacional. Foi fundada em 1991 como sociedade civil de capital limitado e iniciou suas atividades comerciais em 1992. Suas instalações estão localizadas a, aproximadamente, 120 quilômetros de importantes centros de pesquisa, numa região favorecida por clima ameno e 
umidade relativa do ar sem grandes oscilações durante 0 ano, condições favoráveis à atividade da empresa, centrada na biotecnologia vegetal.

Sua especialização está voltada para a produção em laboratório, e em larga escala, de mudas, matrizes e sementes livres de pragas e doenças, através da técnica de micropropagação in vitro (cultura de tecidos vegetais in vitro) e aclimatação controlada em estufas, de cultivares desenvolvidas por outras instituições. Ou seja, a empresa comercializa cultivares sob licenciamento da instituição que as desenvolveu.

Os produtos resultantes do uso da técnica de cultura de tecidos em laboratório são diferenciados pela alta qualidade genética e fitossanitária, certificada por laboratórios credenciados por órgãos oficiais de controle de fitopatologias. Estes aspectos distintivos proporcionam ganho em diferentes formas, tais como produtividade, lucratividade e redução no uso de agroquímicos, entre outros. Atualmente, a empresa disponibiliza produtos (mudas, matrizes e sementes) de espécies agrícolas de importância econômica para a produção de alimentos.

A empresa é gerenciada pelos seus sócios proprietários, dois deles cientistas com formação em nível de pós-graduação na área de fitopatologia e melhoramento genético e propagação de plantas. Dos 28 funcionários, 22 possuem curso técnico, sendo 12 deles em química e 01 na área agrícola.

A Empresa 4 vende seus produtos em todo o país e já está estabelecendo contatos para começar atividades de exportação. $\mathrm{Na}$ sua história, consta o recebimento de prêmios, em nível Estadual e Municipal, de Excelência Empresarial na categoria Indústria e Comércio.

\subsubsection{A Capacidade de Inovação}

A Figura 13 apresenta o Mapa Cognitivo com os vetores de valor da capacidade de inovação da Empresa 4 e a forma como estes se relacionam. 


\subsubsection{A Cultura Organizacional}

A inovação é entendida na empresa como a capacidade de disponibilizar para o mercado produtos agrícolas de alta qualidade genética e com características bem específicas, como por exemplo uma cultivar de determinada fruta destinada à industrialização ou ao consumo in natura, que apresenta características perceptíveis pelo consumidor comum como variedade, coloração, intensidade de sabor. Seguindo esta idéia, a diretoria manifesta compromisso com a inovação e uma clara orientação para o resultado..

Há uma preocupação no sentido de manter na empresa um bom ambiente de trabalho e um diálogo aberto, condições que favorecem a apresentação de sugestões de inovação. Estas sugestões limitam-se a alterações em pequenas rotinas, não sendo aplicadas às técnicas de específicas de micropropagação, cujos protocolos devem ser rigorosamente seguidos. Os funcionários têm liberdade para assumir alguns riscos, mas neste caso a margem de erro deve ser muito pequena a fim de evitar implicações que comprometam o produto final. Essas pequenas, e muitas vezes frustradas, tentativas de melhorar determinado procedimento são consideradas experiências para a aprendizagem. Como o número de funcionários é pequeno, torna-se fácil o contato entre todos. Os diretores estão sempre presentes e os funcionários são estimulados a mostrar suas iniciativas e habilidades.

\subsubsection{Os Processos Internos}

A inovação é um processo contemplado na estratégia da empresa. Desde que os fundadores tiveram a idéia de estabelecer uma empresa para realizar esta atividade, todas as decisões foram planejadas. Nenhum dos diretores é natural da região e a escolha do local foi realizada com base em critérios técnicos e, ainda, pela proximidade a centros de pesquisas e universidades que servem como referências técnicas ou órgãos certificadores.

As instalações físicas sustentam as atuais iniciativas de inovação, produção e controle de qualidade laboratorial dos produtos, mas como a área física é vasta, há planos para o aumento da capacidade ante a perspectiva de 


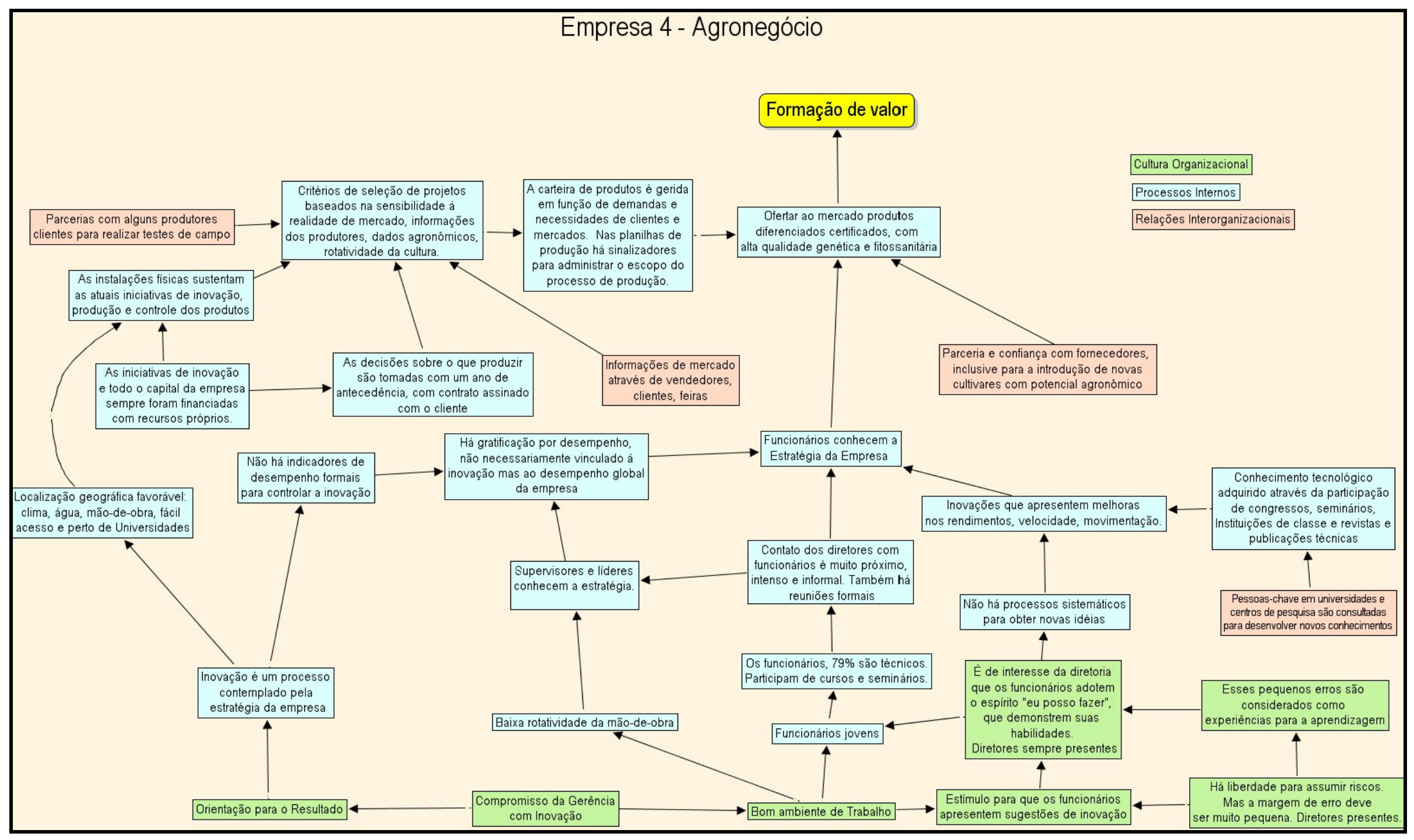

Figura 13: Vetores de valor da Capacidade de Inovação da Empresa 4. Fonte: o autor. 
exportação de seus produtos. Todas a iniciativas de inovação e todo o capital da empresa foi, até o presente, financiado com recursos próprios, não tendo havido tampouco nenhum tipo de benefício fiscal.

As decisões sobre quais cultivares produzir são tomadas com um ano de antecedência e sempre através de contrato assinado com o cliente. Todos os critérios de seleção de projetos estão baseados na sensibilidade à realidade de mercado, informações dos produtores, dados agronômicos e necessidade de rotatividade das culturas. A carteira de produtos é gerida em função das demandas e necessidades dos clientes e mercados. Nas planilhas de produção há sinalizadores para administrar o processo de produção.

Os funcionários da empresa são jovens e assimilam com facilidade as boas práticas de laboratório exigidas para trabalhar em ambientes sob condições controladas. Na produção, $79 \%$ dos funcionários são técnicos de segundo grau, sendo a maioria formada especificamente em curso Técnico em Química, o que facilita que as boas práticas de laboratório aprendidas para trabalhar em laboratórios químicos possam ser adaptadas com mais facilidade ao trabalho em ambientes biológicos. Como forma de treinamento e aperfeiçoamento, os funcionários são estimulados a participar, sempre que possível, de cursos de curta duração e eventos científicos na área de interesse da empresa.

A baixa rotação da mão-de-obra e o contato próximo com os diretores da empresa facilita o conhecimento da estratégia tanto pelos responsáveis pelas diversas atividades produtivas quanto por todos os funcionários de forma geral. Embora não existam indicadores de desempenho formais para controlar o processo de inovação, uma vez que esta se restringe à introdução de uma nova cultivar, as gratificações por desempenho individual são realizadas em função da performance global da empresa.

Não existem processos sistemáticos voltados para a obtenção de novas idéias no que se refere à técnica de cultura de tecidos vegetais in vitro, uma vez que os funcionários não têm o grau de formação necessário para questionar, sugerir ou discutir o tema com base em critérios científicos. Espera-se que os 
funcionários apresentem idéias com relação a outras etapas do processo de produção, as quais ajudem a aumentar o rendimento, a velocidade de determinado processo ou a movimentação.

Os diretores da Empresa 4, que são as únicas pessoas na empresa com capacitação técnica e científica para avaliar e compreender os avanços da ciência, obtêm novos conhecimentos tecnológicos através da participação em eventos científicos, contatos com instituições de classe e através de revistas científicas.

\subsubsection{As Relações Interorganizacionais}

São poucas as relações interorganizacionais estabelecidas pela Empresa 4, se comparadas com as outras três empresas analisadas anteriormente.

Existem parcerias com alguns clientes com a finalidade de realização de testes de campo para os produtos da empresa. Estes parceiros atuam, por sua vez, como formadores de opinião. Neste caso, as parcerias não constituem alianças, como aquelas descritas por Freire (1998), caracterizadas pela complementação de competências como forma de alcançar um objetivo comum, partilhando os custos, os riscos e os benefícios do projeto conjunto. O produtor que cedeu parte da área de plantação para a realização dos testes de campo da nova cultivar, ganha o conhecimento sobre o produto e a oportunidade de ser o primeiro a colocá-lo no mercado.

Informações de mercado são obtidas principalmente através dos próprios clientes, vendedores, feiras e exposições agrícolas. A concorrência é considerada inexistente pela diretoria da empresa, não havendo, portanto, nenhuma preocupação por parte da mesma com esta questão.

Especialistas de universidades e centros de pesquisa são constantemente consultados a fim de buscar o desenvolvimento de novos conhecimentos e tendências. Os produtos da Empresa 4 são certificados, classificados e indexados em centros de pesquisa credenciados pelas autoridades competentes no Estado. O contato com estas instituições é importante para a empresa se manter atualizada, não só com relação à técnica, mas com as tendências de ordem legal. 
A parceria com os fornecedores, detentores dos direitos de comercialização das cultivares, é muito forte e de grande importância para a Empresa 4. Para citar um exemplo, como parte do Acordo de Cooperação Internacional entre o Governo do Estado e o Governo da França, a empresa foi escolhida pela Associação Internacional que desenvolveu a cultivar, para representá-la no Brasil e promover a utilização comercial das cultivares com potencial agronômico. A Empresa 4 detém os direitos de multiplicação destas cultivares no Brasil e deverá ser sempre consultada quando houver interesse na compra de sementes.

\subsubsection{Análise}

A Empresa 4 não desenvolve qualquer atividade de $P \& D$, mas simplesmente faz uso de uma técnica avançada e já estabelecida da biotecnologia vegetal para a obtenção de seus diferentes produtos.

A estrutura organizacional é caracterizada como uma tradicional estrutura funcional que atende bem as necessidades da empresa, uma vez que não requer a flexibilidade e a rapidez para responder às demandas do ambiente externo requeridas por empresas de alta tecnologia que operam em mercados turbulentos.

Com relação ao permanente avanço das técnicas de engenharia genética no setor agrícola e às questões legais pertinentes a biossegurança e a bioética, o diretor entrevistado considera ser muito amplo o horizonte para o uso das técnicas de cultura de tecidos vegetais in vitro para plantas não modificadas geneticamente, o que não significa que estejam alheios aos acontecimentos nesta área. Na eventualidade de liberação para cultivo comercial de qualquer cultivar geneticamente alterada, a empresa já detém a tecnologia necessária à sua micropropagação e estará apta a fornecer os produtos derivados da mesma forma feita para cultivares não engenheirados.

Nos últimos três anos a Empresa 4 introduziu 10 novas variedades de cultivares no mercado e realizou 3 inovações de processo de importância significativa. 


\subsection{Empresa 5 - Empresa Multinacional Produtora de Insumos Químicos}

\subsubsection{Histórico}

A Empresa 5 constitui a Divisão Bioquímica de uma Holding européia composta por 55 empresas que atendem, principalmente, à indústria de alimentos. A Divisão Bioquímica, que neste trabalho será identificada como Empresa 5, é composta por quatro unidades produtivas, que trabalham de forma unificada, e estão localizadas no Brasil, Estados Unidos, Espanha e Holanda. A Empresa 5 produz dois tipos de ácido orgânico e seus sais derivados, os quais têm ampla aplicação nas indústrias de alimentos e bebidas, cosméticos, farmacêutica, implantes médicos, produção de polímeros, papel e celulose e eletrônica.

A tecnologia de produção de um dos ácidos orgânicos, sintetizado especificamente a partir de sacarose de cana-de-açúcar ou beterraba, e que faz desta empresa líder mundial na atualidade, teve seu desenvolvimento originado no Brasil. Uma família de origem francesa, proprietária de plantações de canade-açúcar no interior do Brasil, fundou uma pequena empresa destinada a produzir alguns tipos de solventes orgânicos, álcoois e ácidos orgânicos a partir da tecnologia de fermentação de açúcar de cana. Esta empresa passou por vários processos de aquisição até se tornar, hoje, parte do referido conglomerado europeu. A tecnologia utilizada atualmente por todas as unidades fabris da Empresa 5, para a produção do ácido e seus derivados, pouco difere daquela originalmente desenvolvida pela família que fundou a empresa na metade do século passado. O microrganismo atualmente empregado no processo de fermentação foi, no entanto, isolado na natureza pela atual empresa matriz, que guarda sua identificação como segredo industrial, uma vez que se trata de uma cepa microbiana de alta produtividade, característica fundamental na economicidade do processo fermentativo. Os esforços de P\&D, centralizados nos laboratórios da matriz, estão dirigidos às novas aplicações dos ácidos e seus derivados, na busca pelos mais diversos setores industriais.

A Empresa 5 iniciou sua história de produção e comercialização dos produtos em 1955. Trabalham hoje na unidade brasileira cerca de 160 
funcionários. Não são desenvolvidas atividades de $P \& D$ no País, mas são permanentemente incentivadas as adaptações da tecnologia à realidade local, realizadas nos laboratórios de Desenvolvimento de Melhorias de Processo e de Controle da Qualidade. O faturamento anual está na ordem dos $\mathrm{R} \$ 60 \sim \mathrm{R} \$ 70$ milhões dos quais, aproximadamente $60 \%$ são gerados no mercado nacional.

\subsubsection{A Capacidade de Inovação}

A Figura 14 apresenta o Mapa Cognitivo com os vetores de valor da capacidade de inovação da Empresa 5 e a forma como estes se relacionam.

\subsubsection{A Cultura Organizacional}

Uma das práticas encontradas na Empresa 5 é a divulgação massiva dos valores e crenças que a Empresa Holding deseja que sejam partilhados em todas as empresas do grupo. A veiculação é feita através de folhetos distribuídos periodicamente aos funcionários e a visitantes, e de cartazes, distribuídos por toda a empresa de modo a ter grande visibilidade. A empresa agrupa os valores e crenças nas cinco categorias descritas a seguir:

1. Conciliação dos interesses dos acionistas, funcionários, fornecedores e comunidade, de forma a:

a. buscar a remuneração adequada do capital investido pelo acionista da Holding;

b. favorecer a criação de oportunidades de desenvolvimento e satisfação profissional para os funcionários; agregar valor ao negócio dos clientes e construir uma relação de longo prazo com eles e com os fornecedores;

c. ser um membro respeitável da comunidade e contribuir tanto para a sustentabilidade dos recursos da terra quanto para a proteção do meio ambiente. 


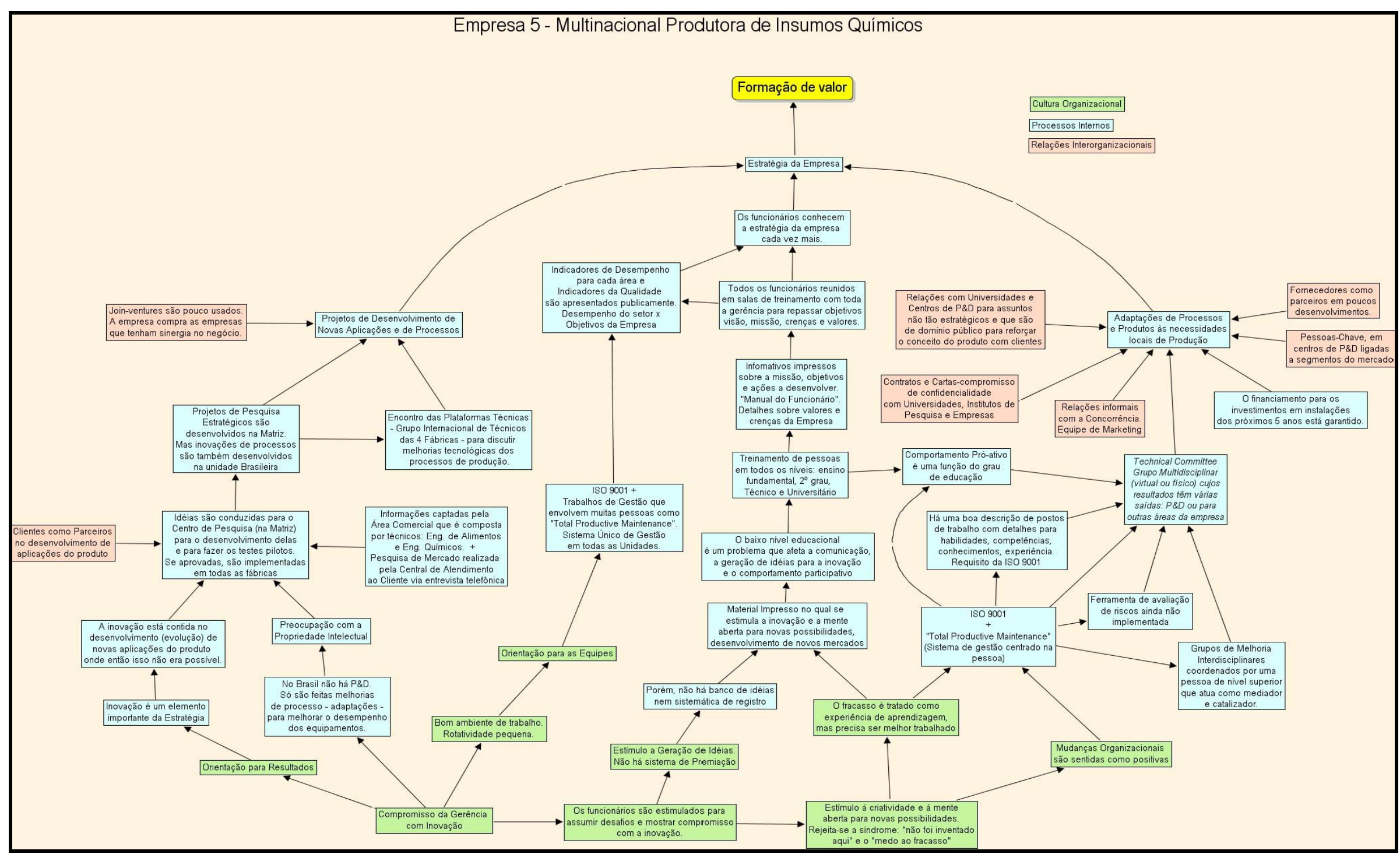

Figura 14: Vetores de valor da Capacidade de Inovação da Empresa 5. Fonte: o autor 
2. Estímulo à inovação:

a. inovar sistematicamente é compreendido como a chave do sucesso sustentável da Empresa 5;

b. estimular a criatividade e manter a mente aberta para novas possibilidades;

c. promover e apoiar programas de pesquisa e desenvolvimento de mercado;

d. rejeitar a síndrome do "não foi inventado aqui", a falta de confiança e de criatividade, e o medo do fracasso.

3. Esforço para melhorar continuamente tudo o que se faz:

a. aprender com os colegas, clientes, fornecedores e competidores;

b. encorajar o desenvolvimento pessoal e profissional entre os funcionários e promover o trabalho em equipe para obter os melhores resultados.

4. Encorajamento do espírito "intra-empreendedor":

a. estimular e recompensar as iniciativas de indivíduos e grupos, a criatividade, a flexibilidade e o comprometimento em todos os níveis da organização;

b. dar liberdade aos funcionários para tomar iniciativas e assumir responsabilidades pelos resultados de suas ações;

5. Abertura:

a. a abertura e a honestidade são pré-condições para um ambiente de trabalho criativo e eficaz e devem ser estimuladas;

b. deve-se rejeitar e desencorajar o segredo, o comportamento político interesseiro e as "portas fechadas". 
Em princípio, estão compreendidos nesta lista todos os valores listados por O'Reilly III, Chatman e Caldwell (1991) e Jassawalla e Sashittal (2002) como aqueles necessários para estabelecer um bom ambiente de trabalho e, desta forma, propiciar alto desempenho na realização das tarefas e satisfação no trabalho e, ainda, sustentar processos de inovação. O gerente entrevistado considera que há um bom ambiente de trabalho na Empresa 5, sendo a baixa taxa de rotatividade um reflexo desta realidade. É bastante comum encontrar casos de funcionários para os quais a empresa é o primeiro e único emprego. Muitas pessoas se aposentaram nessa situação. Por outro lado, a empresa enfrenta uma situação sui generis em função da própria história do local onde está situada a fábrica no Brasil, marcada por um passado de escravatura e pelo baixo nível educacional de um alto percentual de seus funcionários. Se, de um lado, existe uma vontade muito grande por parte da diretoria e da gerência para que os valores e crenças, que a matriz quer que sejam irradiados e imperem em todas suas empresas, sejam assimilados por todos, de outro lado a realidade social local torna-se um obstáculo à incorporação destes valores.

A empresa iniciou um programa denominado "Projeto Educação", em parceria com o SESI (Serviço Social da Indústria) e SENAI (Serviço Nacional de Aprendizagem Industrial), cujo objetivo é recuperar o indivíduo como cidadão participante e propiciar seu aprimoramento técnico. A empresa incentiva, facilita os meios e cobre integralmente os custos relacionados com a Educação Fundamental e de Segundo Grau de seus funcionários. Entre outras finalidades, o programa pretende que os funcionários desenvolvam não só a capacidade de ler, mas também a de interpretar, de forma crítica, as informações divulgadas nos cartazes e folhetos, bem como no próprio Manual do Funcionário, a respeito dos objetivos e metas da empresa. A parceria com o SESI e SENAI visa à obtenção de conhecimentos, melhoria das competências pessoais e aprendizagem de técnicas profissionais necessárias ao desempenho do funcionário como pessoa e como profissional. Com relação à Educação Superior, a empresa subsidia de 50 a 100\% do valor gasto pelo funcionário em cursos universitários.

Dentro desta concepção, o funcionário é responsável pelo seu autodesenvolvimento e qualificação profissional, tendo como encargo participar 
de atividades de treinamento e cursos para os quais for designado. A empresa assume a responsabilidade de mantê-lo devidamente informado sobre as atividades e propostas educacionais e de treinamento.

Em síntese, embora Empresa 5 não realize atividades de P\&D, a gerência manifesta compromisso com a inovação e uma clara orientação para o resultado. Segundo a relação de crenças e valores divulgada de forma impressa pela empresa, os funcionários são estimulados a assumir certos desafios, a mostrar compromisso com a inovação e a adotar uma mente aberta para novas possibilidades, sem medo do fracasso, sendo este visto como uma experiência para a aprendizagem. Verifica-se que há estímulo para a geração de idéias, porém a Gerência admite que não há mecanismos de premiação que atue como reforço a este comportamento. Da mesma forma, acredita-se que o trabalho em equipe propicia a obtenção de melhores resultados, mas a realidade histórica e sócio-cultural da localidade dificulta a incorporação deste valor e muitos outros pelos funcionários.

\subsubsection{Os Processos Internos}

Os ácidos orgânicos tradicionalmente produzidos pela empresa têm sido utilizados na indústria de alimentos como conservante, devido a suas propriedades antagônicas para muitos microrganismos, e como flavorizante, devido a sua boa palatabilidade. Novas aplicações em indústrias como a de papel e celulose, corantes, plásticos, eletrônica, automobilística, bem como no tratamento de couro, vêm substituir produtos e processos nocivos para o homem e/ou para o meio ambiente. Estas alternativas tornam-se viáveis devido à inocuidade destes produtos para os seres humanos. Um dos ácidos fabricado pela empresa constitui uma substância produzida em processos metabólicos normais do corpo humano. Segundo a explicação apresentada pelo entrevistado, na Empresa 5 a inovação é compreendida como "a capacidade de agregar qualidade de vida à população e ao meio ambiente".

Entendida desta forma, a inovação é um elemento importante da estratégia da empresa e seu conceito abrange o desenvolvimento de novas aplicações dos ácidos e seus sais, a fim de conquistar mercados inexplorados. A unidade fabril 
brasileira não realiza atividades de P\&D, mas existem dois grupos de trabalho, identificados como "Grupo da Tecnologia" e "Grupo da Garantia da Qualidade", que têm autonomia para que, dentro das bases tecnológicas definidas pelo Centro de P\&D da matriz, possam realizar adaptações que melhorem o desempenho dos processos. O "Grupo da Tecnologia" está composto por cinco Engenheiros Químicos e dois Biólogos; o "Grupo da Garantia da Qualidade" está composto por três Engenheiros Químicos, um Químico e dez Técnicos em Química. Em todas as unidades fabris, os setores vinculados à produção são identificados através da operação unitária ali desenvolvida, cada um destes sob a responsabilidade de um especialista de nível superior. As operações unitárias compreendem etapas específicas do processo de produção, como por exemplo, esterilização de meios de cultivo, processo fermentativo, separação e purificação do produto, etc.

Existe uma preocupação muito grande com relação ao sigilo do processo de produção e à propriedade intelectual, sendo esta última uma das grandes justificativas para que toda e qualquer atividade de P\&D considerada estratégica seja realizada nos laboratórios da matriz na Europa. A Empresa 5 já foi vítima de espionagem industrial por parte de uma de suas concorrentes atuais. Paoli e Guercini (1997) enumeram argumentos que motivam a centralização das atividades de P\&D no país de origem da empresa, muitos dos quais são partilhados pela Empresa 5:

- a necessidade de obter-se um grau suficientemente alto de proteção das atividades laboratoriais e o sigilo das informações e conhecimentos nelas obtidos, de forma a manter os aspectos tecnológicos que garantem a vantagem competitiva da empresa;

- o desenvolvimento de uma comunicação intrafuncional, cujos requisitos são particularmente altos em $P \& D$, dada às muitas exigências envolvidas na aprendizagem e na produção e disseminação do conhecimento;

- a economia de escala e de massa crítica que podem ser alcançadas quando as atividades de P\&D estão concentradas na matriz da empresa;

- o papel do mercado doméstico na consecução de vantagens tecnológicas específicas. 
O laboratório central de P\&D da Empresa 5, localizado no país sede, está constituído por 40 pesquisadores com grau mínimo de mestrado. Estes pesquisadores estão agrupados de acordo às suas áreas de especialização, as quais constituem setores correspondentes às operações unitárias realizadas nas unidades fabris. A grande maioria dos pesquisadores é natural do país sede.

As informações sobre oportunidades de negócio são captadas pelos técnicos de venda da área comercial, em sua maioria Engenheiros Químicos e Engenheiros de Alimentos, os quais têm contato direto e permanente com os clientes e seus processos produtivos. A empresa conta, adicionalmente, com uma Central de Atendimento ao Cliente que realiza anualmente uma extensa pesquisa telefônica junto a representantes das áreas técnica e comercial dos clientes, de modo a obter informações completares que contribuam para a melhora contínua dos produtos. Dentre os tópicos averiguados está o grau de satisfação com relação à eficiência do produto, às características da embalagem, à qualidade da assistência técnica e ao serviço de atendimento. Os aspectos que apresentam alto grau de insatisfação passam por um programa de melhoria estabelecido nas Normas ISO.

Os problemas identificados na pesquisa de opinião, bem como as idéias referentes às oportunidades de novos negócios trazidas pelos técnicos, são, então, enviadas para o Centro de Pesquisa da matriz para que sejam elaborados projetos pertinentes aos temas e desenvolvidos todos os testes necessários ao desenvolvimento de um novo produto ou processo, inclusive em escala piloto. Uma vez aprovados em todas as etapas, estes são implementados em todas as unidades fabris. Todas as fábricas têm liberdade para que, dentro do escopo dos processos desenvolvidos, sejam feitas adaptações às realidades particulares de cada uma.

Periodicamente, são realizados encontros entre os técnicos responsáveis pelas diferentes atividades operacionais de cada fábrica. Estes encontros, realizados em uma das quatro unidades fabris da empresa, são denominados "Encontros de Plataformas Técnicas" e têm o objetivo de discutir melhorias tecnológicas dos processos de produção e promover a convivência e o 
conhecimento entre técnicos com responsabilidades semelhantes nas diversas realidades sócio-culturais dos países onde estão implantadas as fábricas.

Embora o trabalho em equipe seja um dos valores almejados e incentivados na Empresa 5, na prática é pouco realizado. A implementação da ISO 9001 e do "Total Productive Maintenance - TPM" (Gerenciamento Produtivo Total ${ }^{2}$ ), resultado de recentes decisões da empresa, induz ao trabalho em equipe e deverá mudar esta tendência. A empresa Holding, como um conglomerado que almeja uma máxima eficiência em seus sistemas de produção, decidiu introduzir o TPM em todas as fábricas do grupo. Trata-se de uma metodologia de apoio do sistema de gestão para a identificação de perdas, baseada numa filosofia de melhoria contínua, que garante uma produção com alta qualidade, produtividade e confiabilidade dos equipamentos. Além disso, a técnica promove a integração do pessoal de produção, manutenção e todos aqueles envolvidos indiretamente no sistema produtivo. A metodologia de TPM exige a aprendizagem, por parte de todos os funcionários, da base operacional até a alta gerência, de práticas de trabalho mais eficientes, de maneiras para tornar o local de trabalho mais agradável e de métodos para melhoria da qualidade dos produtos. Potencialmente, o TPM objetiva a eficácia da empresa através de maior qualificação das pessoas e de melhoramentos introduzidos nos processos e equipamentos. Como vantagem adicional, permite a redução / eliminação, de forma participativa, do número de acidentes, promovendo o aumento da segurança dos funcionários, bem como o zelo por sua saúde, e o cuidado com o meio ambiente.

As Normas ISO e a metodologia do TPM estabelecem critérios para que sejam gerados relatórios com indicadores de qualidade e de desempenho para cada área operacional. Estes relatórios são apresentados publicamente, afixados nos murais da empresa para que todas as pessoas tenham acesso às informações. Estes indicadores, uma vez confrontados com os objetivos da empresa, ajuda a criar um ambiente de responsabilidade e compromisso com as

\footnotetext{
${ }^{2}$ Tradução livre utilizada na Empresa 5.
} 
metas estabelecidas e facilita o controle das operações necessárias para seguir a estratégia estabelecida.

Pese as dificuldades relacionadas anteriormente, decorrentes do baixo nível educacional dos funcionários, todos são periodicamente reunidos em salas de treinamento para reforçar as crenças e valores da empresa e apresentar sua missão e visão de longo prazo, e os objetivos que conduzem a estratégia empresarial. Este procedimento permite a que a estratégia seja conhecida por todos, mas não há intervenção dos funcionários com relação às metas a serem cumpridas para alcançar os objetivos propostos. Esta forma de comunicação da estratégia se assemelha ao processo de implementação por intervenção descrito por Nutt (1986) e ao modelo de colaboração descrito por Bourgeois e Brodwin (1984), nos quais os funcionários não participam do processo de elaboração da estratégia. Numa situação em que os funcionários têm que seguir procedimentos discutidos e estabelecidos na Matriz, o método empregado pela Empresa 5 para comunicar e implementar a estratégia parece ser o mais apropriado.

As chamadas Boas Práticas de Fabricação ou Good Manufacturing Practice - GMP, agregam-se à Norma ISO 9001 e à metodologia "Total Productive Maintenance" como diretrizes que regem o comportamento a ser adotado na tomada de decisões relacionadas à inovação e à produção. A adoção das GMPs é obrigatória, segundo a legislação brasileira, para todas as indústrias de alimentos e tem como objetivo garantir a integridade do alimento e a saúde do consumidor através de diretrizes sobre a higiene pessoal, uso de uniformes e de acessórios adequados a cada função, hábitos comportamentais, entre outros.

Este pacote de normas conforma um sistema de gestão centrado na pessoa do funcionário e não na realização da tarefa. Conforme previsto na ISO 9001, há na empresa uma boa descrição dos postos de trabalho, incluindo detalhes sobre habilidades, competências, conhecimentos e experiências. Esta informação é de grande importância para o trabalho do Technical Committee, que compreende um grupo multidisciplinar que se reúne de forma virtual ou presencial com o objetivo de decidir sobre adaptações de processos e produtos para as necessidades de cada unidade produtiva. Participam deste grupo representantes 
das diversas áreas funcionais de apoio e de todas as áreas relacionadas diretamente com a produção.

Como relatado na análise feita para a Empresa 3, de saúde animal, a ISO 9001 oferece ferramentas de avaliação de risco para que indivíduos com idéias inovadoras possam seguir procedimentos e cuidados necessários à sua experimentação. A ferramenta da ISO 9001 que encoraja a experimentação, auxilia a avaliação de riscos e compromete o indivíduo com o resultado da experimentação, não foi ainda implementada, mas há consciência da sua necessidade para assumir, na prática, os valores que a Holding deseja.

O trabalho em equipe está intrínseco na filosofia de gestão empresarial do TPM, como sistema técnico de caráter participativo de origem japonesa. O sistema apresenta diretrizes para que as equipes sejam formadas. Na Empresa 5 estas diretrizes orientam a formação do chamado "Grupo de Melhorias" constituído pelo "Grupo da Tecnologia" e o "Grupo da Garantia da Qualidade", compondo um grupo interdisciplinar que tem autonomia para discutir e sugerir adaptações para a melhoria do desempenho das operações industriais. As sugestões geradas por esse grupo são, posteriormente, discutidas de forma mais ampla pelo Technical Committee que decide sobre as adaptações de processos e produtos. Para que aconteçam na prática, todas estas filosofias participativas pressupõem uma atitude pró-ativa por parte dos funcionários e esta, por sua vez, é uma característica dependente do nível educacional.

O financiamento necessário à sustentação de todas as iniciativas de inovação em produtos e processos, incluindo a modernização e manutenção da estrutura produtiva, está garantido. Na unidade brasileira foi iniciado, há dois anos, um processo de modernização da planta de fabricação, com investimentos na ordem de US\$45 milhões, a serem aplicados em cinco anos.

\subsubsection{As Relações Interorganizacionais}

A Empresa 5 mantém relações de parceria com universidades e centros de pesquisa para a realização de trabalhos em temas que não impliquem no desenvolvimento de qualquer etapa chave para a estratégia da empresa, mas sim 
na geração de pequenas melhorias por meio de técnicas de domínio público. A empresa mantém um cadastro dos pesquisadores destas instituições, que sejam especializados nos segmentos de mercado em que a empresa participa. Novamente, as questões relacionadas à segurança das informações e ao sigilo dos movimentos estratégicos voltam a assumir um papel preponderante.

As relações com a concorrência se limitam à realização de análises dos produtos concorrentes encontrados no mercado pela equipe da área comercial. Há que lembrar que a Empresa 5 é líder mundial na venda de um dos produtos que é produzido na unidade brasileira, não havendo de fato um concorrente de peso.

O relacionamento com fornecedores limita-se ao desenvolvimento de melhores embalagens para os produtos, uma vez que o principal insumo do processo fermentativo é açúcar de cana, um commodity.

Como a equipe de venda é composta principalmente por indivíduos com formação em Engenharia de Alimentos e Engenharia Química, o estreitamento do relacionamento com os clientes é facilitado, e desta forma, os clientes se tornam parceiros para o desenvolvimento de novas aplicações dos produtos. Como estes vendedores técnicos detêm conhecimento que os possibilita analisar criticamente o processo de produção dos clientes, adaptações podem ser realizadas conforme as necessidades específicas do comprador. Novamente, esta parceria limita-se à geração de idéias e testes e não a um trabalho de pesquisa em conjunto.

O uso de join ventures para aumentar a capacidade produtiva ou para partilhar competências complementares é uma política pouco empregada. Quando a Empresa 5 identifica outra empresa que produz um produto que tenha sinergia com sua linha de produção, e esta linha representa uma vantagem estratégica, inicia-se um processo de aquisição.

\subsubsection{Análise}

A introdução de técnicas participativas, como o sistema TPM e a implantação das Normas ISO 9001, desempenha um importante papel estratégico para a produtividade da empresa e, ainda, força a incorporação de novos valores 
na cultura da organização. O sucesso da implementação destes sistemas está condicionado aos resultados do Programa de Educação, que tem como perspectiva preparar funcionários capazes de compreender, de forma crítica, a realidade vivida na empresa e participar de forma pró-ativa. A Figura 15 mostra a importância destes sistemas para a estratégia da empresa.

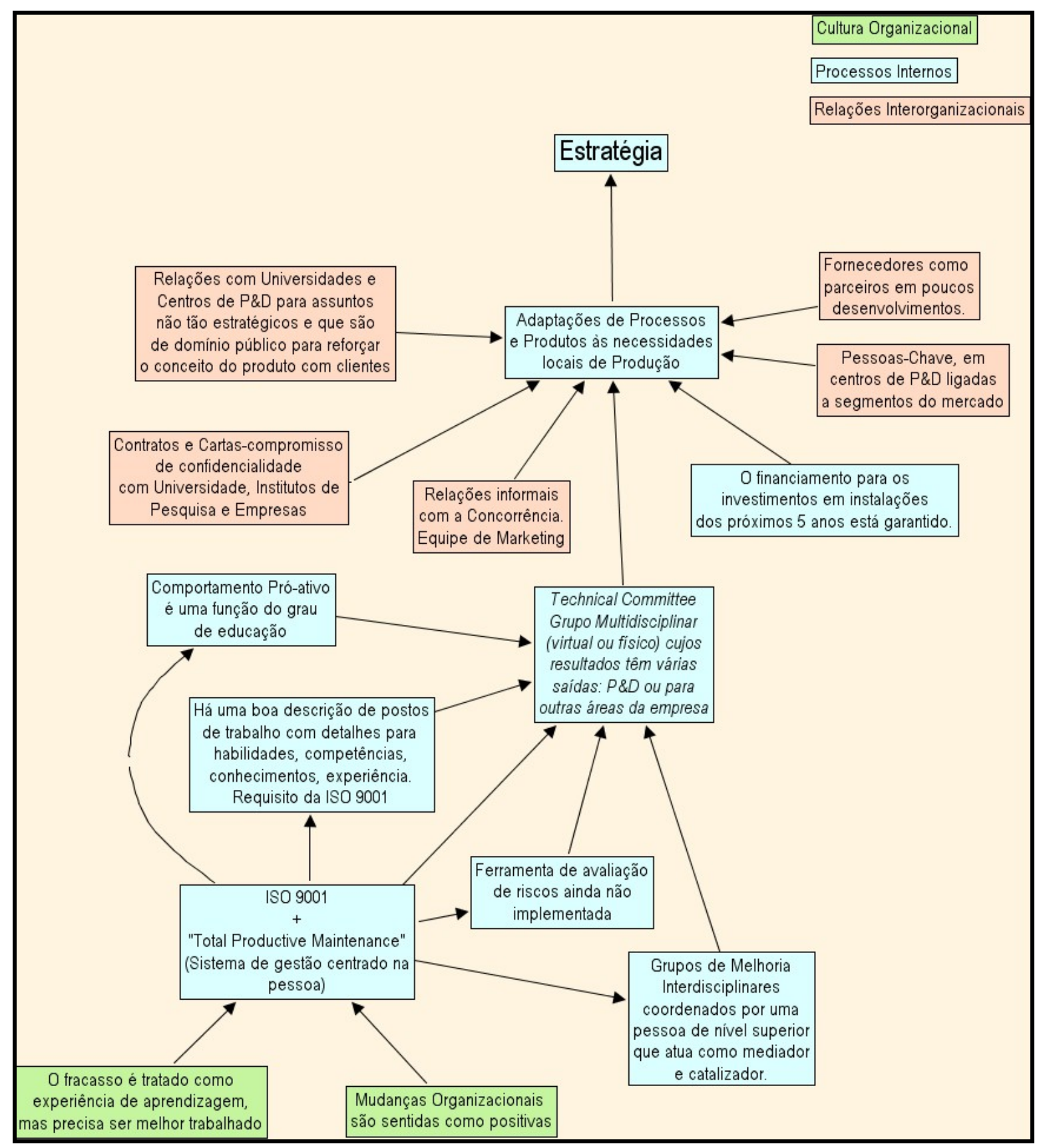

Figura 15: Análise do conceito dominante e de cluster no Mapa Cognitivo da Capacidade de Inovação da Empresa 5. Fonte: o autor 
Nos últimos três anos foram introduzidas 23 novas aplicações para 0 produto no mercado, sendo que 3 delas tiveram sua origem a partir de idéias captadas no mercado brasileiro. Neste mesmo período, cinco inovações organizacionais relacionadas com as práticas de trabalho foram introduzidas. 


\section{Capítulo 5}

\section{Conclusões}

\subsection{Considerações Iniciais}

A principal motivação para a realização deste estudo decorreu da percepção de que o entendimento da interligação das variáveis que compõem a capacidade de inovação de uma empresa e seu impacto no desempenho empresarial era motivo de preocupação e estudo por muitos pesquisadores. A capacidade de inovação foi definida neste estudo como "o potencial interno para gerar novas idéias, identificar novas oportunidades no mercado e desenvolver uma inovação comercializável através dos recursos existentes e competências" (NEELY e HII, 1999, p.7). A característica multidimensional do construto "capacidade de inovação" tem dificultado o estabelecimento, de uma forma precisa, da dinâmica destes fatores e de como estes se alinham, de maneira a influir no desempenho da empresa.

Neely e Hii (1998) identificaram a cultura organizacional, os processos internos e as relações interorganizacionais como sendo os fatores-chave de sucesso das empresas com melhores práticas gerenciais, os quais, por sua vez, caracterizam a capacidade de inovação destas empresas. Com base nesta perspectiva, definiu-se como objetivo deste estudo conhecer a dinâmica dos três fatores que compõem a capacidade de inovação e determinar como estes, nas suas inter-relações, contribuem para a formação de valor das empresas. Os fatores foram caracterizados pela escolha das atividades mais representativas, 
segundo a literatura, da capacidade de inovação de uma empresa, procurando-se observar de que forma estas atividades são alinhadas e transformadas em vetores de valor.

O estudo assumiu características de uma pesquisa exploratória, uma vez que se procurou desenvolver, esclarecer e modificar conceitos e idéias com o intuito de propiciar uma formulação mais precisa de problemas ou de hipóteses de pesquisa em estudos a serem feitos posteriormente neste mesmo tema. A capacidade de inovação é um fenômeno complexo e exige profundidade nas informações necessárias à sua compreensão, uma vez que não existem muitos conhecimentos sobre a dinâmica interna do fenômeno em si. Desta forma, decidiu-se pela adoção da abordagem qualitativa para realizar este estudo, sendo o método de estudo de casos múltiplos a metodologia de pesquisa empírica considerada mais apropriada para este fim. O estudo dos casos foi realizado simplesmente para elucidar o fenômeno "capacidade de inovação", sem qualquer intenção de mostrar o manejo correto ou incorreto da gestão administrativa das empresas. De modo a melhor demonstrar como determinados aspectos da capacidade de inovação propiciam a formação de valor e de que forma estes se inter-relacionam, pergunta que norteou o objetivo deste trabalho de pesquisa, foi utilizada, para a análise dos cinco casos estudados, a técnica de Mapas Cognitivos, ferramenta que permitiu evidenciar de forma clara os vetores de valor e os elos existentes entre eles.

Buscando seguir a lógica do modelo de pesquisa proposto, será apresentada a seguir, uma síntese comparativa das variáveis contribuintes da capacidade de inovação para os cinco casos. A intenção é facilitar a compreensão das informações coletadas possibilitando a realização de análises comparativas entre os casos estudados. Na seqüência, serão apresentadas as contribuições evidenciadas pelo estudo, além de considerações relativas às suas limitações e, finalmente, as propostas para outros trabalhos que venham a ser desenvolvidos sobre o tema aqui tratado. 


\subsection{Síntese do Estudo}

O Quadro 8 traz as informações relativas à Cultura Organizacional, mostrando os valores e comportamentos característicos em cada uma das cinco empresas avaliadas. Como pode ser observado, as Empresas 1, 2 e 3 apresentam praticamente todas as variáveis apontadas por O'Reilly III, Chatman e Caldwell (1991) como sendo variáveis intervenientes, capazes de promover um maior desempenho na organização e afetar a satisfação dos funcionários, bem como as variáveis assinaladas por Jassawalla e Sashittal (2002) como características das culturas organizacionais que apóiam processos de inovação. Coincidentemente, estas três empresas dependem mais da realização de inovações radicais, conforme concepção de Rousell et al. (1992), ou de inovações descontínuas, como denominadas por Miller e Morris (1999), que as Empresas 4 e 5 .

Nas Empresas 1, 2 e 3, a busca por inovações é caracterizada por concentrar-se no pensamento divergente e por tentativas de descoberta de novos conhecimentos, relacionados tanto com as necessidades do mercado quanto com a capacitação tecnológica além das fronteiras existentes. Por outro lado, as Empresas 4 e 5 trabalham com inovações incrementais, segundo denominação de Rousell, et al. (1992), ou inovação contínua, de acordo com Miller e Morris (1999). Este tipo de inovação está baseado na aplicação de conhecimentos tecnológicos e de engenharia já estabelecidos. A demanda futura dos consumidores, neste caso, pode ser conhecida através das informações existentes no mercado atual e, em geral, não apresenta grandes desafios para a própria estratégia. 


\begin{tabular}{|c|c|c|c|c|c|}
\hline Fatores & $\begin{array}{c}\text { Empresa } 1 \\
\text { Saúde Humana }\end{array}$ & $\begin{array}{c}\text { Empresa } 2 \\
\text { Saúde Vegetal }\end{array}$ & $\begin{array}{c}\text { Empresa } 3 \\
\text { Saúde Animal }\end{array}$ & $\begin{array}{c}\text { Empresa } 4 \\
\text { Agronegócio }\end{array}$ & $\begin{array}{c}\text { Empresa } 5 \\
\text { Multinacional }\end{array}$ \\
\hline $\begin{array}{l}\text { Cultura } \\
\text { Organizacional } \\
\text { - } \quad \text { Valores } \\
\text { - } \quad \text { Comportamentos }\end{array}$ & $\begin{array}{l}\text { • Compromisso da } \\
\text { gerência com a } \\
\text { inovação; } \\
\text { • Orientação para o } \\
\text { resultado; } \\
\text { • Estímulo à } \\
\text { criatividade; } \\
\text { - Forte orientação } \\
\text { para trabalho em } \\
\text { equipe. } \\
\text { • Funcionário de P\&D } \\
\text { está compromissado } \\
\text { com a inovação; } \\
\text { • Funcionários com } \\
\text { altos níveis de Co- } \\
\text { criatividade e } \\
\text { comportamento } \\
\text { colaborativo; } \\
\text { • Erros dentro dos } \\
\text { projetos são } \\
\text { considerados } \\
\text { experiências para a } \\
\text { aprendizagem; } \\
\text { • Características de } \\
\text { lideranças são } \\
\text { identificadas e } \\
\text { estimuladas; }\end{array}$ & $\begin{array}{l}\text { - Compromisso da } \\
\text { gerência com a } \\
\text { inovação; } \\
\text { - Orientação para o } \\
\text { resultado; } \\
\text { - Estímulo à } \\
\text { criatividade, espírito } \\
\text { "eu posso fazer" ; } \\
\text { - Forte orientação } \\
\text { para trabalho em } \\
\text { equipe; } \\
\text { - Funcionário de P\&D } \\
\text { está compromissado } \\
\text { com a inovação; } \\
\text { - Funcionários com } \\
\text { altos níveis de Co- } \\
\text { criatividade e } \\
\text { comportamento } \\
\text { colaborativo; } \\
\text { - Erros dentro dos } \\
\text { projetos são } \\
\text { considerados } \\
\text { experiências para a } \\
\text { aprendizagem. } \\
\text { - Características de } \\
\text { lideranças são } \\
\text { identificadas e } \\
\text { estimuladas. }\end{array}$ & $\begin{array}{l}\text { - Compromisso da } \\
\text { gerência com a } \\
\text { inovação; } \\
\text { • Orientação para o } \\
\text { resultado; } \\
\text { - Estímulo à geração } \\
\text { de idéias; } \\
\text { - Forte orientação } \\
\text { para trabalho em } \\
\text { equipe; } \\
\text { • Funcionário de P\&D } \\
\text { está compromissado } \\
\text { com a inovação; } \\
\text { - Funcionários com } \\
\text { altos níveis de Co- } \\
\text { criatividade e } \\
\text { comportamento } \\
\text { colaborativo; } \\
\text { • Assunção de riscos } \\
\text { nos processos de } \\
\text { inovação. } \\
\text { • Mudanças } \\
\text { organizacionais são } \\
\text { sentidas como } \\
\text { positivas; } \\
\text { - Características de } \\
\text { lideranças são } \\
\text { identificadas e } \\
\text { estimuladas; }\end{array}$ & $\begin{array}{l}\text { - Compromisso da } \\
\text { gerência com a } \\
\text { inovação; } \\
\text { - Orientação para o } \\
\text { resultado; } \\
\text { - Bom ambiente de } \\
\text { trabalho; } \\
\text { - Estímulo para } \\
\text { apresentação de } \\
\text { sugestões. } \\
\text { - Interesse em que os } \\
\text { funcionários adotem o } \\
\text { espírito "eu posso } \\
\text { fazer" e demonstrem } \\
\text { suas habilidades; } \\
\text { - Há liberdade para } \\
\text { que os funcionários } \\
\text { possam assumir } \\
\text { certos riscos, mas a } \\
\text { margem de erros } \\
\text { deve ser muito } \\
\text { pequena. Os } \\
\text { diretores estão } \\
\text { sempre presentes; } \\
\text { - Pequenos erros são } \\
\text { considerados } \\
\text { experiência para a } \\
\text { aprendizagem. }\end{array}$ & $\begin{array}{l}\text { - Compromisso da } \\
\text { gerência com a } \\
\text { inovação; } \\
\text { - Orientação para o } \\
\text { resultado; } \\
\text { - Bom ambiente de } \\
\text { trabalho; } \\
\text { - Tentativa de } \\
\text { introduzir valores } \\
\text { definidos pela Matriz; } \\
\text { - Estímulo à } \\
\text { criatividade; } \\
\text { - Orientação para } \\
\text { realização do trabalho } \\
\text { em equipe; } \\
\text { - Estímulo à geração } \\
\text { de idéias, porém não } \\
\text { há sistema de } \\
\text { premiação; } \\
\text { - Fracasso é tratado } \\
\text { como experiência } \\
\text { para a aprendizagem; } \\
\text { - Mudanças } \\
\text { organizacionais são } \\
\text { sentidas como } \\
\text { positivas. }\end{array}$ \\
\hline
\end{tabular}

Quadro 8: Síntese da análise dos principais traços dos valores e comportamentos que caracterizam a Cultura Organizacional. 
O Quadro 9 apresenta uma síntese comparativa das variáveis mais características, relativas aos Processos Internos, contribuintes para a capacidade de inovação, em cada uma das cinco empresas. Foram analisados com mais detalhes a gestão da carteira de projetos, o processo de difusão e implementação da estratégia da empresa e os procedimentos adotados para obter uma melhor contribuição dos recursos humanos.

Como nas Empresas 4 e 5 não há atividade de P\&D, e a Empresa 1 está organizada por projetos totalmente financiados pelos clientes, estas não têm necessidade de realizar a atividade de gestão da carteira de projetos. Na Empresa 4, a escolha dos produtos a serem colocados no mercado é decidida com um ano antes do lançamento do produto, escolha esta feita de acordo com uma necessidade específica do mercado e com a garantia de um contrato assinado, reduzindo o risco do investimento.

Na Empresa 2 existem 20 projetos em andamento, considerados ainda em estágio embrionário. Para a escolha dos temas dos projetos, a empresa utilizou como critérios a necessidade do mercado por uma nova solução tecnológica e a expectativa de retornos financeiros. Devido ao estágio inicial dos projetos, a escolha do mix de critérios para avaliar a composição da carteira de projetos está, ainda, em desenvolvimento. A Empresa 3, em contraste com as demais empresas estudadas, possui um sistema de captação de idéias, incentivado pela premiação simbólica para as melhores idéias, e um sofisticado sistema multicritério para avaliar o desenvolvimento dos projetos e a composição da carteira de projetos. A gestão da carteira está intimamente alinhada com a estratégia competitiva e a formação de valor no longo prazo.

A formulação, comunicação e implementação do planejamento estratégico têm características participativas nas Empresas 1, 2 e 3. Nas Empresas 2 e 3, o fato de haver a participação de um grande número de funcionários neste processo coincide com a característica descrita por Purser e Cabana (1997) para o que chamaram de Reunião de Identificação. Na Empresa 3, porém, a equipe formada para discutir estas questões é multidisciplinar, contrastando com a interdisciplinaridade da equipe constituída pela Empresa 2 para este fim. 


\begin{tabular}{|c|c|c|c|c|c|}
\hline Fatores & $\begin{array}{c}\text { Empresa } 1 \\
\text { Saúde Humana }\end{array}$ & $\begin{array}{c}\text { Empresa } 2 \\
\text { Saúde Vegetal }\end{array}$ & $\begin{array}{c}\text { Empresa } 3 \\
\text { Saúde Animal }\end{array}$ & $\begin{array}{c}\text { Empresa } 4 \\
\text { Agronegócio }\end{array}$ & $\begin{array}{c}\text { Empresa } 5 \\
\text { Multinacional }\end{array}$ \\
\hline $\begin{array}{l}\text { Processos Internos } \\
\text { - Gestão da Carteira de } \\
\text { Projetos } \\
\text {-Difusão e } \\
\text { implementação da } \\
\text { Estratégia } \\
\text { - Contribuição dos } \\
\text { Recursos Humanos }\end{array}$ & $\begin{array}{l}\text { • Organização por } \\
\text { projetos sob } \\
\text { encomenda e 100\% } \\
\text { financiados; } \\
\text { • Formulação e } \\
\text { implementação } \\
\text { participativa da } \\
\text { Estratégia; } \\
\text { • Sofisticado sistema } \\
\text { de controle dos } \\
\text { projetos por } \\
\text { indicadores; } \\
\text { - Não há indicadores } \\
\text { claros de avaliação } \\
\text { de desempenho; } \\
\text { • Equipes } \\
\text { interdisciplinares; } \\
\text { - Alto percentual do } \\
\text { corpo técnico de } \\
\text { pesquisa em nível de } \\
\text { pós-graduação; } \\
\text { - Problemas com as } \\
\text { atitudes de } \\
\text { pesquisadores em } \\
\text { ambiente } \\
\text { empresarial. }\end{array}$ & $\begin{array}{l}\text { - Critérios de } \\
\text { mercado e } \\
\text { financeiros para } \\
\text { hierarquizar projetos; } \\
\text { - Formulação e } \\
\text { Implementação } \\
\text { participativa da } \\
\text { Estratégia. Reunião } \\
\text { de Identificação; } \\
\text { - Indicadores para } \\
\text { controle de projetos; } \\
\text { - Indicadores de } \\
\text { avaliação de } \\
\text { desempenho; } \\
\text { - Equipes } \\
\text { interdisciplinares } \\
\text { - Alto percentual do } \\
\text { corpo técnico de } \\
\text { pesquisa em nível de } \\
\text { pós-graduação; } \\
\text { - Não há evidência de } \\
\text { existir problemas com } \\
\text { relação às atitudes } \\
\text { de pesquisadores em } \\
\text { ambiente } \\
\text { empresarial. }\end{array}$ & $\begin{array}{l}\text { - Sistema sofisticado } \\
\text { e multi-critério para } \\
\text { gestão da carteira de } \\
\text { projetos; } \\
\text { - Sistema de } \\
\text { captação de idéias e } \\
\text { premiação; } \\
\text { - Formulação e } \\
\text { Implementação } \\
\text { participativa da } \\
\text { Estratégia. Reunião } \\
\text { de Identificação. } \\
\text { - Sofisticado sistema } \\
\text { de controle por } \\
\text { indicadores; } \\
\text { - Indicadores de } \\
\text { avaliação de } \\
\text { desempenho; } \\
\text { - Normas ISo 9001; } \\
\text { • Equipes } \\
\text { Multidisciplinares } \\
\text { - Alto percentual do } \\
\text { corpo técnico de } \\
\text { pesquisa em nível de } \\
\text { pós-graduação; } \\
\text { - Não houve } \\
\text { evidência de existir } \\
\text { problemas com } \\
\text { relação às atitudes } \\
\text { de pesquisadores em } \\
\text { ambiente } \\
\text { empresarial. }\end{array}$ & $\begin{array}{l}\text { - Não há P\&D nem } \\
\text { necessidade de } \\
\text { gestão de carteira de } \\
\text { projetos; } \\
\text { • Seleção de projetos } \\
\text { com base na } \\
\text { sensibilidade a } \\
\text { necessidades de } \\
\text { mercado; } \\
\text { • Os funcionários são } \\
\text { informados da } \\
\text { estratégia; } \\
\text { - Não há indicadores } \\
\text { de desempenho; } \\
\text { - Não há trabalho em } \\
\text { equipe; } \\
\text { • Diretores } \\
\text { proprietários } \\
\text { cientistas em nível de } \\
\text { pós-graduação. }\end{array}$ & $\begin{array}{l}\text { - Não há P\&D nem } \\
\text { necessidade de } \\
\text { gestão de carteira de } \\
\text { projetos; } \\
\text { - Adaptação de } \\
\text { tecnologia de } \\
\text { produtos e processos } \\
\text { à realidade local; } \\
\text { - Os funcionários são } \\
\text { informados da } \\
\text { estratégia; } \\
\text { - Indicadores de } \\
\text { avaliação de } \\
\text { desempenho; } \\
\text { - Normas ISO 9001 + } \\
\text { TPM + GMPs. } \\
\text { - Formação de } \\
\text { poucas equipes } \\
\text { - Laboratórios de } \\
\text { apoio composto por } \\
\text { funcionários em nível } \\
\text { técnico e de } \\
\text { graduação. Há } \\
\text { deficiências } \\
\text { educacionais na } \\
\text { estrutura de } \\
\text { produção. }\end{array}$ \\
\hline
\end{tabular}

Quadro 9: Síntese da análise dos principais traços das variáveis estudadas nos Processos Internos. 
A participação multidisciplinar permite juntar todas os profissionais que detêm os conhecimentos econômicos, comerciais, técnicos e sociais da organização para que, em conjunto, seja traçado o melhor caminho para atingir os objetivos e metas da empresa e assim tornar fácil a implementação da estratégia, conforme justificado por Aughton (1996).

Na Empresa 1, de menor tamanho em número de funcionários, a discussão da estratégia ocorre entre os líderes técnicos, ou seja, numa equipe interdisciplinar. A Empresa 4, também uma empresa de pequeno porte em número de funcionários, a formulação do planejamento estratégico é uma prerrogativa dos sócios proprietários, que também são os que apresentam a mais alta formação técnico-científica dentro da empresa. A comunicação e a implementação da estratégia da empresa é realizada através da interação e convívio diário dos sócios com todos os funcionários. Na Empresa 5, o planejamento estratégico é realizado pela empresa Holding na sede da matriz na Europa. Os funcionários no Brasil são reunidos em salas de treinamento, onde recebem explanações sobre os desafios a serem assumidos por todos com relação a objetivos e metas. Além disto, os objetivos, metas e ações a serem empreendidos são amplamente divulgados em mídia escrita, utilizando o Manual do Funcionário, boletins e cartazes.

A prática do controle gerencial dos projetos através do uso de indicadores varia em grau de sofisticação nas Empresas 1, 2, 3 e 5 . Na Empresa 1, os clientes têm acesso aos indicadores de andamento dos seus projetos em qualquer instante. O sistema está em desenvolvimento e não contempla ainda mecanismos claros de avaliação de desempenho dos funcionários. Na Empresa 3, o sistema de indicadores acompanha não só o andamento dos projetos, mas todas as atividades da empresa, de modo a buscar um alinhamento com a estratégia e a formação de valor no longo prazo. Na Empresa 5, um conjunto de tecnologias de controle ainda em desenvolvimento e em processo de implementação, como Normas ISO 9001, TPM e GMPs, emprega indicadores financeiros e não financeiros, estando todos estes alinhados com a estratégia da empresa. A Empresa 4 não utiliza um sistema de indicadores para o controle da suas atividades gerenciais. 
As Empresas 1, 2 e 3 mantêm nos seus quadros de pesquisa um alto percentual de funcionários em nível de pós-graduação. Na Empresa 1 há evidências de problemas de adaptação dos pesquisadores com relação às atitudes requeridas pelo ambiente empresarial, fenômeno não observado nas duas outras. A alta qualificação dos funcionários destas três empresas contrasta fortemente com a deficiente, ou às vezes inexistente, qualificação dos funcionários da área de produção da Empresa 5. Este problema dificulta a compreensão, por parte dos funcionários desta última empresa, de novos procedimentos produtivos, a geração de novas idéias e até a própria atitude participativa e pró-ativa.

O Quadro 10 sintetiza as principais variáveis encontradas concernentes às Relações Interorganizacionais. As cinco empresas estudadas apresentam o modelo organizacional categorizado como arquitetura aberta por Powell (1999) e por Judice (2001), porém com diversos graus de abertura, de modo a satisfazer necessidades bem específicas.

Todas as empresas mantêm relações estreitas com seus clientes seja para a obtenção de novas idéias e/ou a realização de testes de campo de seus produtos. A Empresa 1, por ser uma empresa que trabalha com projetos contratados pelos clientes, é a única na qual o cliente participa ativamente do desenvolvimento do projeto e até do controle do mesmo.

A importância dada pelas empresas estudadas à parcerias com fornecedores varia entre dois extremos. Para a Empresa 4, por exemplo, o relacionamento com os fornecedores, os quais são detentores da propriedade de cultivares, é essencial para a estratégia da empresa, uma vez que entre os assuntos negociados encontra-se a distribuição, em exclusividade, de determinada cultivar. Por outro lado, a Empresa 2 não mantém qualquer tipo de relacionamento com fornecedores na realização de suas pesquisas.

Entre as cinco empresas estudadas, somente na Empresa 3 foi constatada a existência de parcerias com concorrentes, restrita à área comercial e visando a realização de estudos de mercados. Tais estudos não poderiam ser realizados sem a existência desta parceria. 


\begin{tabular}{|c|c|c|c|c|c|}
\hline Fatores & $\begin{array}{c}\text { Empresa } 1 \\
\text { Saúde Humana }\end{array}$ & $\begin{array}{c}\text { Empresa } 2 \\
\text { Saúde Vegetal }\end{array}$ & $\begin{array}{c}\text { Empresa } 3 \\
\text { Saúde Animal }\end{array}$ & $\begin{array}{c}\text { Empresa } 4 \\
\text { Agronegócio }\end{array}$ & $\begin{array}{c}\text { Empresa } 5 \\
\text { Multinacional }\end{array}$ \\
\hline $\begin{array}{l}\text { Relações } \\
\text { Interorganizacionais } \\
\text { •Relações com } \\
\text { clientes } \\
\text { •Relações com } \\
\text { fornecedores } \\
\text { •Relações com } \\
\text { competidores } \\
\text { •Relações com } \\
\text { Institutos de Pesquisa } \\
\text { e Universidades } \\
\text { •Relações com } \\
\text { Organizações de } \\
\text { classe. }\end{array}$ & $\begin{array}{l}\text { - Relação estreita com } \\
\text { o cliente no } \\
\text { desenvolvimento dos } \\
\text { projetos. Controle } \\
\text { conjunto dos projetos; } \\
\text { - Parceria com } \\
\text { fornecedores; } \\
\text { - Não há parceria } \\
\text { com concorrentes, } \\
\text { mas podem ser vistas } \\
\text { como positivas para o } \\
\text { desenvolvimento da } \\
\text { empresa; } \\
\text { - Relações intensas } \\
\text { com universidades e } \\
\text { institutos e pesquisa. } \\
\text { Conhecimento de } \\
\text { pessoas-chave }\end{array}$ & $\begin{array}{l}\text { - Interação com } \\
\text { clientes ou futuros } \\
\text { clientes como meio de } \\
\text { obter informações } \\
\text { sobre a realidade do } \\
\text { mercado; } \\
\text { - Não há parceria com } \\
\text { fornecedores; } \\
\text { - Não há parceria com } \\
\text { concorrentes, mas } \\
\text { estes são } \\
\text { monitorados; } \\
\text { - Relações intensas } \\
\text { com universidades e } \\
\text { institutos e pesquisa. } \\
\text { Conhecimento de } \\
\text { pessoas-chave }\end{array}$ & $\begin{array}{l}\text { - Clientes como } \\
\text { parceiros na } \\
\text { inovação. Testes de } \\
\text { campo em algumas } \\
\text { fazendas; } \\
\text { - Parceria com } \\
\text { fornecedores; } \\
\text { - Parceria com } \\
\text { concorrentes para } \\
\text { realização de } \\
\text { pesquisas de } \\
\text { mercado; } \\
\text { - Relações intensas } \\
\text { com universidades e } \\
\text { institutos e pesquisa. } \\
\text { Conhecimento de } \\
\text { pessoas-chave } \\
\text { - Relações com } \\
\text { órgãos de Classe. }\end{array}$ & $\begin{array}{l}\text { - Clientes como } \\
\text { parceiros na } \\
\text { realização de testes } \\
\text { de campo e para } \\
\text { informações de } \\
\text { mercado; } \\
\text { - Parceria com } \\
\text { fornecedores de } \\
\text { novas cultivares; } \\
\text { - Não há parceria com } \\
\text { concorrentes; } \\
\text { - Relações com } \\
\text { Universidades, } \\
\text { Institutos de Pesquisa } \\
\text { e órgãos reguladores; } \\
\text { - Relações com } \\
\text { órgãos de Classe e } \\
\text { Agências } \\
\text { Reguladoras. }\end{array}$ & $\begin{array}{l}\text { - Clientes como } \\
\text { parceiros no } \\
\text { desenvolvimento de } \\
\text { idéias para novas } \\
\text { aplicações do } \\
\text { produto; } \\
\text { - Parceria com } \\
\text { fornecedores para o } \\
\text { desenvolvimento de } \\
\text { novas embalagens; } \\
\text { - Não há parceria com } \\
\text { concorrentes; } \\
\text { - Algumas iniciativas } \\
\text { de relacionamento } \\
\text { com Universidades e } \\
\text { Institutos de } \\
\text { Pesquisa; } \\
\text { - Relações com } \\
\text { órgãos de Classe. } \\
\text { - Grande preocupação } \\
\text { com relação à } \\
\text { Propriedade } \\
\text { Intelectual }\end{array}$ \\
\hline
\end{tabular}

Quadro 10: Síntese da análise dos principais traços das variáveis estudadas nas Relações Interorganizacionais. 
Todas as empresas relacionam-se com universidades e centros de pesquisa no Brasil e no exterior, o que facilita a identificação de pesquisadores que detêm conhecimentos importantes para o desenvolvimento de suas linhas de produto. Nas Empresas 1, 2 e 3, este relacionamento é muito intenso e contrasta com o discreto relacionamento externo da Empresa 5, pelo menos em sua unidade brasileira. Para esta empresa, a manutenção do sigilo e a preservação dos direitos de Propriedade Intelectual com relação aos processos de produção e desenvolvimento de novas aplicações de seus produtos são consideradas de importância vital.

A Empresa 4 considera muito importante o relacionamento com órgãos de classe e Agências Reguladoras, uma vez que a certificação dos seus produtos representa diferencial competitivo à vista dos seus clientes. Esta preocupação não foi constatada nas demais empresas.

No modelo de pesquisa proposto neste estudo foram destacados, como outros fatores capazes de influir na capacidade de inovação das empresas, a sua localização geográfica e outras práticas gerenciais não contempladas entre as atividades típicas que compõem o construto "Capacidade de Inovação". As Empresas 1, 2 e 4 estão localizadas perto de universidades e centros de pesquisa. Para as Empresas 1 e 2 estas instituições servem como referência técnico-científica para o desenvolvimento de suas pesquisas. Na Empresa 4, este relacionamento visa, sobretudo, manter um estreito contato com algumas destas instituições que também são credenciadas como órgãos avaliadores e certificadores de qualidade. A Empresa 3 escolheu para a localização de suas instalações fabris e da maioria de seus laboratórios de pesquisa uma região que, embora longe dos centros de reconhecido saber, oferece benefícios fiscais e boa infra-estrutura de transporte aéreo e terrestre. No caso da Empresa 5, as instalações fabris estão localizadas próximas à fonte da principal matéria-prima utilizada no processo produtivo, numa cidade que também possui uma boa infraestrutura de transporte aéreo e terrestre. Embora haja um grande número de instituições universitárias na cidade e nos municípios vizinhos, o relacionamento da Empresa 5 com as mesmas, é inexistente. Porém, a empresa mantém um 
discreto relacionamento com instituições universitárias e centros de pesquisa situados em outras cidades e estados.

As cinco empresas, nos seus distintos ambientes e mercados puderam realizar, nos últimos três anos, diferentes tipos de inovação. A importância atribuída por cada empresa às inovações organizacionais, de produto ou de processo, determinou o direcionamento de suas ações e, conseqüentemente, os resultados alcançados. No Quadro 11 é apresentada uma síntese destas inovações, ressaltando-se o fato de que, em cada um dos estudos de caso realizados, os diretores e/ou gerentes entrevistados demonstraram, no mínimo, satisfação com o desempenho da empresa nos últimos três anos e, ainda, uma postura otimista com relação ao futuro da organização.

\begin{tabular}{|c|c|}
\hline EMPRESAS & $\begin{array}{l}\text { INOVAÇÕES REALIZADAS } \\
\text { NOS ÚLTIMOS } 3 \text { ANOS }\end{array}$ \\
\hline Empresa 1 Saúde Humana & • 01 projeto concluído \\
\hline Empresa 2 Saúde Vegetal & -20 projetos em andamento. \\
\hline Empresa 3 Saúde Animal & $\begin{array}{l}\text {-20 novos produtos lançados ao mercado; } \\
\text {-01 inovação de processo; } \\
\text {-03 inovações organizacionais (novas práticas } \\
\text { de trabalho e mudanças organizacionais) }\end{array}$ \\
\hline Empresa 4 Agronegócio & $\begin{array}{l}\text {-10 novos produtos lançados ao mercado; } \\
\text { • } 03 \text { inovações de processos. }\end{array}$ \\
\hline Empresa 5 Multinacional & $\begin{array}{l}\text { - } 23 \text { novas aplicações para seu produto, três } \\
\text { destas originárias de idéias brasileiras; } \\
\text { - } 05 \text { inovações organizacionais (práticas de } \\
\text { trabalho e mudanças organizacionais) }\end{array}$ \\
\hline
\end{tabular}

Quadro 11: Síntese das inovações alcançadas. 


\subsection{Considerações finais}

Ao iniciar este estudo, acreditava-se que a estrutura organizacional requerida por empresas de biotecnologia, com fins lucrativos, para realizar suas operações gerenciais, teria que ser necessariamente ágil, dada a velocidade com que a ciência da Biotecnologia gera resultados e é divulgada pelos meios de comunicação. Esta idéia se mostrou equivocada ao longo do desenvolvimento do trabalho. Verificou-se que o fato de ser esta uma ciência de alta tecnologia não implica que todas as biotécnicas apresentem o mesmo grau de dinamismo e de consolidação, o que se mostrou evidente na conformação das diferentes estruturas organizacionais encontradas. Estruturas mais ágeis, como a estrutura de equipes ou a estrutura matricial, foram encontradas em ambientes que requeriam agilidade, seja por um imperativo da ciência ou do mercado. Este foi o caso das Empresas 1, 2 e 3. Por outro lado, a estrutura funcional se mostrou suficiente para as Empresas 4 e 5.

O estudo foi estruturado com base na premissa que certas atividades da empresa, compreendidas no construto "capacidade de inovação", poderiam ser consideradas como variáveis contribuintes, passíveis de serem associadas com a formação de valor no logo prazo. Os Mapas Cognitivos construídos para cada uma das empresas estudadas evidenciaram a forma pela qual estas atividades relacionam-se entre si. Porém, revelaram também uma variável não contemplada na proposta inicial deste trabalho como sendo preponderante para a formação de valor: o fator humano. Neste sentido, recomenda-se, com base nos dados obtidos, que este fator seja cautelosamente monitorado pelas empresas e visto como um poderoso vetor que impulsiona as atividades tradicionalmente associadas à capacidade de inovação e à gestão da inovação tecnológica.

O monitoramento citado pode ser feito, por exemplo, de acordo com a proposta de Edvinsson e Malone (1998). Os autores propõem uma série de indicadores a serem utilizados por empresas de alta tecnologia para potencializar sua capacidade de inovação, ou mesmo como parte dos processos de gestão de inovação tecnológica. Estes indicadores podem ser agrupados da seguinte forma: 
* Foco na Renovação e Desenvolvimento

1 Despesas com desenvolvimento de competências / funcionários (\%)

2 Índice de satisfação dos empregados

3 Percentagem das horas de treinamento

4 Percentagem de horas de desenvolvimento

5 Despesas de P\&D / despesas Administrativas (\%)

6 Despesas de treinamento / funcionários (\$)

7 Despesas de treinamento / despesas administrativas (\%)

8 Porcentagem de empregados com menos de 40 anos

9 Investimento em treinamento / cliente

10 Comunicações diretas com o cliente / ano

* $\quad$ Foco Humano

1 Rotatividade dos empregados

2 Número médio de tempo de casa

3 Número de gerentes

4 Idade média dos funcionários

5 Tempo de treinamento (dias/ano)

6 Formação acadêmica dos funcionários / número de funcionários (\%)

7 Percentagem dos gerentes da empresa com especialização em:

$>$ Gestão de negócios (\%)

$>$ Disciplinas científicas e engenharia (\%)

$>$ Ciências humanas (\%)

No presente trabalho, ao estudar os cinco casos, foram observadas diferentes práticas gerenciais passíveis de serem utilizadas para administrar ativos intangíveis na forma de conhecimento. Da mesma forma, ficou evidente que estes ativos eram considerados vitais, pela gerência, para alavancar o desempenho da empresa. Estes ativos, segundo a literatura, compreendem o conceito denominado "capital intelectual".

Na definição proposta pela Society of Management Accountants - SMAC (DZINKOWSKI, 2000, p.33), da Grã Bretanha, o capital intelectual se refere aos "ativos baseados no conhecimento, de propriedade da empresa, com capacidade de produzir um fluxo futuro de benefícios". De forma mais ampla, o capital 
intelectual é definido por EDVINSSON e MALONE (1998, p. 40) como "a posse do conhecimento, experiência aplicada, tecnologia organizacional, relacionamento com clientes e habilidades profissionais que proporcionam [...] uma vantagem competitiva no mercado"

Nos últimos 20 anos, as fontes de valor têm migrado da gestão dos ativos representados nas demonstrações financeiras (hard assets) para outras fontes não tão claramente definidas, reconhecidas hoje como capital Intelectual (DZINKOWSKI, 2000). A gestão estratégica do capital intelectual, a identificação dos diversos elementos que o compõem, bem como sua mensuração é o desafio das empresas da era do conhecimento. Como o que não é mensurável não pode ser gerido de forma eficiente e eficaz, a primeira tarefa a ser executada pela gerência consiste na identificação da composição das fontes de valor (ou vetores de valor) para, então, determinar indicadores que permitam seu gerenciamento. Isto reforça a importância do uso de indicadores financeiros e não financeiros que captem a essência do capital intelectual com o objetivo de auxiliar a formulação, comunicação e a gestão do planejamento estratégico. KING e HENRY (1999) relatam a ocorrência de empréstimos bancários que tiveram como garantia a avaliação do capital intelectual. Os autores lembram que uma marca, uma tecnologia ou outros intangíveis não mantêm um valor estático no tempo. Se o valor concedido pelos avaliadores ao capital intelectual é suficiente e válido para que bancos o utilizem como garantia confiável, é também evidente que seriam confiáveis para serem abertos nas notas explicativas das demonstrações financeiras. Mostrar indicadores de tendências que reflitam o esforço da empresa na formação de capital intelectual permite uma melhor apreciação do risco associado à consecução dos fluxos de caixa futuros. Esta prática reveste-se de extrema importância nos processos de avaliação de empresas em ambientes de fusões e aquisições, comum nos diversos setores em que operam as empresas de base biotecnológica.

O valor e a riqueza que o capital intelectual pode gerar não depende do investimento em um ativo intangível de forma isolada, mas no conjunto de todos os ativos e na estratégia que os une (KAPLAN e NORTON, 2000; 2000b). Diversos são os fatores que impedem que as mensurações financeiras 
tradicionais, baseadas na acumulação de custo, estabeleçam a ordem de grandeza financeira dos elementos que integram o capital intelectual e os relacionem com a criação de valor. O valor resultante do investimento nos ativos intangíveis é indireto e o impacto nos resultados financeiros é função de relações de causa e efeito, envolvendo ainda resultados intermediários. Os valores do capital intelectual dependem do contexto em que se encontram, i.e., a organização, a estratégia e os ativos complementares. Os ativos intangíveis possuem valor potencial, mas, para criar valor, precisam estar associados a outros ativos intangíveis ou tangíveis. De acordo com Steward (1998), na identificação e composição do capital intelectual, a ênfase recai no seu uso e propósito dirigidos a uma estratégia. São exemplos o talento das pessoas dedicadas às atividades que resultam em inovação e renovação, a capacidade de entrar no mercado, ampliar as relações e ganhar fidelidade do cliente, e os mecanismos e instrumentos que facilitam a transmissão, a partilha e a alavancagem do conhecimento. Ou seja, se o talento e as habilidades dos funcionários ou a rede de comunicação interna não são levados em consideração na estratégia da empresa, não constituem capital intelectual.

Neste trabalho, nos cinco casos estudados, os mapas cognitivos não evidenciaram objetivos conflitantes entre as atividades características da capacidade de inovação. Em situação contrária, com a existência de objetivos conflitantes, uma atividade ocasionaria a destruição do valor gerado por outra. Especificamente no caso da Empresa 5, a dificuldade encontrada pela gerência para promover certas atitudes e atividades pode estar incidindo negativamente na formação de valor. Neste caso, porém, não houve evidência de conflitos de objetivos, sendo as próprias características do fator humano da empresa uma possível causa do problema.

Em todos as cinco empresas avaliadas, todas as atividades relacionadas à capacidade de inovação e relatadas neste trabalho estavam contempladas na sua estratégia competitiva. Tomando como base a afirmação de Steward (1998), a vinculação das práticas gerenciais adotadas para promover a inovação com a estratégia competitiva transformaria o resultado destas atividades em capital intelectual, com reflexos na formação de valor no longo prazo. 
A Figura 16 apresenta o processo cíclico sustentável necessário para a formação de valor no longo prazo no modelo gerencial fundamentado na Administração Baseada no Valor.

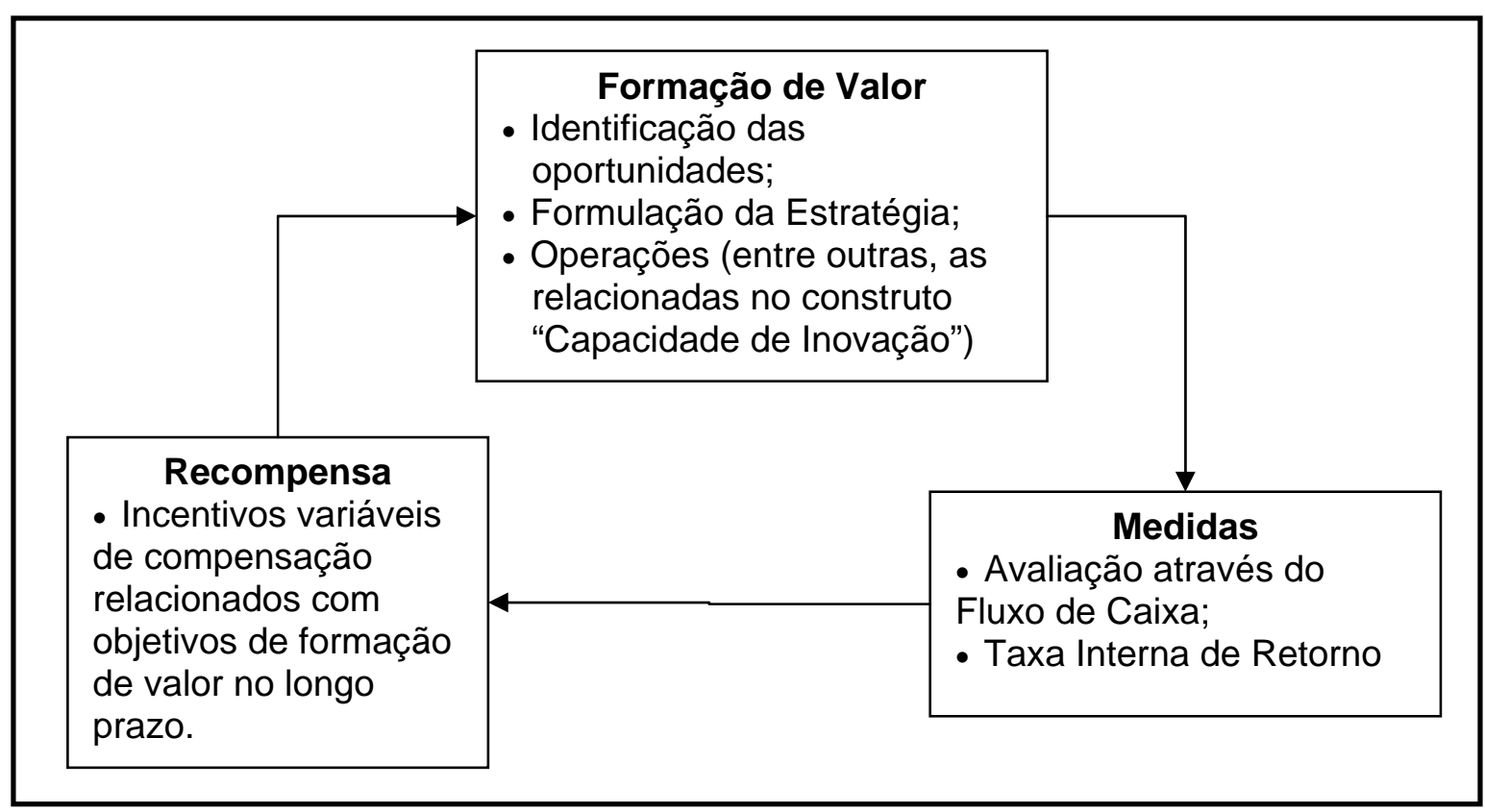

Figura 16: Construção de um Ciclo sustentável de formação de valor. Fonte: Adaptado de Martin e Petty $(2000$, p. 6$)$.

\subsection{Limitações}

As considerações realizadas neste estudo devem ser entendidas como contribuições iniciais para o entendimento da questão "capacidade de inovação". Por ser um estudo preliminar e de caráter exploratório, foram considerados apenas alguns casos dentro do amplo escopo da indústria de biotecnologia. Não se trata, pois, de uma análise que possibilite generalizações, restrição já ressaltada na fase de definição da metodologia de pesquisa.

Todas as informações obtidas refletem a ótica dos gerentes ou diretores entrevistados em cada empresa, sem que tenha havido a oportunidade de confrontar as informações com outros gerentes / diretores ou funcionários destas mesmas empresas. Esta limitação é decorrente, principalmente, de razões 
financeiras e de tempo, visto que as empresas estão localizadas em diferentes cidades, distantes umas das outras.

Ressalta-se que os mapas cognitivos não constituem apenas uma descrição gráfica das informações dadas pelo entrevistado, mas principalmente uma interpretação do que ele considera significativo e relevante para o assunto abordado. Mapas cognitivos elaborados a partir de informações ou percepções de outros executivos da mesma empresa poderiam apresentar relações diferentes daquelas apresentadas aqui. Estas diferenças na interpretação dos fatos por diferentes executivos gerariam mapas com configurações distintas e, conseqüentemente, mostrariam diferentes relações causais na atividade gerencial, podendo levar a decisões diferentes para uma mesma questão ou problema.

A experiência de Eden e Ackermann (1992) demonstra que o número de construtos elucidados numa entrevista é dependente, sobretudo, da duração da entrevista e da habilidade do entrevistador para fazer os registros e codificá-los no mapa. Neste trabalho, foi utilizado, com a anuência do entrevistado, um microgravador, a fim de amenizar os efeitos negativos desta limitação.

\subsection{Propostas para outros trabalhos}

A temática principal deste estudo, a capacidade de inovação como formadora de valor, é um campo fértil e necessita de novos aportes para consolidar suas bases e fundamentos. Aprofundar estes estudos, abrangendo um maior número de empresas e setores de aplicação da indústria da biotecnologia, bem como um maior número de pessoas entrevistadas por empresa, constitui uma forma de alavancar o setor, uma vez que os subsídios gerados contribuirão para melhorar as práticas gerenciais destas empresas.

Pesquisas de campo devem ser realizadas com amostras estatisticamente representativas, aplicando estatística multivariada e levando em consideração as variáveis identificadas no presente estudo, contemplando, porém, indicadores relacionados com o fator humano. Considera-se interessante um estudo que relacione modelos participativos de gestão e fatores humanos, como aqueles 
apontados na seção anterior, com a formação de valor ou com um determinado conjunto de indicadores de desempenho. A importância da gestão dos grupos informais em empresas de alta tecnologia, como a biotecnologia, constitui outro tema com potencial para ser investigado, o que segundo a ótica de Cross, Borgatti e Parker (2002), objetiva facilitar a implementação da estratégia empresarial. 


\section{REFERÊNCIAS BIBLIOGRÁFICAS}

ALVES-MAZZOTTI, A. J.; GEWANDSZNAJDER, F. O Método nas Ciências Naturais e Sociais: Pesquisa Quantitativa e Qualitativa. 2 ed.. São Paulo: Pioneira, 1999.

AMOROSO, R. Alianças e Parcerias. 128f. Dissertação (Mestrado em Administração) São Paulo: PPGA/FEA/USP: 1994.

ANDERSON, C. Value-based management. The Academy of Management Executive. v. 11, n. 4, p. 25-46, Nov/1997.

AUGHTON, P. Participative design within a strategic context. The Journal for Quality and Participation. Cincinnati: v. 19, n. 2, p, 68 - 75, mar. 1996.

BARBOSA FILHO, M. Introdução à Pesquisa: Métodos, Técnicas e Instrumentos. João Pessoa: Editora Universitária/UFPB, 1978.

BARROS, A.J.P. Projeto de Pesquisa: Propostas Metodológicas. $3^{a}$ ed. Petrópolis: Vozes, 1994.

BATEMAN, T.; SNELL, S. Administração: Construindo Vantagem Competitiva. São Paulo: Atlas, 1998.

BIOTECHNOLOGY INDUSTRY ASSOCIATION. Disponível em: $<$ http://www.bio.org >. Acesso em 17/04/2004.

BOURGEOIS, L.J. III; BRODWIN, D.R. Strategic Implementation: five appoaches to an elusive phenomenon. Strategic Management Journal. Chichester: v. 5, n. 3 , p. 241-264.

BRANNEN, J.. Combining qualitative and quantitative approaches: an overview. IN BRANNEN, J. (Edit.). Mixing Methods: Qualitative and Quantitative Research. England: Avebury, 1995. 
BRASIL. Ministério do Meio Ambiente. Convenção sobre a Diversidade Biológica. Série Biodiversidade n. 1, Brasília: 2000. Disponível em: <http://www.mma.gov.br/port/sbf/chm/doc/cdbport.pdf> Acessado em 26 de março de 2002.

BREALEY, R.; MYERS, S. Principles of Corporate Finance. USA: Irvin/McGraw-Hill, 2000.

BRENNER, M. Practical R\&D Project Priorization. Research Technology Management. v. 37, n. 5, p. 38-42, set/out. 1994.

BUBSHAIT, A.A.; FAROOQ, G. Team Building and Project Success. Cost Engineering. v. 41, n. 7, p. 34-38, Jul. 1999.

CLARK, K.B.; WHEELWRIGHT, S.C. Organizing and leading "Heavyweight" development teams. California Management Review. Berkeley, v. 34, n.3, p. 928, Spring 1992.

CLARKE, P.; TYLER, F. Implementing a balanced scorecard: an Irish example. Irish Business and Administrative Research. Dublin, v. 1, n. 2, p. 137156.2000.

CONDON, J.; GOLDSTEIN, J. Value based management - the only way to manage for value. Accountancy Ireland. v. 30, n. 5, p. 10-12, Oct/1998.

COOPER, R.; EDGETT, S.; KLEINSCHMIDT, E. Portfolio Management for New Products. USA: Addison Wesley, 1998.

New problems, new solutions: making portfolio management more effective. Research Technology Management. v. 43, n. 2, p. 18-83, mar/abr. 2000.

COPELAND, T.; KOLLER, T.; MURRIN, J. Avaliação de Empresas

"Valuation": Calculando e Gerenciando o Valor das Empresas. São Paulo: Makron Books, 2000.

CRESWELL, J.W. Research Design: Quality and Quantitative Approaches. USA: Sage, 1994.

CROSS, R.; BORGATTI, S.; PARKER, A. Making Invisible Work Visible: Using Social Network Analysis to Support Human Networks. California Management Review. Berckely, v. 44, n. 2, p. 25-46. Winter 2002.

CUNHA, J. C. O Impacto do Uso Estratégico da Tecnologia no Desempenho da Empresa. 161 f. Tese (Doutorado em Administração) São Paulo: PPGA/FEA/USP: 1994.

DAMODARAN, A. Avaliação de Investimentos: Ferramentas e Técnicas para a Determinação do Valor de Qualquer Ativo. Rio de Janeiro: Qualitymark Ed., 1997. 
DAVIS, J.; FUSFELD, A.; SCRIVEN, E.; TRITLE, G. Determining a project's probability of success. Research Technology Management. v. 44, n. 3, p. 5157, mai/jun. 2001.

DEVLIN, G.; BLEACKY, M. Strategic alliances guidelines for success. Long Range Planning, England, October, vol. 21, n. 5, p.18-23, 1998.

DZINKOWSKI, Ramona The measurement and management of intellectual capital: an introduction. Management Accounting. London: v. 78, n. 2, p. 32-36, Feb. 2000.

DUYCK, J. Value Based Management: Developing a systematic approach to creating shareholder value. The Academy of Management Executive. v. 12, n. 2, p. 102-104, May/1998.

EDEN, C. Analyzing Cognitive Maps to help structure issues or problems. European Journal of Operational Research. (in press).

EDEN, C.; ACKERMANN, F. Cognitive mapping expert views for policy analysis in the public sector. European Journal of Operational Research. Amsterdam: v. 152, n. 3, p. $615-630$, Feb. 2004.

The analysis of cause maps. Journal of Management Studies. v. 29, n. 3, p. 309-324, may 1992.

EDEN, C.; ACKERMANN, F.; CROPPER, S. The Analysis of Cause Maps. Journal of Management Studies. v. 29, n. 3, p. 309 - 324, May 1992

EDVINSSON, L.; MALONE, M. Capital Intelectual: Descobrindo o Valor Real da sua Empresa pela Identificação de seus Valores Internos. São Paulo: Makron Books, 1998.

ERNST \& YOUNG. Global Home. Disponível em: http://www.ey.com/global/Content.nsf/International/Biotechnology Books 2003. Acessado em 17/04/2004.

FISCHMANN, A. Implementação de estratégias: identificação e análise de problemas. 207 f. Tese (Livre-docência) São Paulo: FEA/USP, $1987 .$.

FISCHMANN, A.; ZILBER, M. Utilização de indicadores de desempenho como instrumento de suporte à gestão estratégica. in XXIII ENANPAD, 23, set. 1999, Foz do Iguaçu, PR. Anais Enanpad '99. CD-ROM.

FLEURY, A.; FLEURY, M. T. L. Estratégias Empresariais e Formação de Competências: Um Quebra-Cabeça Caleidoscópio da Indústria Brasileira. São Paulo: Atlas, 2000.

FORCADELL, F.; GUADAMILLAS, F. A case study on the implementation of a knowledge management strategy oriented to innovation. Knowledge and Process Management. Chichester: v. 9, n. 3, p. 162 - 171, Jul/Sep 2002. 
FRANCIS, G.; MINCHINGTON, C. Value-Based management in practice. Management Accounting. v. 78, n. 2, p. 46-47, Feb./2000.

FREEDMAN, M. The genius is in the implementation. The journal of Business Strategy. Boston: v. 24, n. 2, p. 26-31, mar/apr 2003.

FREIDHEIM JR, C. The battle of alliances. Management Review, p. 46-51, set. 1999.

FREIRE, A. Estratégia. Portugal: Verbo, 1998.

FRIGO, M. I. Strategic execution and value-based management. Strategic

Finance. v. 84, n. 4, Oct/2002a. Nonfinancial performance measures and strategic execution. Strategic

Finance. v. 84 , n. 2, p. 6-9, Aug/2002b. Strategy, value creation, and the CFO. Strategy Finance. v. 84, n. 7, p. 9-11, Jan/2003.

GALBRAITH, J., LAWLER III, E. e Associados. Organizando para Competir no Futuro. São Paulo: Makron Books, 1995.

GIL, A.C. Como Elaborar Projetos de Pesquisa. São Paulo: Atlas, 1988. Métodos e Técnicas de Pesquisa Social. São Paulo: Atlas, 1987.

GRAVES, S.; RINGUEST, J.; CASE, R. Formulating optimal R\&D portfolios. Research Technology Management. v. 43, n. 3, p. 47-51, mai/jun 2000.

GRESSLE, M. Value-based management enhances shareholder value in the New Economy. Directorship. v. 27, n. 1, p. 14-17, Jan/2001

HALL, L.; BAGCHI-SEN, S. An Analysis of R\&D, innovation and business performance in the US biotechnology industry. International Journal of Biotechnology. v. 3, n. 3/4, p. 267-286, 2001,

HASPESLAGH, P.; NODA, T.; BOULOS, F. Managing for value: It's not just about the numbers. Harvard Business Review. v. 79, n. 7, p. 65-73, Jul-Aug/2001.

INSTITUTE FOR HUMAN AND MACHINE COGNITION. CMapTools:

knowledge modeling kit. Version 3.3: The University of West Florida, Mar. 2004. Disponível e:< http://cmap.ihmc.us/download/index.php?myPlat=Win $>$ Acesso em 16 de abril de 2004.

JASSAWALLA, A.; SASHITTAL, H. Cultures that support product-innovation processes. Academy of Management Executive. v. 16, n. 3, p. 42-54, 2002.

JOLY, P.B. Innovating through networks: a case study in plant biotechnology. International Journal of Biotechnology. n. 1, p. 67-81, 1999. 
JUDICE, V. Parque Nacional de Empresas de Biotecnologia. Belo Horizonte: Fundação BIOMINAS. 2001. Disponível em:

$<$ http://www.mct.gov.br/temas/biotec/parque nacional.pdf $>$ Acessado em 26 de março de 2002.

KANTER, R. Collaborative advantage: the art of alliances. Harvard Business Review. v. 72, n.4, Jul-Aug/1994.

KAPLAN, R.; NORTON, D. A Estratégia em Ação. Rio de Janeiro: Campus, 1997.

. Having trouble with your strategy? Then map it. Harvard Business

Review. v. 78, n. 5, p. 167-176, set./out. 2000.

Organização orientada para a estratégia: como as empresas que adotam o balanced scorecard prosperam no novo ambiente. Rio de Janeiro: Campus, 2000b.

KAUFFMANN, $\mathrm{P}$ et al. A model for allocating resources to research program by evaluating technical importance and research productivity. Engineering Management Journal. v. 12, n. 1, mar/2000.

KELLY, G. A. The psychology of personal constructs, New York, Norton, 1955.

KERLINGER, F. N. Metodologia da Pesquisa em Ciências Sociais: um Tratamento Conceitual. São Paulo: EPU, 1980.

KIM, S. Participative Management and Job Satisfaction: Lessons for Management Leadership. Public Administration Review. Washington: v. 62, n.2, p. 231- 241, mar. labr. 2002.

KING, A.; HENRY, J. Valuing intangible assets through appraisals. Strategic Finance. Montvale, USA: v. 81, n. 5, p. 32-37, Nob. 1999.

KNIGHT, J.A. Value-Based Management : Developing a Systematic Approach to Creating Shareholder Value. New York: McGraw-Hill, 1997.

LAKATOS, E.M.; MARCONI, M.A. Fundamentos de Metodologia Científica. $3^{a}$ ed. São Paulo: Atlas, 1991.

Técnicas de Pesquisa. São Paulo: Atlas, 1982.

LAWRENCE, P.; LORSCH, J. Organización y ambiente. Barcelona: Editorial Labor, 1973.

LIEDTKA, J. In Defense of Strategy as Design. California Management Review. Berkeley: v. 42, n. 3, p. $8-30$, Spring 2000.

LINCOLN, Y.S.; GUBA, E.G. Naturalistic Inquiry. Newbury Park: Sage, 1990. 
LOFLAND, J.; LOFLAND, L.H. Analyzing Social Settings: A Guide to Qualitative Observation and Analysis. Belmont, CA: Wadsworth Inc., 1984.

LUDKE, M.; ANDRE, M. Pesquisa em Educação: Abordagens Qualitativas. $2^{\mathrm{a}}$ ed. São Paulo: EPU, 1988.

MALCOLM, D.G. On the need for improvement of O.R. Management Science. v. 11, n. 4, p. B48 - B58, Feb. 1965.

MALEK, J.; BREGGAR, M. The new R\&D Paradigm. Pharmaceutical Executive. v. 21, n. 2, p. 78-86, Feb/2001.

MARCOVITCH, J.; MAXIMIANO, A.C.A. The Behavior of Knowledge workers on R\&D Projects In: DINSMORE, P. The AMA Handbook of Project Management. American Management Association, 1993.

MARSHALL, C.; ROSSMAN, G.B. Designing Qualitative Research. $2^{\text {nd }}$ ed. Thousand Oaks, Calif.: Sage, 1995.

MARTIN, J.D.; PETTY, J.W. Value Based Management: the corporate response to the shareholder revolution. Boston: Harvard Business School Press, 2000.

MARTINO, J. Research and Development Project Selection. NY: John Wiley \& Sons Inc., 1995.

MATTAR, F.N. Pesquisa de Marketing: Metodologia, Planejamento, Execução e Análise. V. 1, SP: Atlas, 1994.

MAXIMIANO, A.C.A.; SBRAGIA, R.; KRONER, W. O Gerente de Projeto "Peso Pesado": um estudo de caso. Economia \& Empresa. São Paulo, v. 4, n. 1, p. 3344, jan.-mar. 1997.

MAXIMIANO, A.C.A. Teoria Geral da Administração: da Revolução Urbana à Revolução Digital. São Paulo: Atlas, 2002.

MILES, M.B.; HUBERMAN, M.A. Qualitative Data Analysis: an Expanded Sourcebook. $2^{\text {nd }}$. ed. Thousand Oaks: Sage, 1994.

MILLER, W.L.; MORRIS, L. $4^{\text {th }}$ Generation R\&D: Managing Knowledge, Technology and Innovation. New York: John Wiley \& Sons, Ltd. 1999.

MOLINA-PALMA, M.A.; DACORSO, A.L.R.; SBRAGIA, R. Gestão da Carteira de Projetos: um Estudo de Caso. Simpósio de Gestão da Inovação Tecnológica (11: 2002: São Paulo). XXII Simpósio de Gestão da Inovação Tecnológica: São Paulo, 2002: Anais / Núcleo de Política e Gestão Tecnológica da Universidade de São Paulo. Salvador, Bahia: nov/2002. CD-ROM

MORBEY, G.K. R\&D: Its relationship to company performance. Journal of Product Innovation Management. n. 5, 1988. 
NEELY, A.; HII, J. Innovation and Business Performance: a Literature Review. Government Office of the Eastern Region. University of Cambridge:1998. Disponível em:

$<$ http://www.som.cranfield.ac.uk/som/cbp/literaturereviewcomplete.pdf> Acessado em 05/02/2003.

The Innovative Capacity of Firms. Report commissioned by the Government Office for the East of England. Fev. 1999.

NOVAK, J. D. The theory underlying Concept Maps and how to construct them. <http://cmap.coginst.awf.edu/info/printer.html>. Acessado em 23 de maio de 2003.

NUTT, P. Tatics of Implementation. Academy of Management Journal. v. 9, n. 2, p. $230-261.1986$.

OECD. The Measurement of Scientific and Technological Activities Proposed Guidelines for Collecting and Interpreting Technological Innovation Data - Oslo Manual. Paris: 1997.

The Measurement of Scientific and Technological Activities Proposed Standard Practice for Surveys on Research and Experimental Development - Frascati Manual. Paris: 2002.

OLIVEIRA, D.P.R. Planejamento Estratégico: Conceitos, Metodologias e Práticas. 14ª ed. São Paulo: Atlas, 1999.

O'REILLY, C.; CHATMAN, J.; CALDWELL, J. People and organizational culture: a profile comparison approach to assessing person-organizational fit. Academy of Management Journal. v. 34, n. 3, p. 487-516, Sep/1991.

PAOLI, M; GUERCINI, S. R\&D internationalisation in the strategic behaviour of the firm. University of Sussex, Brighton, Jan. 1997, StEEP Discussion Paper $\mathrm{n}^{\circ}$ 39. Disponível em:

<http://www.sussex.ac.uk/spru/publications/imprint/steepdps/39/steep39.hmtl> Acesso em: 22/05/2004.

PAPACONSTANTINOU, G. Technology and industrial performance. The OECD Observer, OECD, n 204, Feb/Mar, 1997. Disponível em:

$<$ http://www1.oecd.org/publications/observer/204/ob204e.html> Acesso em 29/05/2003.

PARNELL, J.A. Measuring Strategic Diffusion: Examining a Strategy's dissemination within American and Egyptian Organizations. Middle East Business Review. v. 3, n. 2, p. 1-19, 1999.

PARNELL, J.A.; CARRAHER, S.; HOLT, K. Participative Management's influence on effective strategic diffusion. Journal of Business Strategy. Huntsville: v. 19, n. 2, p. $161-179$, Fall 2002. 
PEREIRA, J.C.R. Análise de Dados Qualitativos: Estratégias Metodológicas para as Ciências da Saúde, Humanas e Sociais. $3^{\mathrm{a}}$ ed. São Paulo: EDUSP, 2001.

PITMAN, B. Liderar para valorizar. Harvard Business Review. v. 81, n. 4, p. 2933, Apr/2003.

PORTER, M. Vantagem Competitiva: Criando e Sustentando um Desempenho Superior. Rio de Janeiro: Campus,1992.

POWELL: W.W. The social construction of an organizational field: the case of biotechnology. International Journal of Biotechnology, n. 1, p. 42-66, 1999.

PURSER, R.; CABANA, S. Involve employees at every level of strategic planning. Quality Progress. Milwaukee: v. 30. n. 5. mai 1997.

RAPPAPORT, A. Creating Shareholder Value: a Guide for Managers and Investors. New York: The Free Press, 1998.

REIS, A.H.M. Pesquisa Qualitativa em Marketing. 151 f. Dissertação (Mestrado em Administração). São Paulo: PPGA/FEA/USP, 1994.

ROBBINS, S. Comportamento Organizacional. São Paulo: Prentice Hall, 2002.

ROUSSEL P.; SAAD, K.; BOHLIN, N. Pesquisa e Desenvolvimento: Como Integrar P\&D ao Plano Estratégico e Operacional das Empresas como Fator de Produtividade e Competitividade. São Paulo: Makron Books, 1992.

SALLES-FILHO, S.; BONACELLI, M. B. e MELLO, D. Estudos em Biotecnologia: Instrumentos de Apoio à Definição de Políticas em Ciência e Tecnologia. Campinas: MCT/FINEP/UNICAMP, 2001.

SBRAGIA, R. P\&D: Como apreciar sua contribuição para a empresa. Anais V Seminário Latino-Americano de Gestión Tecnológica, ALTEC, Bogotá, 19-22/set. 1993.

SBRAGIA, R. The interface between Project and functional managers in matrix organized new products development projects. In: International Conference on Management of Technology, 9, 2000, Miami, Proceedings... Miami: 2000, CDROM.

SCHEIN, E. Organizational Culture and Leadership. San Francisco: JosseyBass Publishers, 1985.

SELLTIZ, C.; WRIGHTSMAN, L.S.; COOK, S. Métodos de Pesquisa nas Relações Sociais. São Paulo: E.P.U., 1974.

SINGH, G. Skill requirements for the biotechnology industry: moving from research and development to commercialization. International Journal of Biotechnology. v. 3, n. 3/4, p. 245-256, 2001. 
SPRADLIN, T.; KUTOLOSKI, D. Action-Oriented Portfolio Management. Research Technology Management. v.42, n.2, p. 26-32, Mar/Apr/1999.

SCHUMPETER, J.A. Essays on Entrepreneurs, Innovations, Business Cycles, and the Evolution of Capitalism. New Brunswick: Transaction, 1991.

SOTIRLOU, D.; WITTMER, D. Influence methods of Project managers: perceptions of team members and Project managers. Project Management Journal. v. 32, n. 3, p, 12-20, 2001.

SOUSA, J.E.R. Gestão Tecnológica e Competitividade em Empresas do Setor de Autopeças. 142 f. Tese (Doutorado em Administração) São Paulo: FEA/USP: 1993.

SOUZA PAULA, M.C. (Coord.). COOPERAÇÃO INTERNACIONAL EM BIOTECNOLOGIA NO BRASIL. Brasília: MCT, 2001. <http://www.mct.gov.br/temas/biotec/estudos biotec coop int.htm>. Acessado em 20 de agosto de 2002.

STAKE, R. Case Studies. IN: DENZIN, N.; LINCOLN, Y. (Ed.). Handbook of Qualitative Research. USA: Sage, 1994.

STEWARD, T.A. Capital Intelectual: a Nova Vantagem Competitiva das Empresas. Rio de Janeiro: Campus, 1998.

STRÖH, U; JAATINEN, M. New approaches to communication management for transformation and change in organizations. Journal of Communication Management. London: v.6, n. 2, p. 148 - 165, Dec. 2001.

SUBRAMANIAM, N.; ASHKANASY, N. The effect of organizational culture perceptions on the relationship between budgetary participation and managerial job-related outcomes. Australian Journal of Management. v. 26, n. 1, p. 35-54, Jun/2001.

THAMHAIN, H. Effective Leadership for Building Project Teams, motivating people, and creating optimal organizational structures. In: DINSMORE, P. (Ed.). The AMA handbook of project management. New York: AMACOM, 1995.

TRIPODI, T.; FELLIN, P.; MEYER, H. Análise da Pesquisa Social. Rio de Janeiro: Livraria Francisco Alves Editora, 1975.

TRITLE, G.; SCRIVEN, E.; FUSFELD, A. Resolving uncertainty in R\&D portfolios. Research Technology Management. v. 43, n.6, p. 47-55, Nov/Dic/2000.

TVORICK, S.; BOISSONEAU, R.; PEARSON, N. Performance parameters as indicators of success and predictors of failure in strategic. Journal of

Professional Services Marketing. v. 17, n. 2, p. 41-67, 1998.

UNIVERSIDADE ESTADUAL DE CAMPINAS, Laboratório de Bioinformática, Instituto de Computação. Xyllela fastidiosa Genomic Project. Campinas, 2000. Disponível em: http:/laeg.lbi.ic.unicamp.br/xf/ Acesso em: 30 mai. 2004. 
VASCONCELLOS, E.; HEMSLEY, J. Estrutura das organizações. São Paulo: Pioneira, 1997

WALSH, S. Portfolio management for the commercialization of advanced technologies. EMJ. v. 12, n. 1, p. 33-37, Mar/2001.

WALSH, V. Demand, public markets and innovation in biotechnology. Science and Public Policy, n. 20, p. 138-156, 1993.

WILLIAMS, S.; HANKS. K. The biotechnology industry: how to take the plunge without taking a bath; a template for successful biotech investing. Robertson Stephens Ltd. Mar/2001.

WONCESTER, R.M. Consumer Market Research Handbook. $3^{\text {rd }}$ ed. Amsterdam: ESOMAR, 1991.

YIN, R. K. Case Study Research: Design and Methods. Applied Social Research Methods Series, v.5. USA: Sage Publications, 1994. 


\section{APÊNDICE}

\section{INSTRUMENTO DE COLETA DE DADOS}

1. O que é inovação para vocês?

2. A inovação é um elemento controlado na estratégia da empresa. Quais considerações sobre o nível de inovação são levadas em conta.

3. Os funcionários conhecem a estratégia da empresa? De que forma os funcionários tomam conhecimentos da estratégia? Como ela é comunicada? Isso depende do que?

4. A alta gerência manifesta compromisso com a inovação. Eles estimulam, apóiam e lideram iniciativas em toda a empresa.

5. Os funcionários da empresa se sentem à vontade para assumir desafios. Eles adotam o espírito de "eu posso fazer" e mostram um compromisso com a inovação.

6. Os funcionários são encorajados a assumir riscos controlados sempre que uma nova situação chama para a experimentação. O fracasso é tratado como uma experiência para a aprendizagem.

7. Um sistema compreensível e válido de medidas de desempenho da inovação existe na empresa. Essas medidas se relacionam com a estratégia e são usadas de forma consistente para controlar o desempenho da inovação. 
8. Os funcionários inovadores são reconhecidos e recompensados. Incentivos financeiros e não financeiros são contemplados nas avaliações de desempenho.

9. O financiamento para todas as iniciativas de inovação em andamento está seguro e o financiamento para as futuras iniciativas está sendo explorado. Existem planos para acessar financiamento para as inovações.

10. Existem procedimentos de seleção claros para financiar P\&D, aquisições tecnológicas e as atividades relacionadas com a inovação. Estes procedimentos são revisados e melhorados consistentemente pelas pessoas envolvidas em atividades relacionadas com a inovação.

11. A geração de novas idéias é ativamente encorajada e fortemente apoiada em todos os níveis da empresa.

12. Existe um bom entendimento sobre as habilidades requeridas para sustentar a inovação. Existem planos de treinamento para melhorar habilidades.

13. A parcerias ou sub-contratações são usadas para aumentar a carteira de habilidades da empresa.

14. As instalações físicas sustentam as atuais iniciativas de inovação. Existem planos para adquirir novos recursos físicos para futuras iniciativas.

15. As parcerias ou sub-contratações são usadas para aumentar a capacidade de recursos físicos da empresa

16. Processos sistemáticos para obter novas idéias dos funcionários existem e estão ativos.

17. Como são administrados os Projetos de novos produtos ou de desenvolvimento de processos desde seu início até seu lançamento. O escopo dos projetos, suas fases, sinalizadores ou indicadores, procedimentos de revisão são explícitos.

18. Como é adquirido o conhecimento e/ou informações de mercado (pesquisas, informações de vendedores). Informações do mercado são acumuladas consistentemente e combinadas com conhecimento tecnológico para explorar os últimos desenvolvimentos inovadores. 
19. O conhecimento tecnológico é constantemente adquirido através de mecanismos bem estabelecidos.

20. O trabalho em equipe é adotado quando há uma situação ou problema não familiar e é realizado sem nenhum direcionamento gerencial.

21. As habilidades para resolver problemas através de equipes interdisciplinares são utilizadas quando apropriadas. Equipes de trabalho são motivadas a identificar áreas de oportunidade para melhorias.

22. Os consumidores são vistos como parceiros na organização. "Satisfação do cliente" é um lema na estratégia de marketing. Informações dos consumidores são intensamente trabalhadas e levadas em consideração quando são desenvolvidos produtos, processos ou soluções organizacionais.

23. Existe um relacionamento de parceria e confiança com os fornecedores. Os fornecedores participam ativamente das atividades de inovação e realizam trabalhos em conjunto. A cadeia de fornecedores é constantemente usada para gerar novas idéias e oportunidades de inovação.

24. Existem ligações com concorrentes através de redes informais. As atividades dos competidores são monitoradas ativamente e servem como estímulo para novas idéias. As informações sobre concorrentes são utilizadas nas atividades de inovação de produtos, processos e organizacionais.

25. A empresa procura ativamente por contatos externos e know-how. Joinventures, licenciamentos e co-desenvolvimento são usados para reunir informação sobre as tecnologias e competências emergentes que se encontrem fora da empresa.

26. Pessoas-chave em universidades/centros de pesquisa são consultadas de modo que novos conhecimentos nas diferentes áreas - técnico, mercado, gerencial - seja desenvolvido continuamente.

27. Uma ampla gama de fontes de informação são ativamente usadas (Internet, associações de classe, conferências, feiras, etc.) por todos os níveis da empresa para acessar e gerar novo conhecimento e idéias sobre oportunidades potenciais de negócio. 
28. Durante os últimos 3 anos estamos satisfeitos com o que conseguimos em termos de:
a. Inovações de produtos: $\square$ pouco $\square$ médio $\square$ muito $\square$ extremamente satisfeitos
b. Inovações de processos: $\square$ pouco $\square$ médio $\square$ muito $\square$ extremamente satisfeitos
c. Inovações organizacionais: $\square$ pouco $\square$ médio $\square$ muito $\square$ extremamente satisfeitos

29. Inovação de produtos (introdução de novos produtos / melhoras significativas em produtos ou novos serviços no mercado). Aproximadamente, quantos produtos inovadores, de importância significativa, foram introduzidos nos últimos 3 anos?

30. Inovação de processos (a adoção de um novo processo de produção ou serviço). Aproximadamente, quantas inovações de processos, de importância significativa, foram introduzidas nos últimos 3 anos?

31. Inovação organizacional (a adoção de novas práticas de trabalho ou mudanças significativas na organização). Aproximadamente, quantas inovações organizacionais, de importância significativa, foram introduzidas nos últimos 3 anos?

32. Redução de custos decorrentes de melhorias no processo de produção.

$\square$ nenhuma $\square$ pequena $\square$ média $\square$ grande

33. Indicadores de desempenho empresarial

\begin{tabular}{|l|l|}
\hline Faturamento Bruto anual (R\$) & \\
\hline Volume de vendas no mercado nacional & \\
\hline Volume de vendas no mercado internacional & \\
\hline Número de funcionários & \\
\hline
\end{tabular}

Informações adicionais:

Nome da empresa:

Ano de início de atividade industrial:

Ano de início de atividade comercial:

Contato:

Cargo:

Tempo no cargo:

Endereço:

CEP:

Cidade: Estado:

Fone: Fax:

E-mail: 